
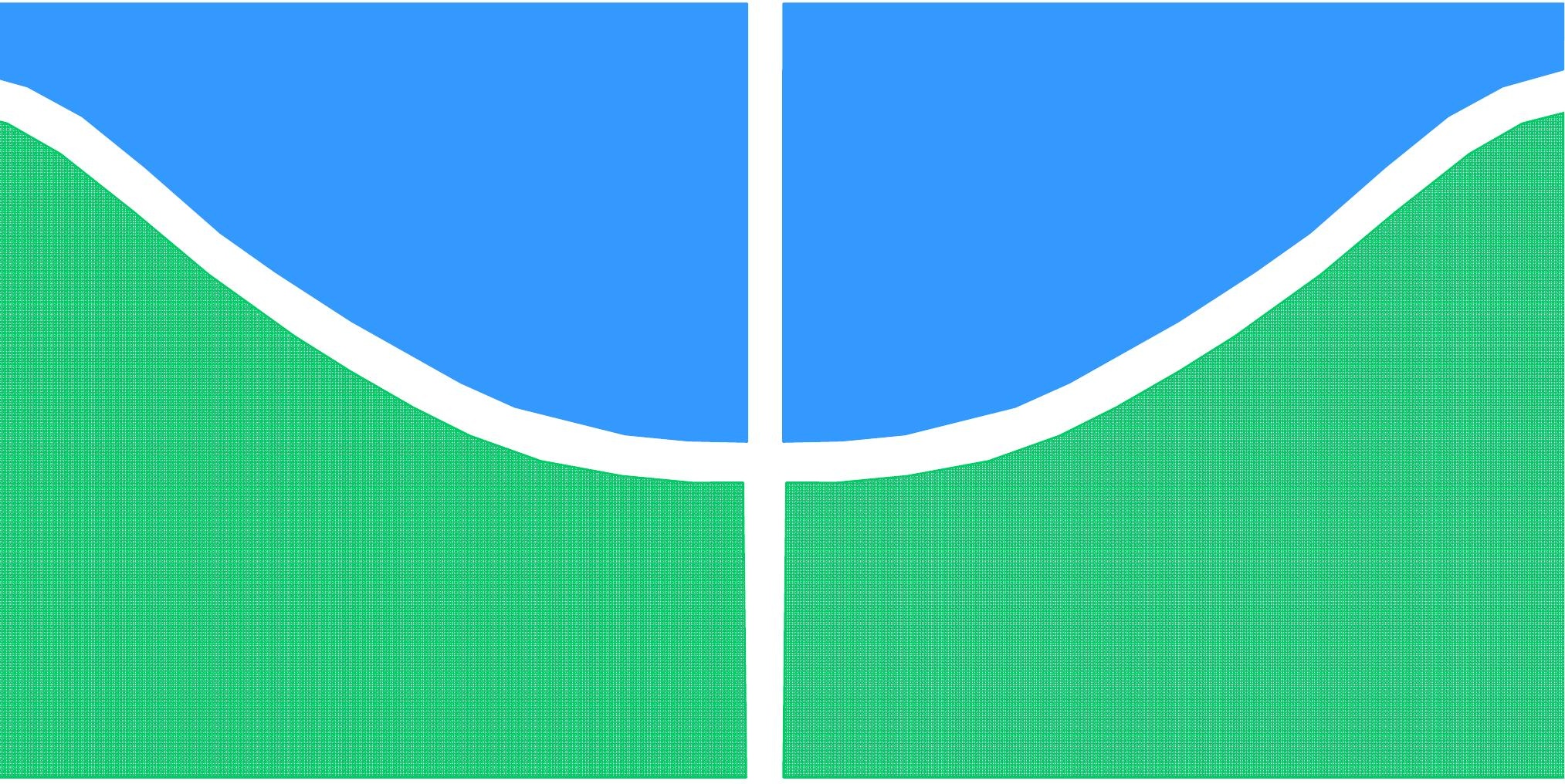

PROJETO FINAL DE GRADUAÇÃO

\title{
ESTUDO PRELIMINAR DE IMPLANTAÇÃO DE PARQUE GERADOR EÓLICO
}

\author{
RAFAEL CAMBRAIA TRAJANO \\ VÍTOR CASTRO DE ALBUQUERQUE BARROS
}

Brasília, dezembro de 2009.

\section{UNIVERSIDADE DE BRASILIA}

FACULDADE DE TECNOLOGIA

UNIVERSIDADE DE BRASILIA

Faculdade de Tecnologia 
UNIVERSIDADE DE BRASÍLIA

FACULDADE DE TECNOLOGIA

DEPARTAMENTO DE ENGENHARIA ELÉTRICA

\title{
ESTUDO PRELIMINAR DE IMPLANTAÇÃO DE PARQUE GERADOR EÓLICO
}

\author{
RAFAEL CAMBRAIA TRAJANO \\ VÍTOR CASTRO DE ALBUQUERQUE BARROS
}

ORIENTADOR: IVAN MARQUES DE TOLEDO CAMARGO PROJETO FINAL DE GRADUAÇÃO EM ENGENHARIA ELÉTRICA

BRASÍLIA/DF, DEZEMBRO - 2009 
UNIVERSIDADE DE BRASÍLIA

FACULDADE DE TECNOLOGIA

DEPARTAMENTO DE ENGENHARIA ELÉTRICA

\title{
ESTUDO PRELIMINAR DE IMPLANTAÇÃO DE PARQUE GERADOR EÓLICO
}

\author{
RAFAEL CAMBRAIA TRAJANO \\ VÍTOR CASTRO DE ALBUQUERQUE BARROS
}

PROJETO FINAL DE GRADUAÇÃO EM ENGENHARIA ELÉTRICA APROVADO POR:

Prof. Ivan Marques de Toledo Camargo, UnB, Dr. (Orientador)

Prof. Francisco Damasceno Freitas, UnB, Dr.

Prof. Rafael Amaral Shayani, UnB, Msc.

BRASÍLIA/DF, 02 DE DEZEMBRO DE 2009 
FICHA CATALOGRÁFICA

\begin{tabular}{l}
\hline BARROS, VÍTOR CASTRO DE ALBUQUERQUE; TRAJANO, RAFAEL CAMBRAIA. \\
Estudo preliminar de implantação de parque eólico, 91p., 210 x 297 mm (ENE/FT/UnB), \\
Projeto Final de Graduação - Universidade de Brasília. Faculdade de Tecnologia. \\
$\begin{array}{ll}\text { Departamento de Engenharia Elétrica } & \text { 2.Implantação de parque eólico } \\
\text { 1.Energia eólica } & \text { II. Título (série) } \\
\text { I. ENE/FT/UnB }\end{array}$
\end{tabular}

\section{REFERÊNCIA BIBLIOGRÁFICA}

BARROS, V.C.A, TRAJANO, R.C., Estudo preliminar de parque gerador eólico.Projeto Final de Graduação, Departamento de Engenharia Elétrica, Universidade de Brasília, Brasília, 2009.

\section{CESSÃO DE DIREITOS}

AUTORES: Vítor Castro de Albuquerque Barros e Rafael Cambraia Trajano

TÍTULO: Estudo preliminar de implantação de parque gerador eólico

GRAU: Engenheiro Eletricista

ANO: 2009

É concedida à Universidade de Brasília permissão para reproduzir cópias deste projeto final de graduação e para emprestar ou vender tais cópias somente para propósitos acadêmicos e científicos. Os autores reservam outros direitos de publicação e nenhuma parte dessa dissertação de mestrado pode ser reproduzida sem autorização por escrito dos autores.

Rafael Cambraia Trajano

Vítor Castro de Albuquerque Barros 


\section{AGRADECIMENTOS}

Agradeço à minha família pelo incentivo e apoio, à minha namorada pelo amor e compreensão, aos meus mestres e orientador pelo exemplo de dedicação e comprometimento, aos meus amigos pelo sincero companheirismo e, especialmente, à minha mãe pelo amor incondicional, pela confiança e apoio irrestritos e pelas dificuldades enfrentadas sem hesitação em nome do meu sucesso.

Rafael Cambraia Trajano

À minha família, que sempre me apoiou nos momentos mais difíceis.

À minha namorada, pelo apoio e paciência na minha ausência.

Ao Prof. Ivan Marques de Toledo Camargo, orientador deste trabalho, pelos seus ensinamentos e amizade durante todo o curso.

Aos amigos, pelo incentivo.

Vítor Castro de Albuquerque Barros 
Dedicado à minha mãe, Maria José Cambraia, e a meu pai, Ricardo Wagner Trajano de Faria (in memorian)

Rafael Cambraia Trajano

Dedicado aos meus pais, Lincoln José Silva de A. Barros e $\mathrm{M}^{\mathrm{a}}$ de Fátima Castro de Albuquerque Barros Vítor Castro de Albuquerque Barros 


\section{RESUMO}

\section{ESTUDO PRELIMINAR DE IMPLANTAÇÃO DE PARQUE GERADOR EÓLICO}

\section{Autores: Rafael Cambraia Trajano e Vítor Castro de Albuquerque Barros}

\section{Orientador: Ivan Marques de Toledo Camargo}

\section{Brasília, dezembro de 2009}

Este trabalho apresenta um estudo preliminar de implantação de um parque gerador eólico com base em um atlas eólico. Inicialmente, são apresentados os conceitos relacionados à geração de energia elétrica através da conversão da energia cinética dos ventos. Após a apresentação dos conceitos é feito um estudo de caso em que se simula a implantação parcial de um parque eólico em um sítio escolhido no Estado da Bahia.

O estudo de caso realizado é baseado nos resultados obtidos por uma planilha de cálculos desenvolvida pelos autores com base na revisão bibliográfica do tema. Após a simulação de implantação do parque eólico no sítio escolhido considerando diversos modelos de aerogeradores disponíveis comercialmente, é feita uma comparação dos resultados do sítio escolhido com os resultados de um segundo sítio escolhido. Por fim, faz-se uma comparação entre os dados obtidos com a planilha desenvolvida e os resultados obtidos por um software livre especializado. 


\section{ABSTRACT}

\section{PRELIMINARY WIND FARM DEPLOYMENT STUDY}

Authors: Rafael Cambraia Trajano and Vítor Castro de Albuquerque Barros

\section{Supervisor: Ivan Marques de Toledo Camargo}

\section{Brasília, december of 2009}

This work presents a preliminary wind farm deployment study based on a wind atlas. First, electrical energy generation from wind energy conversion concepts are presented. After this presentation, a case study is made by simulating a partial deployment of a wind farm in a chosen site in the state of Bahia, in Brazil.

The case study is based on a spreadsheet developed by the authors on the grounds of bibliographic review on the subject. After the deployment simulation is made, considering several wind turbine models commercially available, a comparison between the results from both sites is made. Finally, the results obtained with the spreadsheet developed are compared with the results from a specialized free software. 


\section{SUMÁRIO}

1. INTRODUÇÃ

2. SITUAÇÃO ATUAL NO MUNDO E NO BRASIL............................................. 3

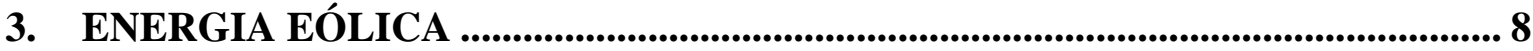

3.1 CLASSIFICAÇÃO DOS VENTOS 8

3.2 MASSAS DE AR 9

3.3 CIRCULAÇÃO GERAL DOS VENTOS 9

3.4 POTÊNCIA DO VENTO 11

3.5 POTÊNCIA APROVEITÁVEL 12

3.6 ANÁLISE DA DISTRIBUIÇÃO DAS VELOCIDADES. 13

3.7.1 Determinação dos parâmetros de Weibull 16

3.8 ANÁLISE DA DIREÇÃO DAS VELOCIDADES. 17

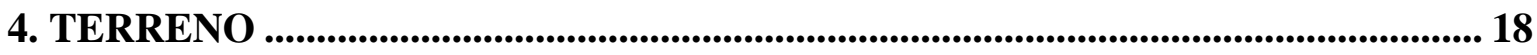

$\begin{array}{ll}\text { 4.1 CAMADA LIMITE } & 18\end{array}$

4.2 RUGOSIDADE 22

4.3 OBSTÁCULOS 24

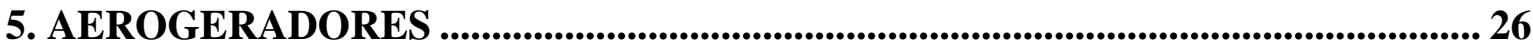

5.1 COMPONENTES BÁSICOS DE UM AEROGERADOR 26

5.2 AERODINÂMICA DOS AEROGERADORES 27

5.2.1 Fluxo de vento na pá 29

5.3 CONTROLE DE POTÊNCIA DOS AEROGERADORES 30

5.3.1 Controle passivo de potência (Estol) 30

5.3.2 Controle ativo de potência (pitch) 31

5.4 CONTROLE DE FREQUÊNCIA DE AEROGERADOR 33

5.4.1 Aerogerador com velocidade constante 34

5.4.2 Aerogerador com velocidade variável 34

5.5 CONFIGURAÇÕES DE AEROGERADORES 36

6. DISPOSIÇÃO DOS AEROGERADORES EM UM PARQUE EÓLICO ................. 40

6.1 VELOCIDADE DO VENTO ATRÁS DE UMA TURBINA EÓLICA 40

6.2 ARRANJOS DE AEROGERADORES EM UM PARQUE EÓLICO 44

6.2.1 Arranjo em uma fila 45

6.2.2 Arranjo em várias filas 46 
6.2.3 Arranjo definido pelo relevo

7. ESTUDO DE CASO: PROJETO DE UM PARQUE EÓLICO NO MUNICÍPIO DE CONDE 48

7.1 ATLAS EÓLICO DA BAHIA 48

7.2 ÁNALISE DOS DADOS ANEMOMÉTRICOS DO SÍTIO 49

7.3 ESTIMATIVA DA ENERGIA PRODUZIDA POR UM AEROGERADOR 51

7.4 DISPOSIÇÃO DOS AEROGERADORES (MICROSITING) 53

7.4.1 Disposição em uma fila 53

7.4.2 Disposição em 2 filas 57

7.5 ESTIMATIVA DA ENERGIA PRODUZIDA PELO PARQUE EÓLICO 59

7.5.1 Disposição em 1 fila 60

7.5.2 Disposição em 2 filas 61

7.6 ANÁLISE COMPARATIVA 62

7.6.1 Comparação com o programa ALWIN 75

8. CONCLUSÕES. 76

8.1 CONCLUSÕES GERAIS 76

8.2 RECOMENDAÇÕES PARA ESTUDOS FUTUROS 76 REFERÊNCIAS 78 


\section{LISTA DE FIGURAS}

Figura 1.1 - Crescimento da potência instalada no mundo. ............................................... 2

Figura 2.1 - Potência instalada no mundo ao final de 2008................................................ 3

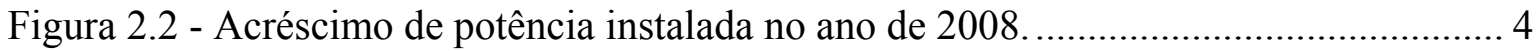

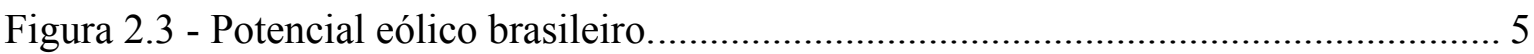

Figura 2.4 - Potencial eólico do estado do Rio Grande do Sul.............................................. 5

Figura2.5 - Variação do potencial eólico estimado com a altura de medição........................ 5

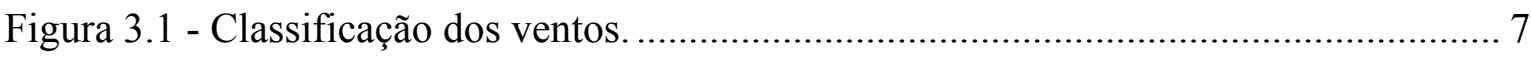

Figura 3.2 - Circulação geral dos ventos simplificada. ..................................................... 8

Figura 3.3 - Circulação geral dos ventos na superfície da Terra, suposta homogênea .................9

Figura 3.4 - Variação da potência disponível no vento de acordo com a velocidade do vento.

Figura 3.5 - Representação da máxima potência extraível do vento................................. 12

Figura 3.6 - Histograma das freqüências de ocorrência das velocidades........................... 13

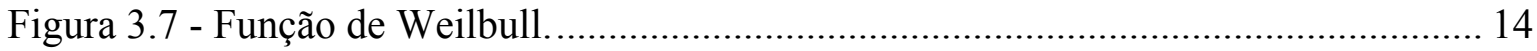

Figura 3.8 - Representação da direção dos ventos........................................................... 16

Figura 4.1 - Balanço de forças para formação do vento geostrófico.................................. 17

Figura 4.2- Balanço de forças para formação do vento próximo à superfície...................... 18

Figura 4.3 - Perfil da camada limite atmosférica.. ........................................................... 19

Figura 4.4 - Comportamento do vento antes e após passagem por obstáculo..................... 23

Figura 5.1 - Perfil básico de aerogerador moderno. …...................................................... 25

Figura 5.2 - Diagrama de forças em uma pá..................................................................... 27

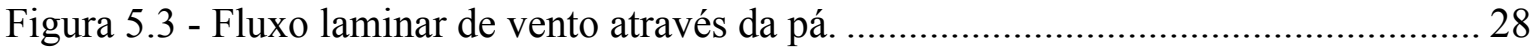

Figura 5.4 - Fluxo turbulento de vento através da pá......................................................... 29

Figura 5.5 - Curva de potência de turbina com controle passivo de velocidade. ................ 30

Figura 5.6 - Curvas de potência para diferentes ângulos de ataque para um aerogerador de $500 \mathrm{~kW}, 40 \mathrm{~m}$ de diâmetro com controle de potência por passo, com velocidade nominal de 33 r.p.m. 31

Figura 5.7 - Relação de uso de controle pitch por uso de controle estol. ........................... 32

Figura 5.8 - Coeficiente de potência $(\mathrm{Cp})$ versus tip speed ratio para diversos tipos de

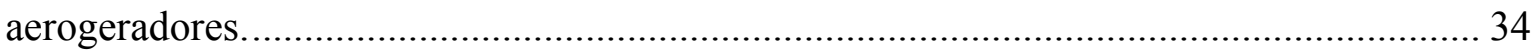

Figura 5.9 - Configurações mais comuns de aerogeradores. ........................................... 36

Figura 6.1 - Efeito esteira após aerogeradores em parque eólico off-shore ........................ 39 
Figura 6.2 - Representação gráfica do efeito esteira em um aerogerador..

Figura 6.3 - Recuperação da velocidade do vento e da potência disponível ao longo da esteira.

Figura 6.4 - Turbinas dispostas em uma única linha.

Figura 6.5 - Efeito esteira sobre aerogeradores vizinhos.

Figura 6.6 - Disposição em várias filas.

Figura 6.7 - Disposição assimétrica de aerogeradores.

Figura 7.1 - Sombra de aerogeradores nos aerogeradores vizinhos. 51

Figura 7.2 - Distribuição de direções do vento no sítio de Conde...... 52

Figura 7.3 - Representação da sombra de uma turbina sobre a turbina vizinha. 53

Figura 7.4 - Comparação entre as Distribuições de Weibull para a $1^{\mathrm{a}}$ e para a $2^{\mathrm{a}}$ fila de aerogeradores 55

Figura 7.5 - Comparativo de energia gerada pelas 17 turbinas para os dois sítios. 63

Figura 7.6 - Gráfico de fator de carga x altura para o fabricante Enercon. 64

Figura 7.7 - Gráfico de fator de carga x altura para o fabricante Gamesa. 64

Figura 7.8 - Gráfico de fator de carga x altura para o fabricante Nordex. 65

Figura 7.9 - Gráfico de fator de carga x potência para o fabricante Enercon. 65

Figura 7.10 - Gráfico de fator de carga x potência para o fabricante Gamesa. 66

Figura 7.11 - Gráfico de fator de carga x potência para o fabricante Nordex. 66

Figura 7.12 - Relação de distribuição de Weibull e da curva de potência com o fator de carga. 67 


\section{LISTA DE TABELAS}

Tabela 4.1 - Classes e comprimentos de rugosidade para diferentes terrenos.

Tabela 7.1 - Dados de medição do vento e de rugosidade na estação de Conde.

Tabela 7.2 - Dados do modelo do aerogerador E70 da ENERCON.....

Tabela 7.3 - Parâmetros da função de Weibull e velocidade média para a altura do aerogerador E70 no município de conde.

Tabela 7.4 - Tabela de potência do gerador E70

Tabela 7.5 - Tabela de recuperação da velocidade do vento em função da distância da primeira turbina. 55

Tabela 7.6 - Dados de medição dos ventos 60

Tabela 7.7 - Dados do terreno 60

Tabela 7.8 - Resultados do estudo para uma turbina livre de obstáculos em Conde 61

Tabela 7.9 - Resultados do estudo para uma turbina livre de obstáculos em Irecê. 62

Tabela 7.10 - Resultado do estudo para o dimensionamento do parque eólico em Conde utilizando os modelos da ENERCON . 68

Tabela 7.11 - Resultado do estudo para o dimensionamento do parque eólico em Conde utilizando os modelos da GAMESA 68

Tabela 7.12 - Resultado do estudo para o dimensionamento do parque eólico em Conde utilizando os modelos da NORDEX

Tabela 7.13 - Resultado do estudo para o dimensionamento do parque eólico em Irecê utilizando os modelos da ENERCON

Tabela 7.14 - Resultado do estudo para o dimensionamento do parque eólico em Irecê utilizando os modelos da GAMESA 70

Tabela 7.15 - Resultado do estudo para o dimensionamento do parque eólico em Irecê utilizando os modelos da NORDEX.....

Tabela 7.16 - Comparação dos resultados obtidos com o programa ALWIN 72 


\section{LISTA DE SÍMBOLOS, NOMENCLATURA E ABREVIAÇÕES}

$A$

$A C$

$A_{t}$

$A_{v}$

$c$

$c_{1}$

$c_{2}$

CERs

COELBA

$C_{\text {omp }}$

$C_{p}$

CRESESB

Cs

$C_{t}$

D

$D_{a}$

$D_{e}$

E

Eaerogerador

Energia $_{e f}$

Energia ${ }_{\text {livre }}$

$E_{\text {parque }}$

$E_{\text {produzida }}$

$f()$

$F_{1}(v)$

$F_{2}(v)$

$\overrightarrow{F_{a}}$

$f_{c}$

$\overrightarrow{F_{C O}}$

$\overrightarrow{F_{p}}$
- área da superfície superior da pá

- centro aerodinâmico

- área da seção transversal

- área varrida pelo rotor da turbina

- fator de escala da função de weilbull

- fator de escala da função de Weilbull no ponto 1

- fator de escala da função de Weilbull no ponto 2

- Certificados de Emissões Reduzidas

- Companhia de Eletricidade do Estado da Bahia

- comprimento do sítio

- coeficiente de potência

- Centro Referência para Energia Solar e Eólica

- coeficiente de sustentação

- coeficiente de empuxo da turbina

- diâmetro do aerogerador

- força de arraste

- diâmetro da esteira

- energia

- estimativa anual de geração de energia por um aerogerador

- energia produzida por cada aerogerador dentro do parque

- energia produzida por um aerogerador em condições de vento livre de obstáculos

- estimativa anual de energia a ser produzida pelo parque

- estimativa anual de energia a ser produzida pelo parque

- função densidade de probabilidade

- probabilidade de ocorrência da velocidade v para a $1^{\mathrm{a}}$ fila

- probabilidade de ocorrência da velocidade v para a $2^{\mathrm{a}}$ fila

- força de atrito exercida pela superfície

- fator de carga

- força de Coriolis

- força resultante do gradiente de pressão 


\begin{tabular}{|c|c|}
\hline GWEC & - Global Wind Energy Council \\
\hline$h$ & - altura em relação ao solo \\
\hline$h_{1}$ & - altura em relação ao solo no ponto 1 \\
\hline$h_{2}$ & - altura em relação ao solo no ponto 2 \\
\hline ICMS & - Imposto sobre circulação de Mercadorias e serviços \\
\hline$K$ & - constante de Von Karman \\
\hline$k$ & - fator de forma da função de Weilbull \\
\hline$k_{1}$ & - fator de forma da função de Weilbull no ponto 1 \\
\hline$k_{2}$ & - fator de forma da função de Weilbull no ponto 2 \\
\hline$k_{p}$ & - constante de perda da esteira \\
\hline$L$ & - força de sustentação \\
\hline$m$ & - massa de ar \\
\hline$\dot{m}$ & - fluxo de massa de ar \\
\hline MDL & - Mecanismo de Desenvolvimento Limpo \\
\hline$N$ & - expoente da equação 4.1 .4 \\
\hline$n$ & - número de aerogeradores \\
\hline$N_{\text {diam }}$ & - distância lateral entre aerogeradores vizinhos \\
\hline$N_{t}$ & - número de aerogeradores por fila \\
\hline$P$ & - potência \\
\hline$p$ & - pressão atmosférica \\
\hline$P(v)$ & - potência de saída do aerogerador para a velocidade $\mathrm{v}$ \\
\hline$P_{\text {inst }}$ & - potência instalada do parque \\
\hline Proinfa & - Programa de Incentivo à Fontes Alternativas \\
\hline$P_{\text {turbina }}$ & - potência nominal do aerogerador utilizado \\
\hline$R$ & - constante do ar \\
\hline$\vec{R}$ & - força aerodinâmica resultante \\
\hline$R_{e}$ & - força de empuxo \\
\hline$R_{t}$ & - raio do aerogerador \\
\hline$S$ & - seção transversal \\
\hline$T$ & - temperatura \\
\hline$t$ & - tempo \\
\hline$\vec{V}$ & - velocidade do vento geostrófico resultante \\
\hline$V$ & - velocidade média do vento \\
\hline
\end{tabular}


- velocidade do vento

- velocidade do vento antes da turbina

- velocidade horizontal do vento no ponto 1

- velocidade horizontal do vento no ponto 2

- velocidade do vento junto ao solo

- velocidade do vento na esteira

- distância da turbina ao local em que se deseja saber informações da esteira

- comprimento de rugosidade do solo

- expoente de camada limite

- ângulo de ataque do vento

- eficiência do parque eólico

- ângulo da turbina em relação à direção principal do vento

- tip speed ratio

- massa específica do ar

- desvio padrão das medições de velocidade do vento

- velocidade de rotação da turbina

- função Gamma 


\section{INTRODUÇÃO}

A energia dos ventos, também conhecida como energia eólica, tem sido utilizada pela humanidade há mais de 3000 anos [ACKERMANN, 2005]. Desde então, em quase todo esse período até os dias atuais, sua utilização tem se restringido apenas à conversão mecânica-mecânica de energia utilizada, sobretudo, em equipamentos como bombas de água e moedores de grãos.

Somente a partir do século XIX, as primeiras turbinas eólicas foram desenvolvidas com a finalidade de geração de energia elétrica. No entanto, essas turbinas mostraram-se altamente ineficazes tanto do ponto de vista tecnológico quanto do financeiro, despertando pouco interesse no desenvolvimento das tecnologias na área.

Porém, a partir da década de 70, com a crise do petróleo, a geração de energia elétrica a partir de fontes alternativas de energia passou a tornar-se viável para os países que dependiam fortemente de combustíveis fósseis para geração de energia. $\mathrm{O}$ alto preço do barril de petróleo possibilitou que os olhares se voltassem também à energia eólica, iniciando, deste modo, uma movimentação em prol do desenvolvimento tecnológico que viabilizasse o uso dessa fonte alternativa de energia. Além disso, a preocupação com as mudanças climáticas, associadas à emissão de carbono na atmosfera, fortaleceu o interesse nessa fonte de energia limpa.

Na década de 90, surge na Alemanha, o primeiro marco regulatório que incentiva a geração de energia por fontes alternativas. A Lei de Fomento à Eletricidade, ou Stromeinspeisungsgesetz, criou a feed-in tariff, no Brasil conhecida como tarifa-prêmio, que garantia aos produtores de energia que utilizassem fonte eólica ou solar a compra de toda a energia gerada por um preço equivalente, no mínimo, a 90\% do preço médio de venda de energia que, em 2004, atingiu a marca de 0,54€/kWh [BRUNEKREEFT, 2004]. Este incentivo, quase prontamente copiado por outros países europeus e pelos Estados Unidos, possibilitou um crescimento bastante expressivo da potência instalada no mundo a partir do meio da década de 90 , chegando a uma taxa de crescimento média de $28,7 \%$ no período entre 1996 e 2008, ver Figura 1.1. 


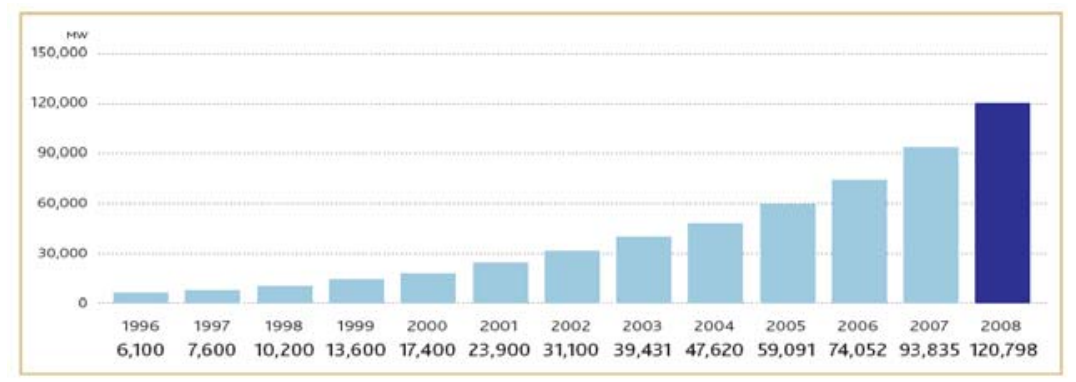

Figura 1.1 - Crescimento da potência instalada no mundo [GWEC, 2009].

No Brasil, a primeira turbina comercial foi instalada em 1992, no arquipélago de Fernando de Noronha, com o intuito de complementar o único gerador da ilha, a diesel. No entanto, pode-se considerar que o início da geração de energia a partir de fonte eólica deu-se em 2002, com o início do PROINFA (Programa de Incentivo às Fontes Alternativas). Ao contrário dos países europeus e dos EUA, o Brasil possui uma matriz de energia elétrica basicamente hídrica, pouco dependente de combustíveis fósseis, o que é um dos possíveis motivos da chegada tardia da tecnologia de geração eólica em território brasileiro.

Considerando a relevância que esta fonte alternativa de energia adquiriu nos últimos anos, conforme foi brevemente comentado, e as suas perspectivas de desenvolvimento no Brasil, surge a motivação de um estudo técnico, ainda que preliminar, dessa nova fonte de geração de energia.

Este trabalho tem como objetivo apresentar conceitos relacionados à geração de energia eólica bem como a aplicação destes conceitos em um estudo preliminar de implantação de um parque eólico tendo como base dados obtidos no Atlas Eólico do Estado da Bahia [AMARANTE, 2001]. Nesse intuito, os tópicos mais relevantes são apresentados nos capítulos subsequentes. O Capítulo 2 trata da situação da energia eólica no Brasil e no mundo. O Capítulo 3, por sua vez, apresenta tópicos relativos ao movimento, à potência $\mathrm{e}$ ao comportamento probabilístico dos ventos. No Capítulo 4, é tratada a influência do terreno e de obstáculos no comportamento do vento. Características estruturais e elétricas dos aerogeradores são tratadas no Capítulo 5. As diversas disposições de aerogeradores e seus efeitos são tratados no Capítulo 6. No Capítulo 7 são apresentados os cálculos e resultados referentes à implantação de um parque eólico em um município brasileiro, além de uma análise comparativa entre dois sítios e, adicionalmente, uma comparação entre os resultados obtidos com as ferramentas desenvolvidas neste trabalho e com um software 
livre. Por fim, no Capítulo 8 são apresentadas as conclusões e recomendações para futuros trabalhos sobre o tema.

\section{SITUAÇÃO ATUAL NO MUNDO E NO BRASIL}

Atualmente, a capacidade instalada de energia eólica no mundo é um pouco maior que 120 GW [GWEC, 2009], que para fins de comparação, é maior do que toda a capacidade instalada no Brasil por todas as fontes de energia elétrica, que é de 108 GW [ANEEL, 2009]. No ano de 2008, os EUA ultrapassaram a Alemanha em capacidade instalada, sendo responsáveis por $20,8 \%$ de toda a potência eólica instalada no mundo. A Alemanha $(19,8 \%)$, Espanha $(13,9 \%)$, China $(10,9 \%)$ e Índia $(8,0 \%)$ completam o rol de países que mais se destacam na produção, conforme mostrado na Figura 2.1.

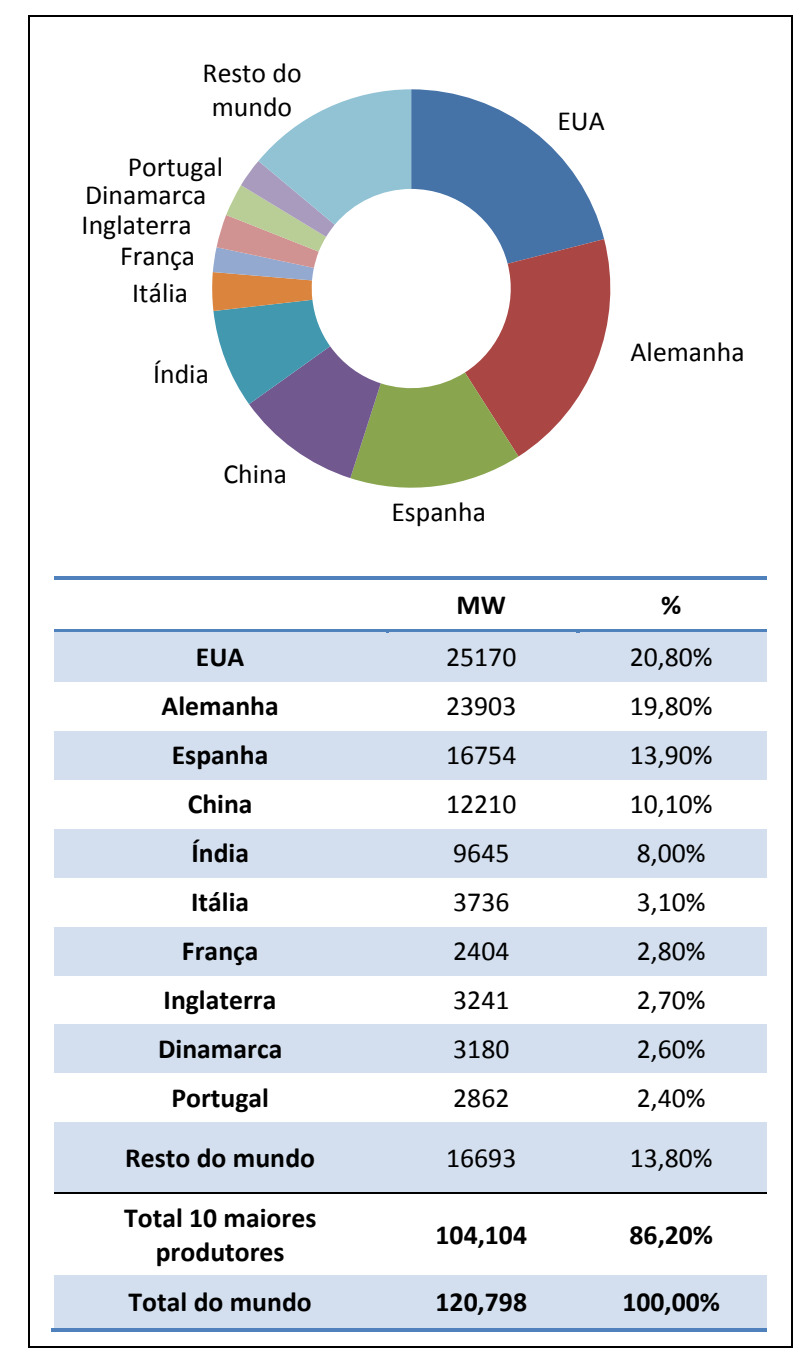

Figura 2.1 - Potência instalada no mundo ao final de 2008 [GWEC, 2009]. 
No que diz respeito ao crescimento da potência instalada, o país que teve maior crescimento foram os EUA, crescendo impressionantes 30,9\% em relação a 2007. A China, em segundo lugar, também apresentou a significante taxa de 23,3\% de crescimento, seguida por Índia (6,7\%), Alemanha (6,2\%) e Espanha (5,9\%).

Estas taxas de crescimento indicam uma possível mudança no ranking de potência instalada, mostrando que a China deve ocupar a segunda colocação em menos de uma década. Os dados que ilustram o crescimento estão disponíveis na Figura 2.2.

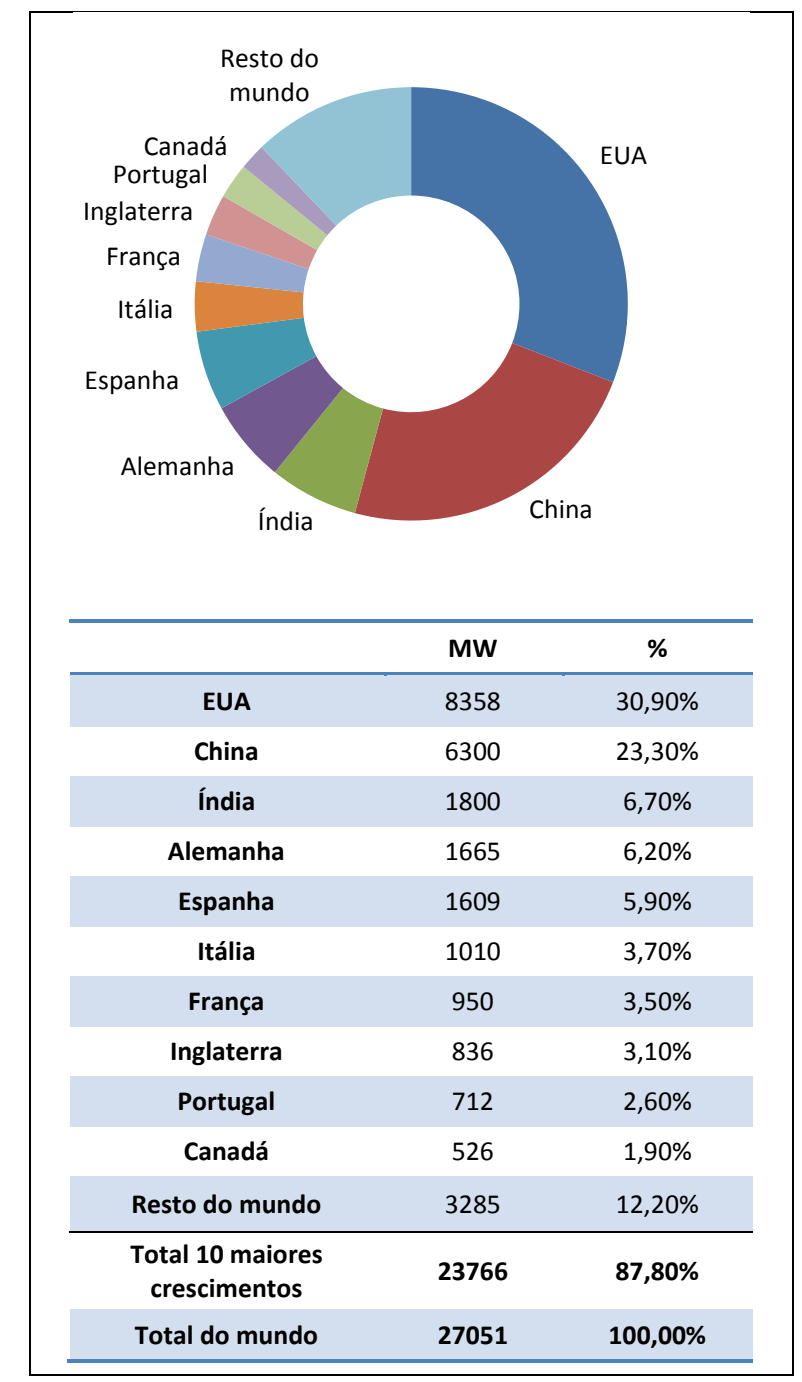

Figura 2.2 - Acréscimo de potência instalada no ano de 2008. [GWEC, 2009]

O Brasil possui uma capacidade instalada de energia eólica muito pequena: $605 \mathrm{MW}$ [ANEEL, 2009] em novembro de 2009, o que representa apenas $0,57 \%$ da potência total 
instalada no país. O maior parque instalado no Brasil é o de Osório, localizado no RS, que tem 75 aerogeradores de $2 \mathrm{MW}$, cada um com diâmetro de rotor de $70 \mathrm{~m}$, colocados a altura de $100 \mathrm{~m}$, totalizando $150 \mathrm{MW}$.

Apesar da pequena participação na matriz energética, existe no Brasil, segundo estudo desenvolvido pelo CRESESB [AMARANTE, 2001], um potencial de $143 \mathrm{GW}$, como mostra a Figura 2.3.

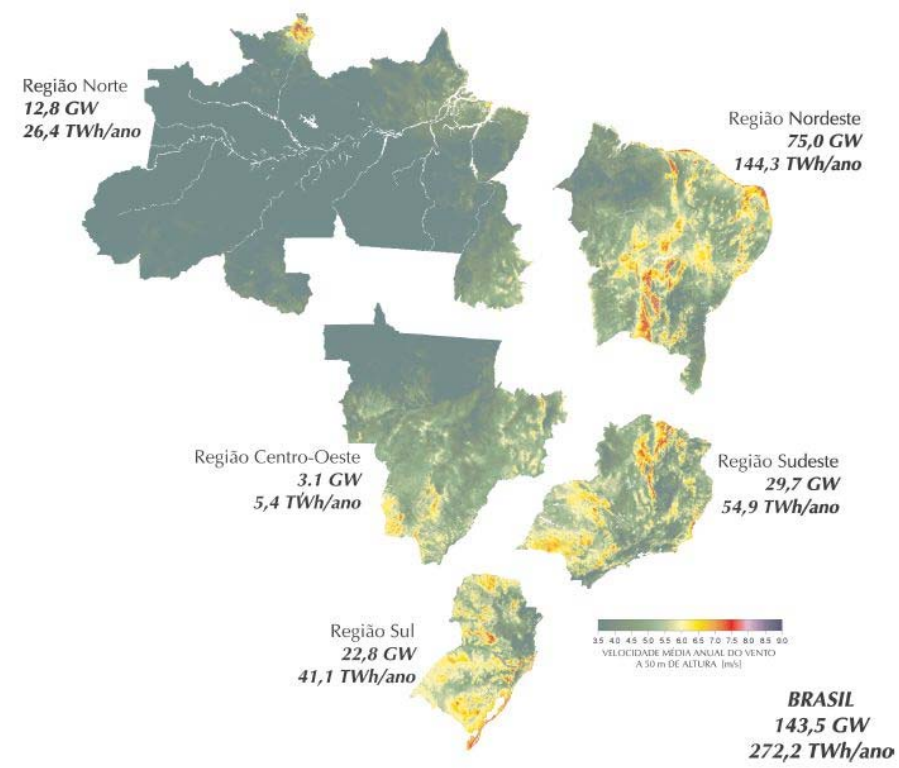

Figura 2.3 - Potencial eólico brasileiro. [AMARANTE, 2001].

Deve-se ressaltar que essas medidas foram feitas utilizando torres anemométricas de $50 \mathrm{~m}$ de altura e, atualmente, os aerogeradores chegam a alturas de mais de $100 \mathrm{~m}$ de altura. Dessa forma, com a tecnologia mais moderna, estima-se que o potencial brasileiro pode ser bem maior do que o publicado anteriormente. Como exemplo disso, pode-se comparar o potencial eólico do estado do Rio Grande do Sul para alturas de 50 m, 75 m e 100 m, de acordo com a Figura 2.4. 


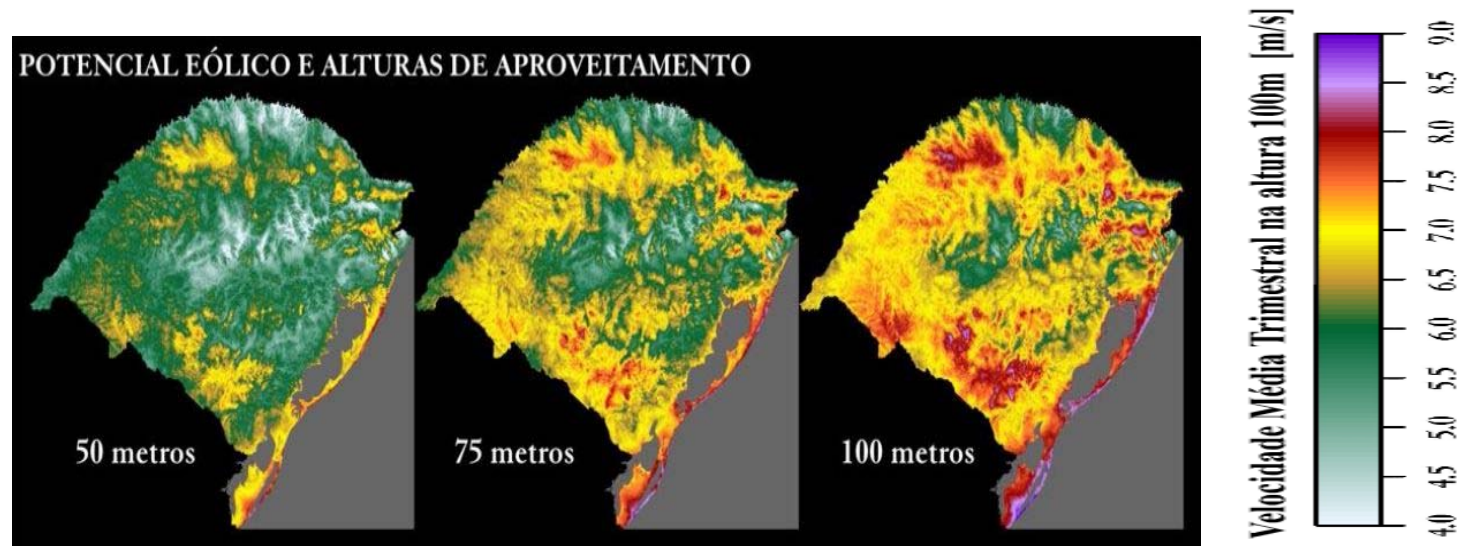

Figura 2.4 - Potencial eólico do estado do Rio Grande do Sul.

Fonte: Camargo Schubert Energia Eólica, 2001

Para uma altura de $50 \mathrm{~m}$, o potencial do RS é de 15,84 GW. Para altura de $75 \mathrm{~m}, 54,43$ GW e para a altura de $100 \mathrm{~m}$ o potencial é de $115,19 \mathrm{GW}$, um acréscimo de $627 \%$ em relação a medida realizada em $50 \mathrm{~m}$ de altura. O aumento expressivo de potencial de acordo com o aumento da altura de medição é ilustrado na Figura 2.5.

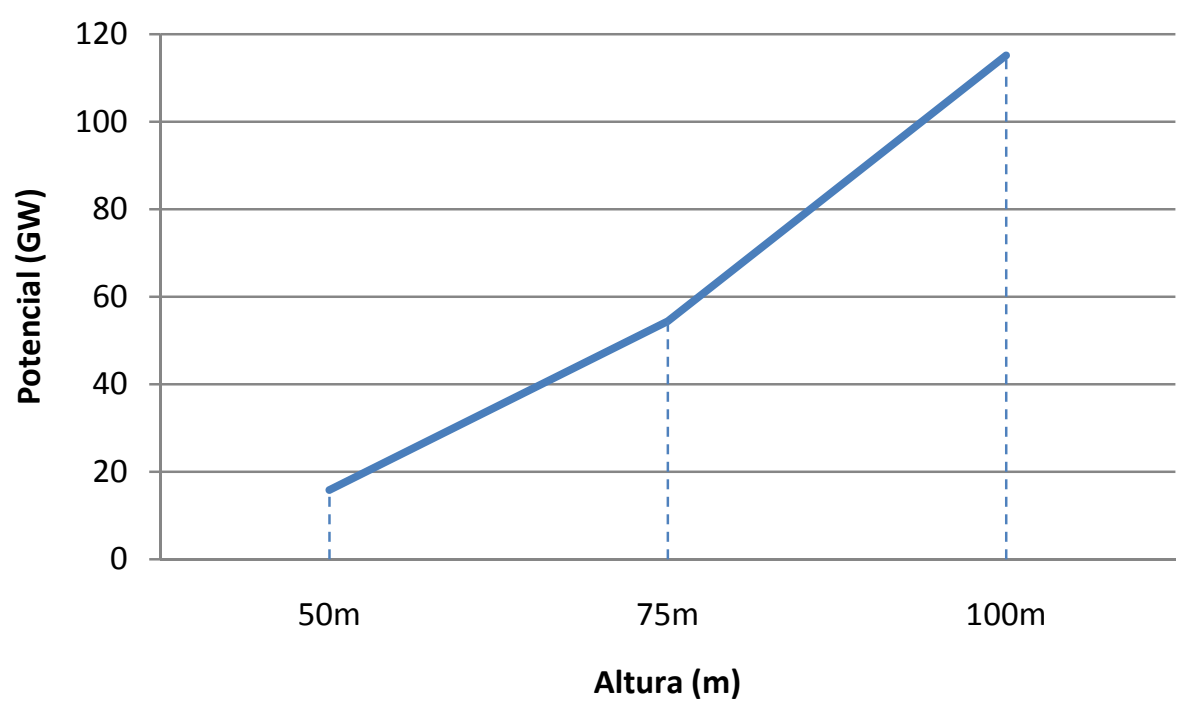

Figura 2.5 - Variação do potencial eólico estimado com a altura de medição

Atualmente, nota-se uma movimentação de alguns estados brasileiros, sobretudo os que possuem território costeiro, em buscar mecanismos que viabilizem a incorporação de usinas eólicas na cadeia de geração de energia elétrica. A maioria dos estados da região Nordeste, Sudeste e Sul já possui estudos, dados e mapas eólicos consolidados, realizados 
independentemente, o que demonstra um posicionamento estratégico diferente do que é previsto no PDE 2008 - 2017 [MME, 2009].

Essa postura favorável por parte dos estados tem gerado incentivos interessantes aos empreendedores, como isenção de ICMS e outros impostos estaduais. Em contrapartida aos incentivos aplicados, os estados esperam geração de novos empregos advindos da instalação de usinas e indústrias, desenvolvimento para as regiões isoladas, que coincidentemente, no caso do Nordeste, possuem grande potencial eólico, e, no caso dos estados carentes de recursos hídricos, diminuição da necessidade de importação de energia de outras regiões.

Outro ponto que tem se destacado como incentivo à fonte eólica, assim como a outras fontes renováveis, é o Mecanismo de Desenvolvimento Limpo (MDL). Através desse mecanismo apresentado no Anexo I do Protocolo de Kyoto, pode-se vender créditos de carbono, obtidos através de reduções certificadas de emissões de carbono (CERs), no mercado internacional. A venda desses créditos aumenta a taxa interna de retorno dos investimentos em energia renovável, tornando-os economicamente mais competitivos. 


\section{ENERGIA EÓLICA}

No início de todo projeto de uma usina eólica, é de grande importância o estudo sobre as condições de vento. Nesse estudo, deve ser feita uma análise das direções dos ventos, da velocidade e da distribuição de frequência dos ventos através de medições realizadas utilizando torres anemométricas.

\subsection{CLASSIFICAÇÃO DOS VENTOS}

Ao se estudar energia eólica, logo se percebe a necessidade de compreender o comportamento do vento. Isto se deve ao fato da potência disponível no vento ser proporcional ao cubo da velocidade.

Uma das principais características do vento é a sua variabilidade e a natureza de seu comportamento estocástico. $\mathrm{O}$ vento varia no tempo e no espaço. A meteorologia classifica o movimento atmosférico em quatro escalas de comprimento de acordo com a duração e dimensões. Essas escalas estão representadas na Figura 3.1.

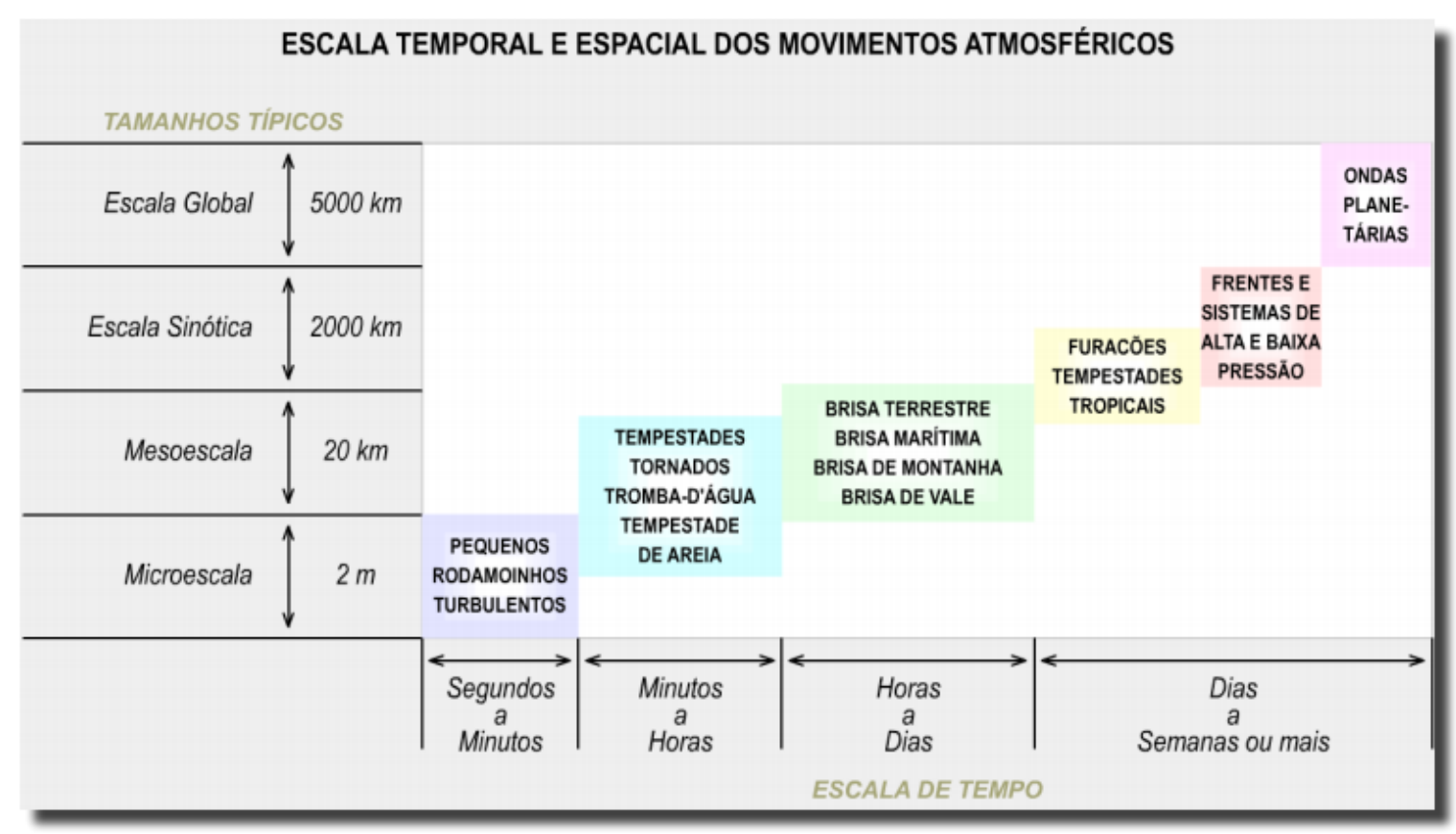

Figura 3.1 - Classificação dos ventos [PEREIRA, 2009]. 


\subsection{MASSAS DE AR}

Grande parte da energia enviada pelo sol para Terra em forma de radiação penetra até a superfície terrestre. No entanto, apenas um pouco mais da metade é absorvida pela Terra. A outra parte da energia é refletida para a atmosfera, chamada de radiação terrestre. Há ainda uma parte de energia absorvida pela Terra que é transferida para atmosfera na forma de calor por condução e convecção, sendo a condução limitada à camada superficial de ar, cerca de milímetros.

Como a radiação do Sol não é uniforme, alguns locais possuem uma temperatura superior a outros. Essa diferença de temperatura irá criar zonas de pressões diferentes, ou gradientes de pressão horizontal e vertical. Estes por sua vez, são a causa do movimento das massas de ar, principalmente o gradiente de pressão horizontal.

\subsection{CIRCULAÇÃO GERAL DOS VENTOS}

A circulação geral dos ventos pode ser entendida a partir das Figuras 3.2 e 3.3:

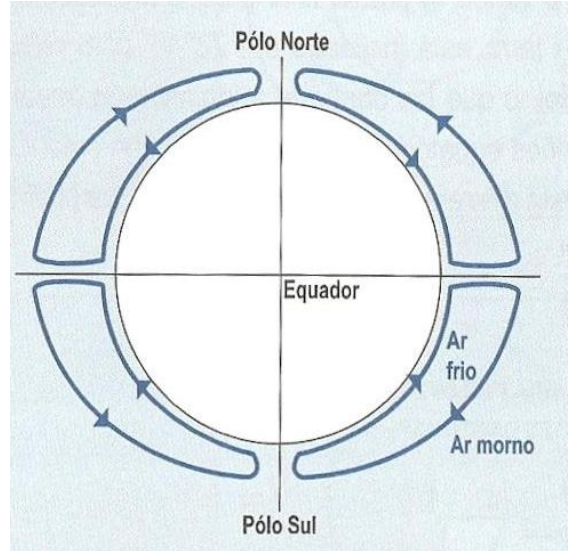

Figura 3.2- Circulação geral dos ventos simplificada [CUSTÓDIO, 2009]. 


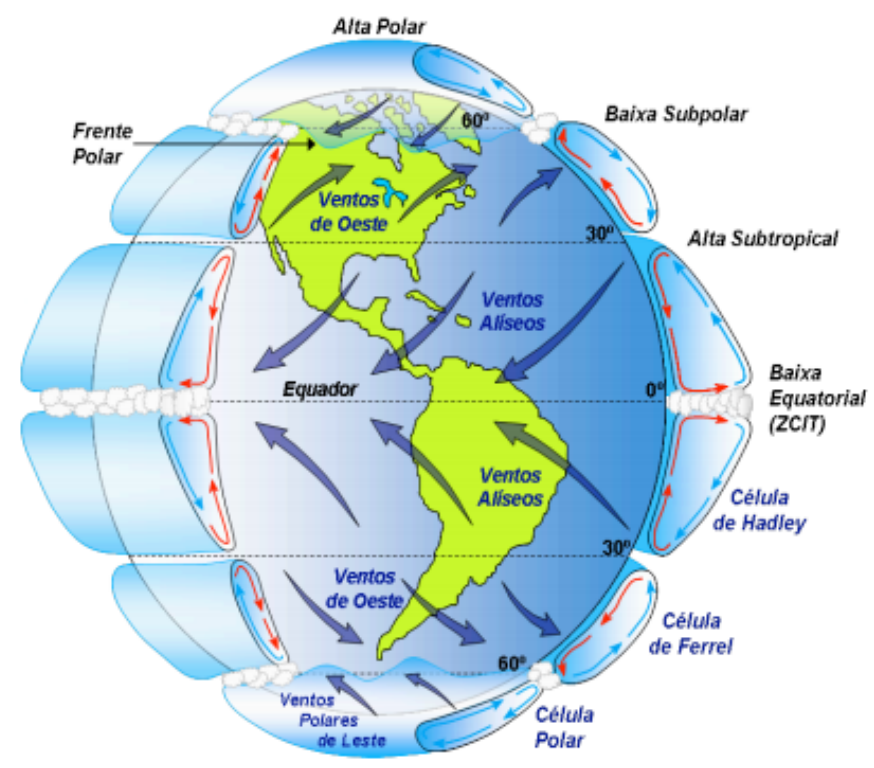

Figura 3.3- Circulação geral dos ventos na superfície da Terra, suposta homogênea [PEREIRA, 2009].

No ano, a região que recebe a maior intensidade de radiação solar é a região equatorial. Por conta dessa diferença de temperatura há um movimento de ar do equador para os pólos. Esse movimento faz com que diminua a pressão na região equatorial e aumente na região polar, ocasionando assim o movimento de ar contrário, dos pólos para o equador.

A partir desse modelo, podemos definir três células de circulação por hemisfério, ilustradas na Figura 3.3: célula tropical (célula de Hadley), célula temperada (célula de Ferrel) e célula polar.

$\mathrm{Na}$ Figura 3.3, nota-se, próximo ao equador, o cinturão de calmarias. Essa região representa um local de baixa pressão, na maior parte do tempo, devido à forte incidência de radiação durante todo o ano. Nessa região os ventos são fracos.

A força de Coriolis, ou efeito de Coriolis, é uma importante força que atua nas massas de ar. Ela é provocada pela rotação da Terra e faz com que as massas de ar possuam uma aceleração angular aparente.

O efeito que essa força causa nas massas de ar é o deslocamento circular, ou em espiral, ao redor de centros de pressão. 


\subsection{POTÊNCIA DO VENTO}

Considere uma massa de ar $m$, com velocidade $v$, que flui através da área $A$ de varredura de uma turbina, que apresenta formato de círculo. A energia cinética presente nessa massa de ar é dada por:

$$
E=\frac{m v^{2}}{2}
$$

$E=$ Energia $[\mathrm{J}]$;

$m=$ Massa de ar $[\mathrm{kg}]$;

$v=$ Velocidade do vento $[\mathrm{m} / \mathrm{s}]$.

A potência dessa massa de ar é dada pela derivada da energia em relação ao tempo:

$$
P=\dot{E}=\frac{d E}{d t}=\frac{\dot{m} v^{2}}{2}
$$

$\mathrm{P}=$ Potência $[\mathrm{W}]$;

$\dot{E}=$ Fluxo de Energia $[\mathrm{J} / \mathrm{s}]$;

$\dot{m}=$ Fluxo de massa de ar $[\mathrm{kg} / \mathrm{s}]$.

Sendo o fluxo de massa de ar dado por:

$$
\dot{m}=\rho v A_{t}
$$

$\rho=$ massa específica do $\operatorname{ar}\left[\mathrm{kg} / \mathrm{m}^{3}\right]$

$A_{t}=$ Área da seção transversal $[\mathrm{m}]$.

Substituindo a equação 3.2 na equação 3.3, a potência disponível no vento é dada por:

$$
P=\dot{E}=\frac{d E}{d t}=\frac{\rho A_{t} v^{3}}{2}
$$

Da equação 3.4, observa-se duas características muito importantes para a geração de energia elétrica a partir da energia eólica. A primeira é a relação da potência com o cubo da velocidade do vento. Assim, uma variação de $10 \%$ na velocidade do vento resulta em uma variação de $33 \%$ na potência disponível. A Figura 3.4 ilustra a variação de potência de acordo com a velocidade: 


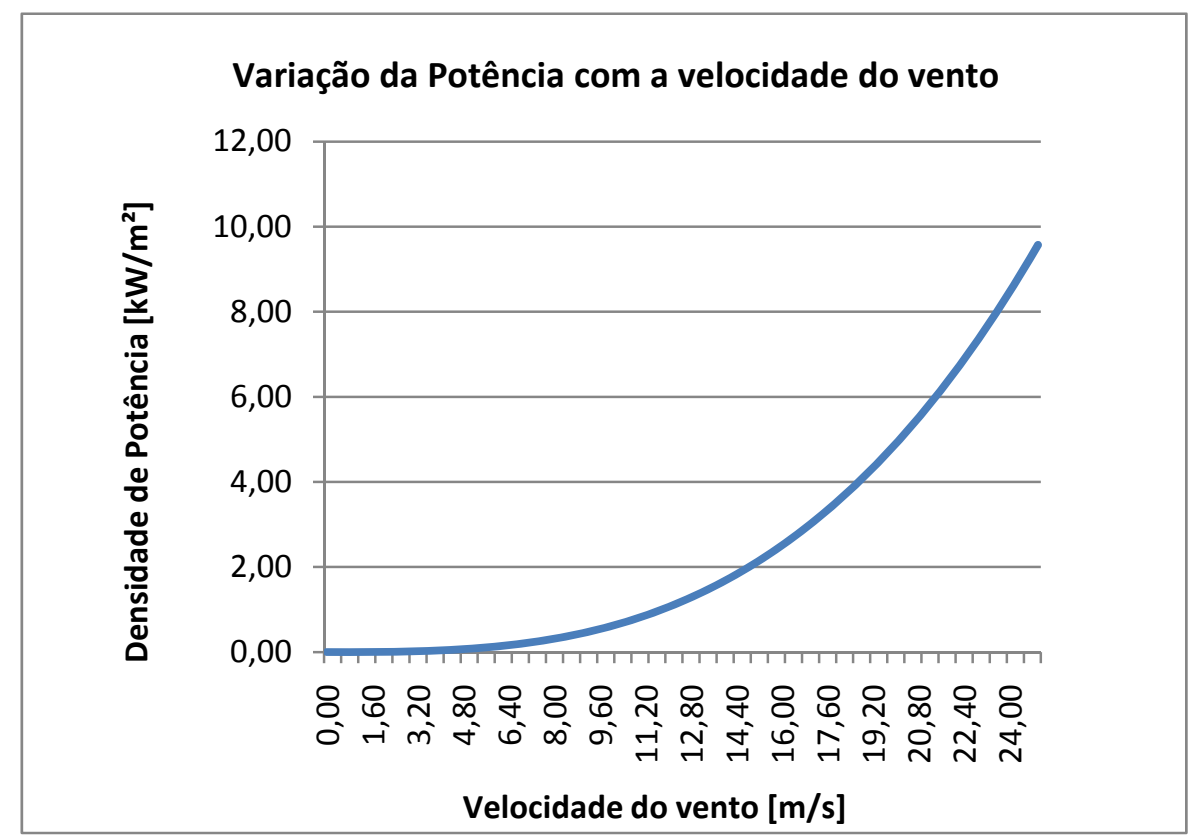

Figura 3.4 - Variação da potência disponível no vento de acordo com a velocidade do vento.

A segunda característica importante é que a potência disponível no vento é proporcional a densidade de ar, $\rho$. Esta por sua vez, é função da pressão ambiente e da temperatura:

$$
\rho=\frac{p}{R T}
$$

$p=$ pressão atmosférica $[\mathrm{Pa}]$;

$R=$ Constante do ar $[287 \mathrm{~J} / \mathrm{kg} . \mathrm{K}]$;

$T=$ Temperatura ambiente $[\mathrm{K}]$;

Como a pressão atmosférica e a temperatura variam com a altitude, então a densidade do ar também varia e por consequência a potência disponível no vento.

\subsection{POTÊNCIA APROVEITÁVEL}

A potência dada pela equação 3.4 é a potência disponível no vento. No entanto, nem toda a energia cinética disponível pode ser transferida para energia mecânica, ou seja, para o rotor da turbina. Se toda a energia cinética fosse transformada em energia mecânica, toda a massa de ar iria parar atrás da turbina. Isto não acontece. 
Quando a massa de ar flui pela turbina, parte de sua energia cinética é transformada em energia mecânica, e com isso a velocidade do vento diminui atrás das turbinas. $\mathrm{O}$ valor máximo teórico de potência que pode ser extraído do vento foi descoberto por Betz, em 1926. O valor ficou conhecido como máximo de Betz ou coeficiente de Betz e equivale a $16 / 27$ ou $59,3 \%$ da potência disponível. De forma prática, a existência da limitação é óbvia já que, se toda a potência disponível fosse retirada, a velocidade do vento na saída das turbinas seria nula.

A Figura 3.5 ilustra a máxima potência disponível e a máxima potência possível de ser extraída do vento.

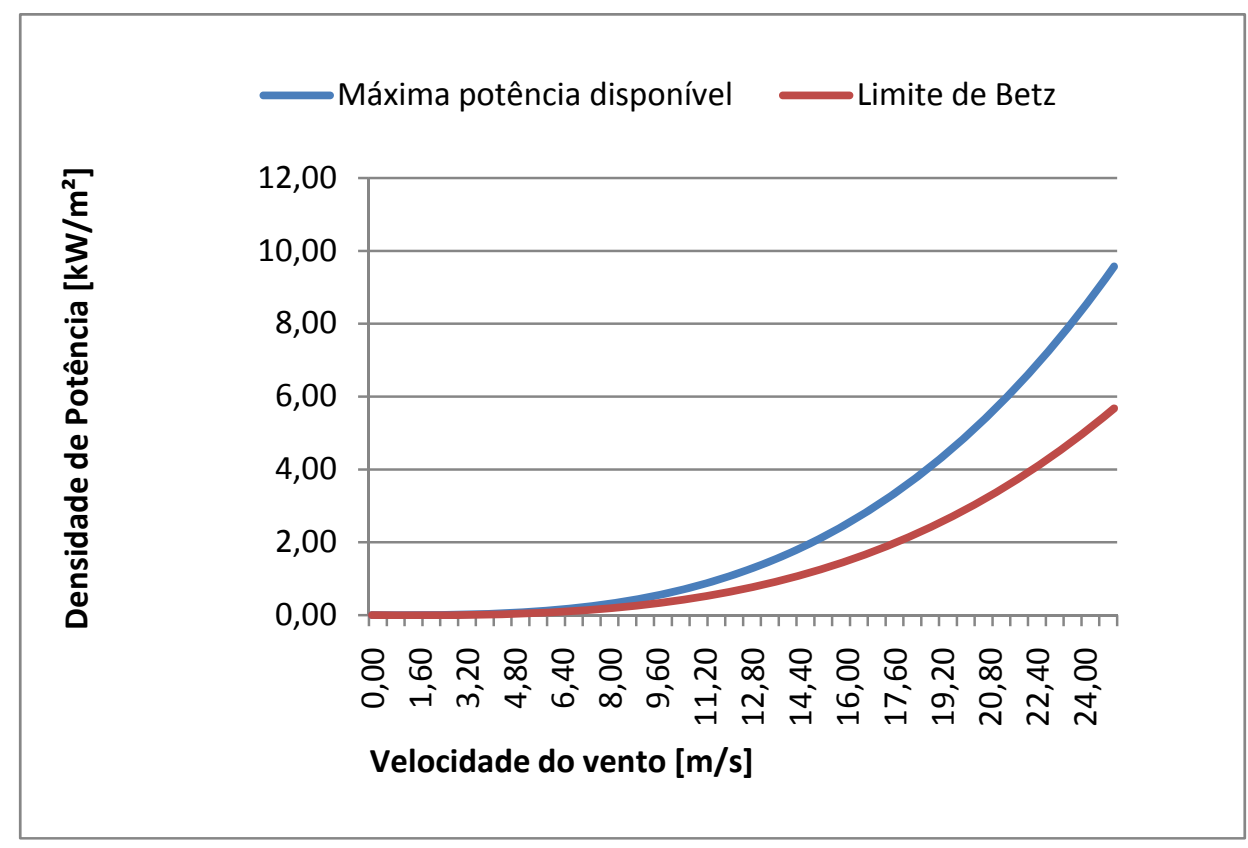

Figura 3.5- Representação da máxima potência extraível do vento

\subsection{ANÁLISE DA DISTRIBUIÇÃO DAS VELOCIDADES.}

No dimensionamento de sítios eólicos, é de grande importância a medição da condição dos ventos no local onde se pretende instalar a usina eólica. E para o correto estudo do potencial eólico, a análise probabilística é essencial.

Depois de feita a medição dos dados no local do sítio onde se pretende instalar a usina, divide-se os dados em faixas de velocidade, tipicamente faixas de $1 \mathrm{~m} / \mathrm{s}$, e analisa-se a 
frequência de ocorrência das medições no intervalo de velocidades. A Figura 3.6 apresenta um histograma típico das frequências de ocorrência das velocidades para a altura de $113 \mathrm{~m}$.

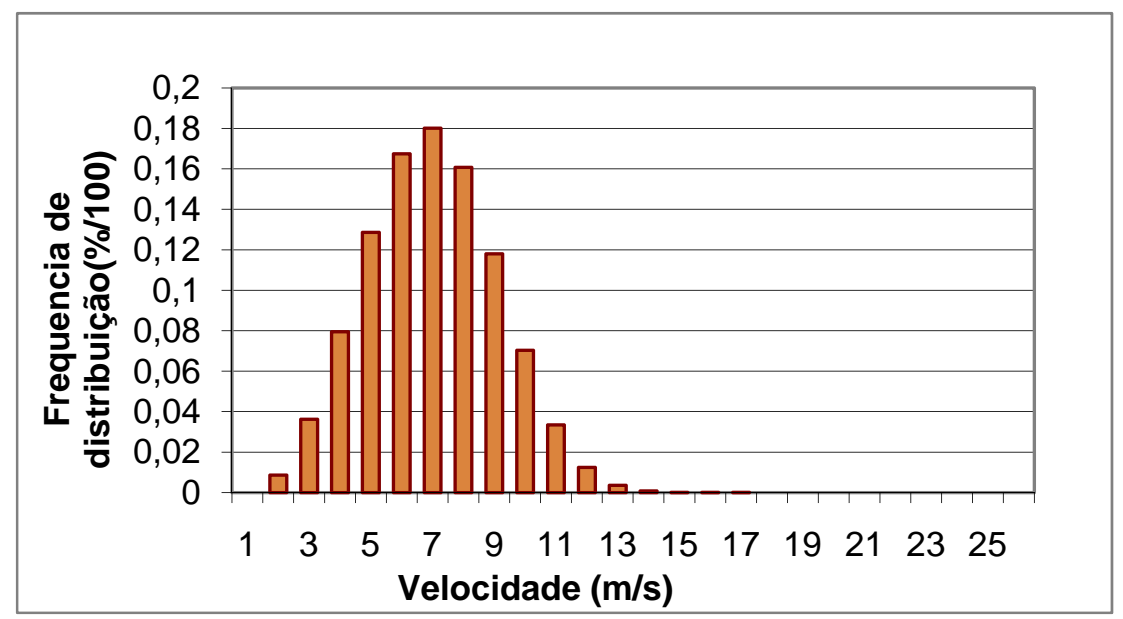

Figura 3.6 - Histograma das frequências de ocorrência das velocidades.

Dos dados medidos, calcula-se a velocidade média do local através da equação 3.6.

$$
V=\frac{1}{n} \sum_{i=0}^{n} v_{i}
$$

$v_{i}=$ Velocidade do vento medida $[\mathrm{m} / \mathrm{s}] ;$

$\mathrm{n}=$ número de registro [adimensional];

$\mathrm{i}$ = identificação do registro.

A frequência de distribuição de velocidade pode ser representada por uma função densidade de probabilidade conhecida por função de Weibull, $f(v)$. Esta função é representada por:

$$
f(v)=\frac{k}{c}\left(\frac{v}{c}\right)^{k-1} e^{-\left(\frac{v}{c}\right)^{k}}
$$

$c=$ fator de escala $[\mathrm{m} / \mathrm{s}]$;

$k=$ fator de forma [adimensional].

A Figura 3.7 abaixo ilustra a função de Weibull para valores de $k$ e $c$ específicos: 


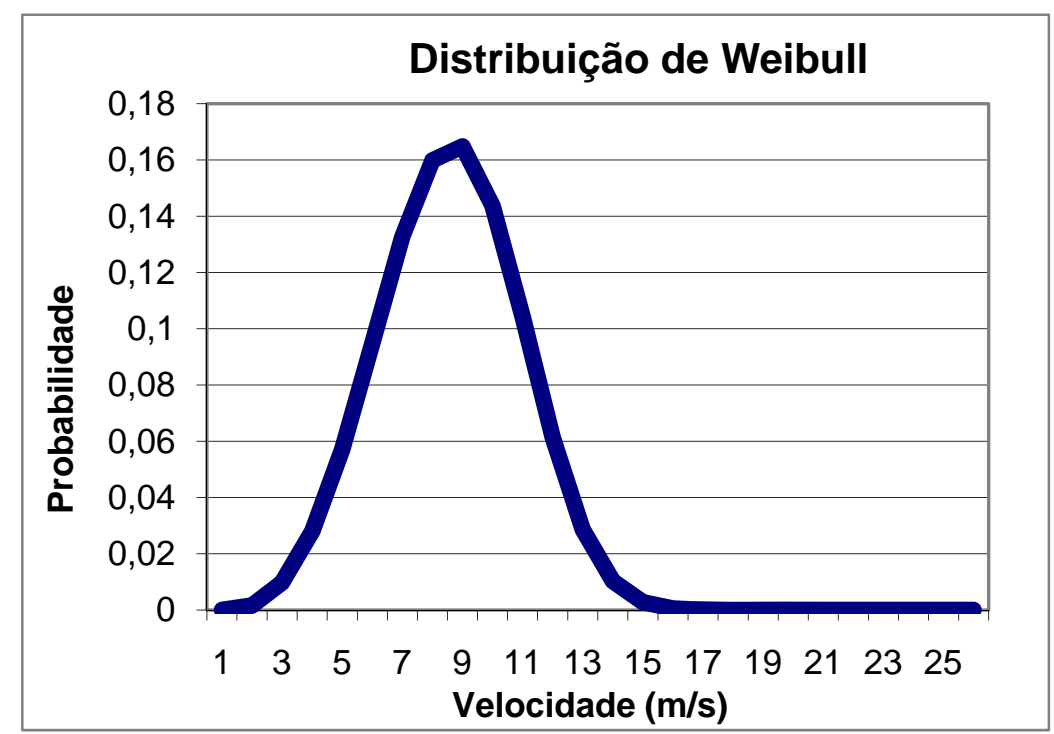

Figura 3.7 - Função de Weibull.

A partir da função de Weibull, pode-se calcular a velocidade média:

$$
V=\int_{0}^{\infty} v f(v) d v
$$

$\mathrm{O}$ fator $k$ representa a forma da curva, ou seja, a variância dos dados em relação à média. $\mathrm{O}$ fator de escala $c$ está relacionado com a velocidade média dos dados obtidos.

A função de Weibull apresenta formas características de funções de densidade de probabilidade conhecidas, dependendo do fator de forma, fator $k$. Alguns exemplos são citados abaixo:

$-k=1$; Função exponencial;

$-k=2$; Função de Rayleigh;

$-k=3,5$; Função Normal.

Em estudos preliminares, quando não se tem os dados das medições, apenas a velocidade média, a função de Rayleigh é uma boa representação do perfil da velocidade. A função de distribuição de velocidades de Rayleigh é dada por:

$$
f(v)=\frac{\pi}{2} \frac{v}{V^{2}} e^{-\left(\frac{\pi}{4}\right)\left(\frac{v}{V}\right)^{2}}
$$

Deve-se verificar que a expressão de Rayleigh não é obtida diretamente da substituição do fator $k$ por 2 na equação 3.7. A correspondência entre as expressões de Weibull e Rayleigh 
no que diz respeito ao fator de forma $k$ restringe-se apenas à forma da curva característica de cada função.

\subsubsection{Determinação dos parâmetros de Weibull}

Para se obter a função de Weibull é necessário definir o fator de escala, $k$, e o fator de forma c. Existem vários métodos de obtenção desses parâmetros. $\mathrm{O}$ método usado nesse trabalho e que será descrito abaixo é o método usando o desvio padrão da velocidade média e a função Gamma, $\Gamma(\mathrm{k})$.

A velocidade média do vento da função de Weibull pode ser expressa por:

$$
V=c \Gamma\left(1+\frac{1}{k}\right)
$$

Da equação 3.11 encontra-se o fator de forma $c$ :

$$
c=\frac{\mathrm{V}}{\Gamma\left(1+\frac{1}{k}\right)}
$$

O desvio padrão dos dados do vento é dado por:

$$
\sigma=\sqrt{\int_{0}^{\infty}(v-V) f(v) d V}
$$

O desvio padrão também pode ser expresso em função da função Gamma:

$$
\sigma=\sqrt{\Gamma\left(1+\frac{2}{k}\right)-\Gamma\left(1+\frac{1}{k}\right)}
$$

Relacionando as expressões 3.10 e 3.13, temos a seguinte equação:

$$
\frac{\sigma^{2}}{V^{2}}=\frac{\Gamma\left(1+\frac{2}{k}\right)}{\Gamma^{2}\left(1+\frac{1}{k}\right)}-1
$$

Dessa forma, supondo valores de $k$, em um processo iterativo, consegue-se traçar uma curva de $\sigma / \mathrm{V}$ em função de $k$.

Para valores de $k$ entre 1,4 e 3,9 [CUSTÓDIO, 2009], pode-se extrair da função $\sigma / \mathrm{V}$ em função de $k$, através de ajuste da curva, a seguinte relação:

$$
k=\left(\frac{\sigma}{V}\right)^{-1,086}
$$




\subsection{ANÁLISE DA DIREÇÃO DAS VELOCIDADES.}

Ao realizar as medições, é muito importante que além de se medir a velocidade dos ventos, seja medido também a direção dos ventos. A importância dessa medição se tornará mais clara na parte de dimensionamento da usina, na disposição dos aerogeradores.

A representação da direção dos ventos medida é feita utilizando a rosa dos ventos dividida em setores de $30^{\circ}$. Nela, representa-se a predominância da direção dos ventos em cada setor. Na Figura 3.8 há um exemplo onde nota-se a predominância de direção dos ventos no setor entre $45^{\circ}$ e $90^{\circ}$ :

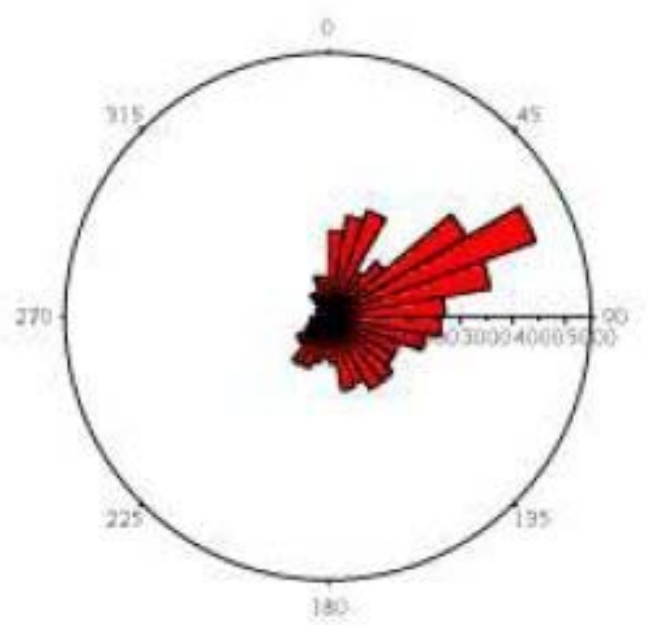

Figura 3.8 - Representação da direção dos ventos [AMARANTE, 2001]. 


\section{TERRENO}

No estudo de implantação de determinado parque eólico, além das características de circulação de vento naquela região, é necessário conhecer as características do terreno a ser utilizado. Tanto as condições topográficas (acidentes geográficos), quanto as condições orográficas (nuances do relevo) influenciam sensivelmente no comportamento do vento e, consequentemente, na produção de energia elétrica, alvo de qualquer empreendimento de energia eólica.

\subsection{CAMADA LIMITE}

$\mathrm{O}$ atrito do ar em movimento com a superfície de determinado terreno provoca alterações no fluxo de ar acima dessa superfície. Essas alterações, contudo, decrescem com o aumento da distância da superfície, chegando a um ponto em que não há mais influência notável da superfície sobre o fluxo de ventos, estado denominado de atmosfera livre.

O vento livre de influência da superfície da Terra é chamado de vento geostrófico. A circulação do vento geostrófico vem do eventual equilíbrio entre a Força de Coriolis causada pela rotação terrestre e a força advinda do gradiente de pressão causado pelas diferenças de temperatura do globo terrestre. A sistemática de forças para formação do vento geostrófico pode ser visto na Figura 4.1, em que $F_{c o}$ é a força de Coriolis, $F_{p}$ é a força resultante do gradiente de pressão e $\mathrm{V}$ é a velocidade do vento geostrófico resultante:

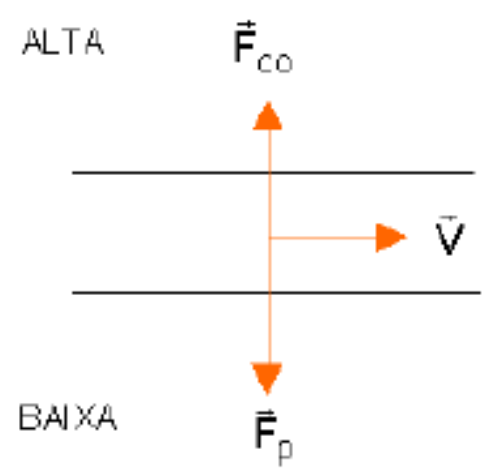

Figura 4.1 - Balanço de forças para formação do vento geostrófico.

Fonte: Garrad Hassan 
No entanto, quanto maior a proximidade da superfície terrestre, maior a força de atrito exercida pela superfície sobre o vento, o que desequilibra o sistema de forças e resulta em uma mudança de direção e intensidade do vetor de velocidade de circulação, resultando na configuração exibida na Figura 4.2, em que $F_{c o}$ é a força de Coriolis, $F_{p}$ é a força resultante do gradiente de pressão, $F_{a}$ é a força de atrito exercida pela superfície e $\mathrm{V}$ é a velocidade do vento geostrófico resultante.

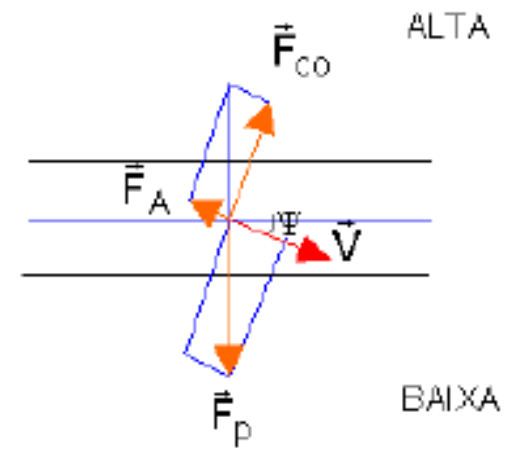

Figura 4.2 - Balanço de forças para formação do vento próximo à superfície.

A alteração do vetor velocidade faz com que se forme uma zona de turbulência próxima à superfície terrestre. A esta zona turbulenta da troposfera dá-se o nome de camada limite atmosférica.

A camada limite pode se estender de dezenas de metros a alguns quilômetros de altura, variando de acordo com as características térmicas da região [GLOSSARY OF METEOROLOGY]. Dessa forma, o conhecimento da camada limite, que resulta no conhecimento do comportamento do vento com a altura, é essencial para o estudo de implantação de turbinas eólicas, visto que o estado da arte atual possibilita instalação de turbinas em alturas entre $100 \mathrm{~m}$ e $150 \mathrm{~m}$. A Figura 4.3 ilustra a forma da camada limite atmosférica. 


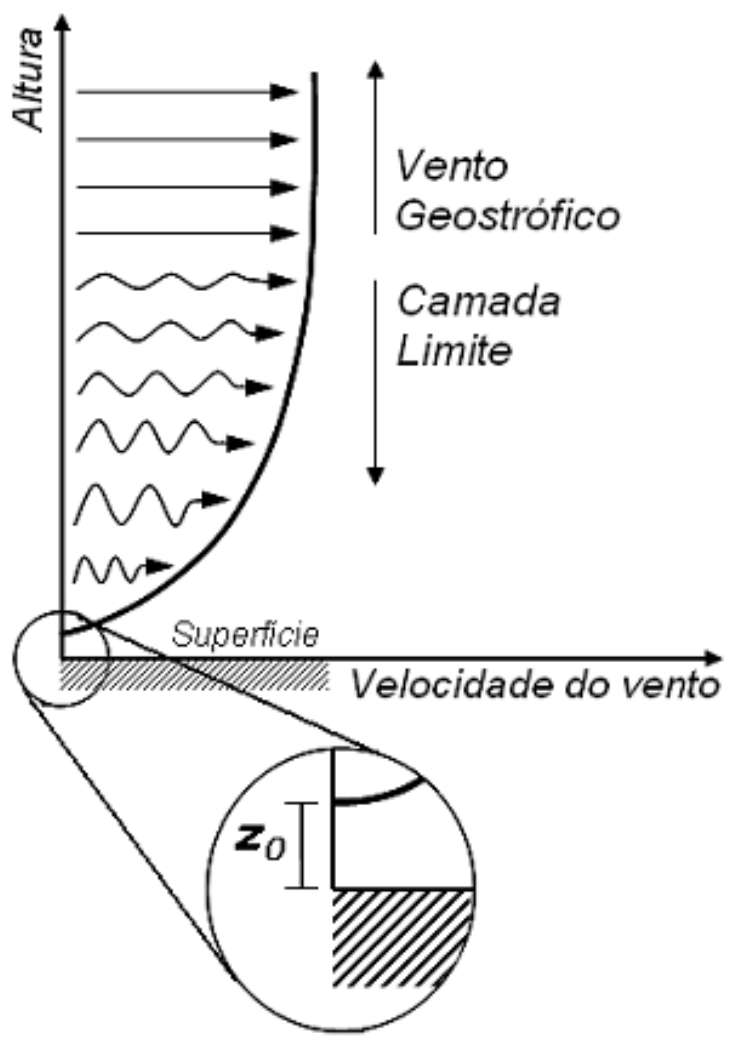

Figura 4.3 - Perfil da camada limite atmosférica [PEREIRA, 2009].

O perfil vertical do vento, que descreve a camada limite, pode ser representado por dois modelos, um exponencial e outro logarítmico. A velocidade horizontal do vento de acordo com o perfil logarítmico é descrita pela seguinte equação:

$$
v=\frac{v_{a t}}{K} * \ln \left(\frac{h}{z_{0}}\right)
$$

Em que:

$v_{a t}=$ velocidade junto ao solo $[\mathrm{m} / \mathrm{s}]$;

$\mathrm{K}=$ constante de $\operatorname{Von} \operatorname{Karman}(0,38$ a 0,41) [adimensional];

$\mathrm{h}=$ altura em relação ao solo $[\mathrm{m}]$;

$z_{0}=$ comprimento de rugosidade do solo $[\mathrm{m}]$.

A velocidade de atrito depende da tensão de cisalhamento da primeira camada de ar acima do solo e da densidade do ar no local da medição. 
$\mathrm{O}$ comprimento de rugosidade, $z_{0}$, corresponde à altura da camada superficial em que pode-se considerar a velocidade do vento como nula [GLOSSARY OF METEOROLOGY]. Isto é, é a altura em relação ao solo em que se inicia a camada limite atmosférica.

Da equação 4.1 pode-se obter a relação de velocidades em diferentes alturas, que pode ser representada pela equação 4.2 :

$$
\frac{v_{1}}{v_{2}}=\frac{\ln \left(\frac{h_{1}}{z_{0}}\right)}{\ln \left(\frac{h_{2}}{z_{0}}\right)}
$$

Em que:

$v_{1}=$ velocidade horizontal no ponto $1[\mathrm{~m} / \mathrm{s}]$;

$v_{2}=$ velocidade horizontal no ponto $2[\mathrm{~m} / \mathrm{s}]$;

$h_{1}=$ altura do ponto $1[\mathrm{~m}]$;

$h_{2}=$ altura no ponto $2[\mathrm{~m}]$;

Da relação 4.2 pode-se, por exemplo, estimar a velocidade em determinada altura a partir de uma medição efetivamente realizada em outras alturas.

Deve-se notar que tanto as expressões 4.1 e 4.2 dependem da rugosidade do terreno. Portanto, depreende-se que as mesmas sejam adequadas somente para pequenas alturas, cerca de 50 m a 150 m [CUSTÓDIO, 2009], em que o terreno tem influência significativa no fluxo de ventos.

Considerando o perfil vertical de vento na forma exponencial, o equivalente à equação 4.2 pode ser representado pela equação 4.3 :

$$
\frac{v_{1}}{v_{2}}=\left(\frac{h_{1}}{h_{2}}\right)^{\alpha}
$$

Em que:

$\alpha=$ expoente de camada limite que se ajuste à curva (tipicamente entre 0,05 e 0,6 ) [adimensional]. 
Por conta do perfil vertical do vento, os fatores de escala, c, e de forma, $\mathrm{k}$, da função de Weibull sofrem alterações. Essa variação com a altura pode ser determinada pelas equações 4.4 e 4.6 :

$$
\begin{gathered}
c_{2}=c_{1}\left(\frac{h_{2}}{h_{1}}\right)^{n} \\
n=\frac{0,37-0,088 \ln c_{1}}{1-0,088 \ln \frac{h_{2}}{10}} \\
k_{2}=k_{1}\left(\frac{1-0,088 \ln \frac{h_{1}}{10}}{1-0,088 \ln \frac{h_{2}}{10}}\right)
\end{gathered}
$$

Onde:

$c_{1}=$ fator de escala no ponto $1[\mathrm{~m} / \mathrm{s}]$;

$c_{2}=$ fator de escala no ponto $2[\mathrm{~m} / \mathrm{s}]$;

$k_{1}=$ fator de forma no ponto $1[\mathrm{~m}]$;

$k_{2}=$ fator de forma no ponto $2[\mathrm{~m}]$;

$\mathrm{n}=$ expoente utilizado na equação 4.4 .

Deve-se notar que as expressões 4.3, 4.4 e 4.6 não dependem da rugosidade, diferentemente das expressões 4.1 e 4.2. Isto significa que as expressões que determinam os parâmetros da função de Weibull para diferentes alturas apresentam um bom resultado apenas para lugares com poucos obstáculos.

\subsection{RUGOSIDADE}

Entende-se por rugosidade de um terreno a influência que a superfície e os acidentes do mesmo exercem sobre o fluxo de ar próximo ao solo [CUSTÓDIO, 2009].

Usualmente, mede-se a rugosidade através do comprimento de rugosidade da superfície $\left(z_{0}\right)$, dado em unidade de comprimento. Na prática, o comprimento de rugosidade consiste na altura em que a velocidade do vento é igual a zero, considerando que o vento tenha um perfil vertical logaritmico [CUSTÓDIO, 2009]. 
Há diversos métodos meteorológicos para obtenção de $z_{0}$. Um deles consiste na relação empírica obtida por Lattau (1969), que pode ser descrita pela equação 4.7.

$$
z_{0}=0,5 \frac{h s}{A}
$$

Em que:

$\mathrm{h}=$ altura do elemento de rugosidade $[\mathrm{m}]$;

$\mathrm{S}=$ Seção transversal, na direção do vento, do elemento de rugosidade $\left[\mathrm{m}^{2}\right]$;

$\mathrm{A}=$ Área horizontal média dos elementos de rugosidade uniformemente distribuídos $\left[\mathrm{m}^{2}\right]$.

Devido à dificuldade de obtenção dos parâmetros utilizados na equação 4.7, pode-se utilizar, em estudos preliminares, valores tabelados de acordo com características básicas do terreno. A Tabela 4.1 apresenta valores de comprimento de rugosidade para diferentes configurações de terreno. 
Tabela 4.1 - Classes e comprimentos de rugosidade para diferentes terrenos. [TROEN, 1989]

\begin{tabular}{|c|c|c|c|}
\hline $\begin{array}{l}\text { Classe de } \\
\text { rugosidade }\end{array}$ & $\begin{array}{l}\text { Comprimento de } \\
\text { rugosidade (m) }\end{array}$ & $\begin{array}{c}\text { Índice de } \\
\text { energia (\%) }\end{array}$ & Tipo de terreno \\
\hline 0,0 & 0,0002 & 100 & Superfície da água \\
\hline 0,5 & 0,0024 & 73 & $\begin{array}{l}\text { Terreno livre de obstáculos com } \\
\text { superfície suave como concreto, } \\
\text { pistas de aeroporto, grama baixa. }\end{array}$ \\
\hline 1,0 & 0,03 & 52 & $\begin{array}{l}\text { Área agrícola sem fendas, vales e } \\
\text { prédios muito dispersos. Colinas } \\
\text { arredondadas }\end{array}$ \\
\hline 1,5 & 0,055 & 45 & $\begin{array}{l}\text { Área agrícola com algumas casas e } \\
\text { abrigos de } 8 \text { metros separados por } \\
\text { distância de aproximadamente } \\
1250 \mathrm{~m} \text {. }\end{array}$ \\
\hline 2,0 & 0,1 & 39 & $\begin{array}{l}\text { Área agrícola com algumas casas e } \\
\text { abrigos de } 8 \text { metros separados por } \\
\text { distância de aproximadamente } 500 \mathrm{~m} \text {. }\end{array}$ \\
\hline 2,5 & 0,2 & 31 & $\begin{array}{l}\text { Área agrícola com muitas casas, } \\
\text { arbustos e plantas, ou abrigos de } 8 \\
\text { metros de altura com distância de } \\
250 \mathrm{~m} \text {. }\end{array}$ \\
\hline 3,0 & 0,4 & 24 & $\begin{array}{l}\text { Vilas, pequenas cidades, área } \\
\text { agrícola com muitos abrigos ou } \\
\text { abrigos muito altos, florestas e } \\
\text { terrenos muito complexos e rugosos. }\end{array}$ \\
\hline 3,5 & 0,8 & 18 & $\begin{array}{llll}\text { Cidades maiores } & \text { com } & \text { grandes } \\
\text { edifícios. } & & & \\
\end{array}$ \\
\hline 4,0 & 1,6 & 13 & $\begin{array}{l}\text { Cidades muito grandes com grandes } \\
\text { edifícios e arranha-céus. }\end{array}$ \\
\hline
\end{tabular}

\subsection{OBSTÁCULOS}

A presença de obstáculos em um sítio onde se pretende instalar um parque eólico deve ser visto com muito cuidado pela dificuldade em se prever o efeito exato que terão sobre o fluxo de vento. 


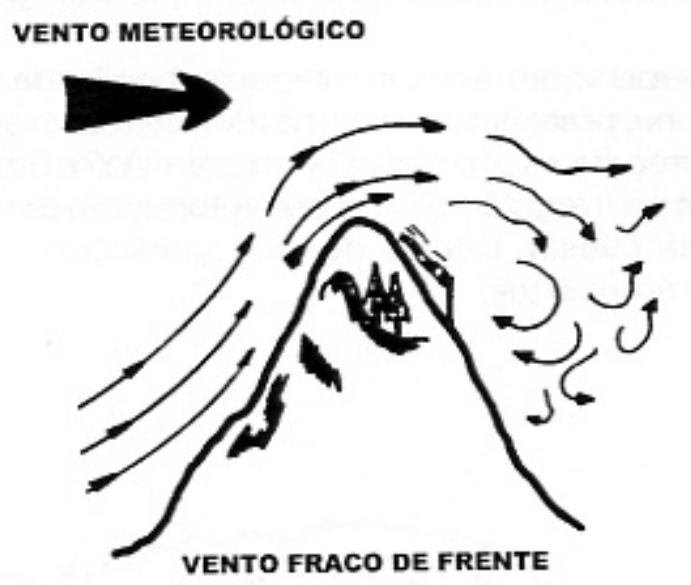

Figura 4.4 - Comportamento do vento antes e após passagem por obstáculo

A dificuldade em prever o comportamento do vento após a passagem por um obstáculo encontra-se no fato desse comportamento depender de muitas variáveis, muitas vezes indisponíveis sem um estudo aprofundado, o que onera ainda mais qualquer investimento a ser feito no local.

Um dos efeitos mais indesejados para um parque eólico consiste na formação de "sombras", que são esteiras de vento com baixa velocidade, o que pode prejudicar drasticamente a eficiência do parque, devendo ser considerado este efeito para análise de Micrositing a ser feita adiante neste trabalho. 


\section{AEROGERADORES}

Conforme foi visto no Capítulo 4, a geração de energia eólica baseia-se na captura de energia cinética presente nos ventos. Toda a conversão dessa energia cinética em energia elétrica dá-se através do aerogerador ou turbina eólica, uma máquina conhecida pelo homem há muito tempo e que, nos últimos anos, passou por uma série de sofisticações e otimizações que a transformassem em um eficiente equipamento para geração de energia elétrica.

\subsection{COMPONENTES BÁSICOS DE UM AEROGERADOR}

De maneira básica, um aerogerador moderno pode ser representado pela Figura 5.1.

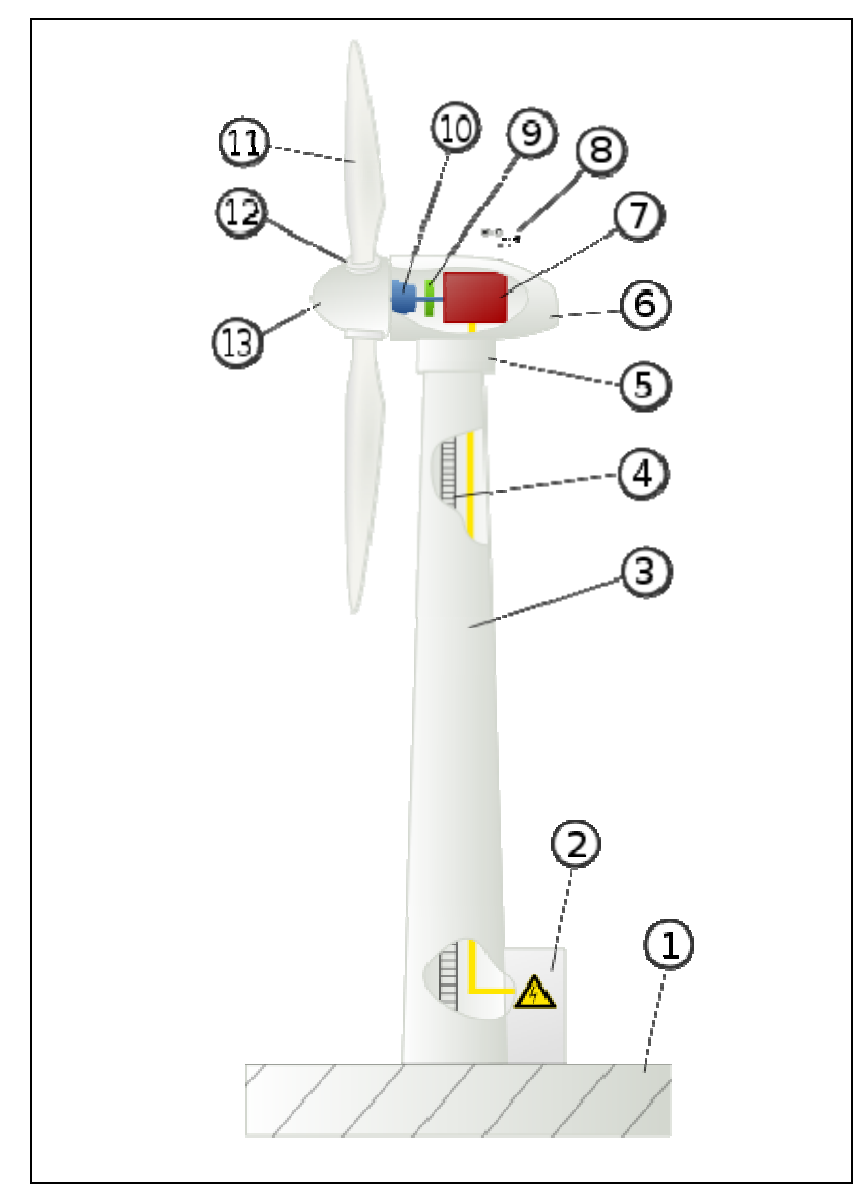

Figura 5.1 - Perfil básico de aerogerador moderno.

As marcações numéricas na Figura 5.1 indicam as seguintes partes básicas de um aerogerador: 
1.Fundação: estrutura que sustenta o aerogerador. Geralmente de concreto ou aço [CUSTÓDIO, 2009];

2. Conexão elétrica do aerogerador: ponto de ligação entre o aerogerador e a rede elétrica disponível;

3. Torre: a torre é a estrutura que sustenta a parte de cima do aerogerador, elevando as estruturas do mesmo até alturas que sejam mais convenientes à geração de energia elétrica;

4. Escada;

5. Base da nacelha: nos aerogeradores modernos pode ser equipada com motores que movimentam a turbina na direção do vento. Este tipo de controle é conhecido como yaw control;

6. Nacelha: compartimento onde se localizam os equipamentos que ficam na parte de cima do aerogerador como geradores, caixas de engrenagens e transformadores;

7. Gerador: onde ocorre, de fato, a geração de energia no aerogerador;

8. Anemômetro: utilizado para monitorar velocidades e direções do vento com o fim de acionar ou não os controles automáticos presentes no aerogerador;

9. Caixa de engrenagens: o rotor do aerogerador gira lentamente. Porém, alguns geradores necessitam de alta velocidade de rotação. A caixa de engrenagens serve para adequar a velocidade de rotação da turbina do aerogerador com a velocidade de rotação do eixo do gerador;

10. Eixo do rotor: transfere a rotação da turbina à caixa de engrenagens;

11. Pá: estrutura responsável por capturar a energia do vento através de seu perfil aerodinâmico. Os modelos de pás mais modernos são construídos em fibra de vidro;

12. Controle das pás: mecanismo de controle de ângulo de ataque da pá. Esse mecanismo de controle existe apenas em modelos de aerogeradores que possuem controle por pitch; 13. Rotor; parte girante do aerogerador.

\subsection{AERODINÂMICA DOS AEROGERADORES}

A captura e conversão de energia cinética em mecânica são feitas pelo rotor do aerogerador, mais especificamente através das pás ligadas ao rotor.

Porém, as pás devem ter um perfil específico para que seja possível que as mesmas capturem a energia do vento, isto é, girem. A aerodinâmica de uma pá segue o mesmo 
princípio das asas de um avião, isto é, deve haver uma força de sustentação que faça com que a pá gire. A Figura 5.2 mostra o diagrama de forças presentes em uma pá.

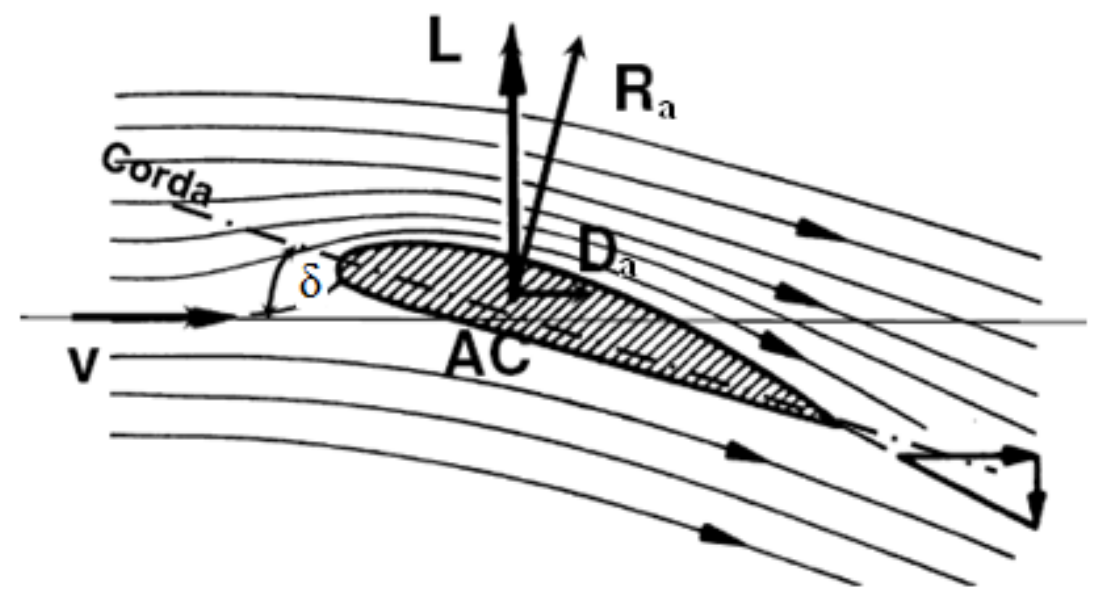

Figura 5.2 - Diagrama de forças em uma pá [MOLLY, 2009].

Em que,

$\mathrm{v}=$ velocidade do vento $[\mathrm{m} / \mathrm{s}]$;

$\mathrm{L}=$ força de sustentação $[\mathrm{N}]$;

$D_{a}=$ força de arraste $[\mathrm{N}]$;

$R_{a}=$ força aerodinâmica resultante $[\mathrm{N}]$;

$\mathrm{AC}=$ centro aerodinâmico;

$\delta=$ ângulo de ataque do vento [rad].

Ao passar pelo perfil de uma pá, há uma alteração no vetor velocidade do vento que passa por cima e por baixo da pá. Conforme a segunda lei de Newton, essa alteração provoca o surgimento de uma força nos dois lados da pá. Dessa forma, o sentido dessa força é determinado de acordo com o gradiente de pressão nos dois lados da pá: se a velocidade é maior em cima, essa zona tem menor pressão, portanto, a força aponta de baixo para cima da pá e o equivalente ocorre para o caso oposto. A força que surge desse balanço de pressão é chamada de força de sustentação, que pode ser quantificada através da equação 5.1 .

$$
L=\frac{\rho}{2} V^{2} C_{s} A
$$

Em que,

$\mathrm{L}=$ Força de sustentação $[\mathrm{N}]$ 
$\rho=$ Densidade do ar $\left[\mathrm{kg} / \mathrm{m}^{3}\right]$

$\mathrm{V}=$ Velocidade do vento $[\mathrm{m} / \mathrm{s}]$

$\mathrm{C}_{\mathrm{s}}=$ Coeficiente de sustentação [adimensional]

$\mathrm{A}=$ Área da superfície superior da pá $\left[\mathrm{m}^{2}\right]$

Nota-se, então, que a força de sustentação varia com o quadrado da velocidade.

A força de arraste, D, é a força que o vento exerce sobre a pá na direção do vento. A soma da força de arraste com a força de sustentação é uma força resultante que efetivamente é a responsável pelo movimento da turbina, também conhecida como força de empuxo. Neste ponto, ocorre a transformação da energia cinética do vento em energia mecânica, responsável pela rotação do rotor. A eficiência dessa transformação obedece ao limiar proposto por Betz, o chamado coeficiente de Betz, já citado no Capítulo 3, item 6, correspondente a $59,3 \%$.

\subsubsection{Fluxo de vento na pá}

De acordo com o ângulo de ataque do vento, de sua velocidade ou da rugosidade da pá pela qual o vento passa, existem diferentes perfis de fluxo de ar sobre a pá.

O escoamento laminar corresponde ao perfil em que as correntes de fluxo encontrem-se alinhadas e as partículas se movimentem ordenadamente, sem variar a posição relativa entre as mesmas. Tal condição pode ser representada pela Figura 5.3.

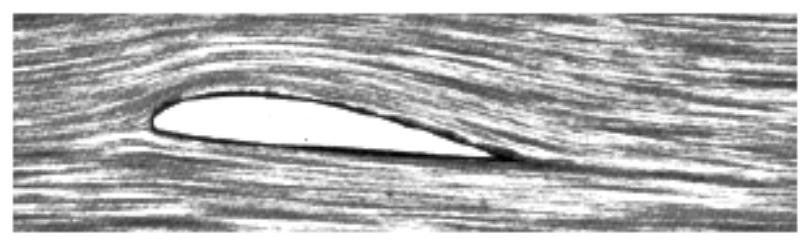

Figura 5.3 - Fluxo laminar de vento através da pá [MOLLY, 2009].

Porém, de acordo com a velocidade, o ângulo de ataque e a rugosidade da pá, pode ocorrer um desordenamento entre as linhas de fluxo, o que acarreta em uma turbulência nas faces da pá. Esse tipo de escoamento é conhecido como escoamento turbulento e apresenta a forma presente na Figura 5.4. 


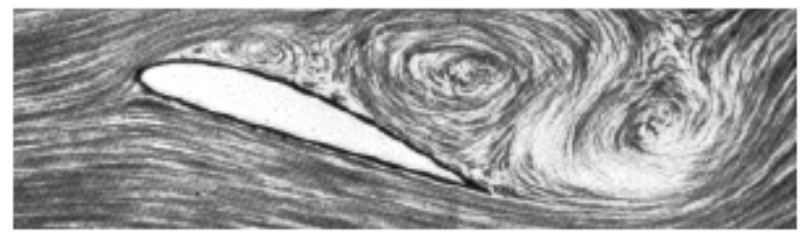

Figura 5.4 - Fluxo turbulento de vento através da pá [MOLLY, 2009].

Os diferentes perfis de escoamento acarretam em diferentes forças resultantes sobre as pás, o que influencia de maneira decisiva no aproveitamento da velocidade do vento pela pá.

\subsection{CONTROLE DE POTÊNCIA DOS AEROGERADORES}

Para que haja um melhor aproveitamento de potência e segurança estrutural da turbina, foram implementados sistemas de controle de potência nas mesmas. Esses sistemas garantem que a turbina opere dentro de uma faixa de velocidades para os quais a mesma foi projetada.

Basicamente, existem sistemas ativos e passivos de controle de potência de um aerogerador.

\subsubsection{Controle passivo de potência (Estol)}

O controle passivo de potência, conhecido como controle por estol consiste em uma utilização do perfil aerodinâmico da pá para que a mesma seja freada quando o vento atinge determinada velocidade.

Como foi descrito na Seção 5.2.1, ocorrem dois tipos de escoamento de vento sobre a pá: escoamento laminar e turbulento. No escoamento laminar mostrado na Figura 5.3, existe um gradiente de pressão provocado pela diferença de velocidade nas faces superior e inferior da pá que faz com que ocorra o surgimento de uma força de sustentação para cima. No caso do escoamento turbulento, a velocidade na parte superior da pá diminui, o que diminui a diferença de pressão entre as faces, fazendo com que a força de sustentação diminua. 
Quando não existe mais a força de sustentação, não há movimentação do rotor, exceto por inércia. Deste modo, ao provocar a ocorrência de um escoamento turbulento sobre a pá, pode-se diminuir a velocidade de rotação do rotor, mantendo-o sempre numa faixa desejável. É baseado nessa ideia que funciona o controle por estol, puramente passivo.

O controle por estol foi largamente utilizado no começo da implantação de turbinas eólicas para geração de energia em grande escala e apresenta algumas vantagens como o baixo preço, baixos custos de manutenção e autocontrole de potência.

A principal desvantagem do controle por estol reside no fato de que há apenas uma velocidade ótima de operação em que a potência da turbina se iguala a potência nominal. Antes e após esta velocidade, a potência da turbina é menor do que a nominal, como o ilustra a curva de potência típica de uma turbina com controle por estol disponível na Figura 5.5.

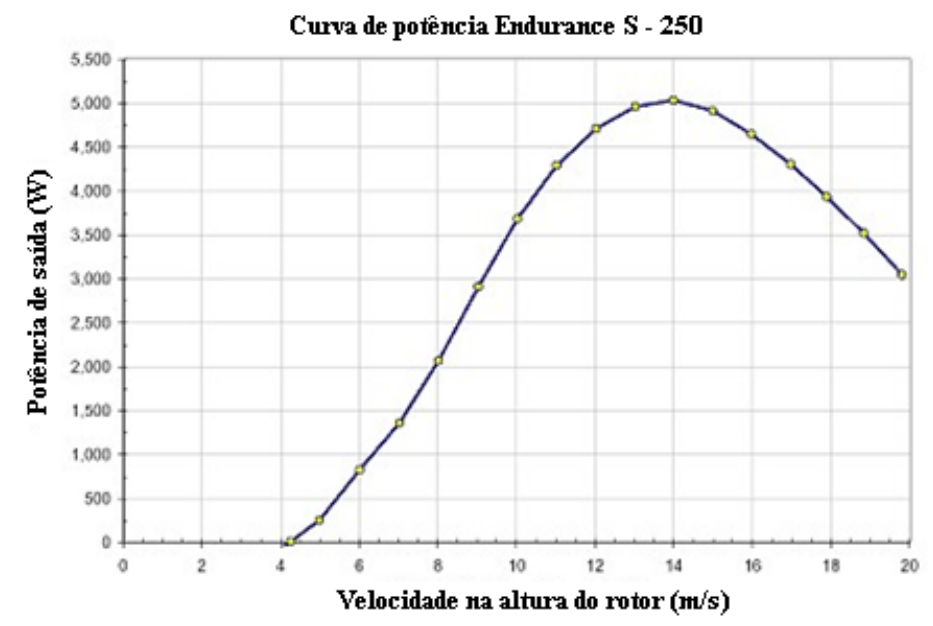

Figura 5.5 - Curva de potência de turbina com controle passivo de velocidade. Fonte: Endurance Wind Power

\subsubsection{Controle ativo de potência (pitch)}

O controle por passo é um controle de sistema ativo que necessita de um sinal do aerogerador. Este sistema de controle varia o ângulo de ataque, $\alpha$, de toda ou parte das pás da turbina no eixo longitudinal fazendo com que a potência de saída seja a melhor para aquela velocidade de vento devido à maior força de sustentação. 
A Figura 5.6 ilustra várias curvas de potência para diferentes ângulos de ataque para um aerogerador de $500 \mathrm{~kW}, 40 \mathrm{~m}$ de diâmetro com controle de potência por passo, com velocidade nominal de $33 \mathrm{rpm}$ :

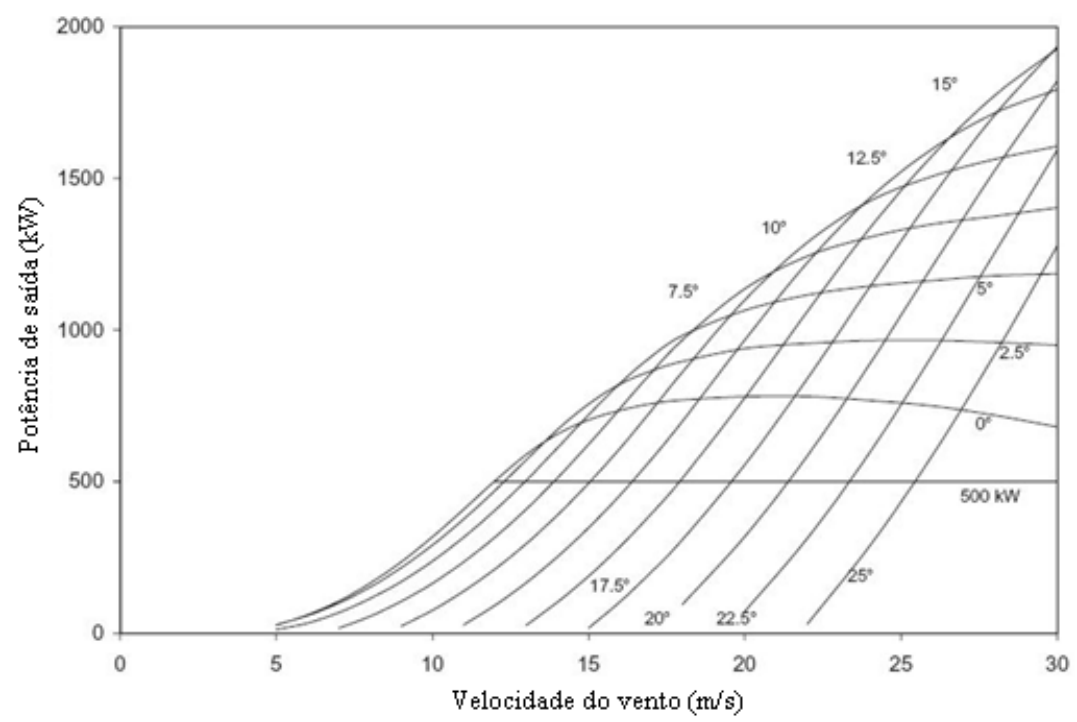

Figura 5.6- Curvas de potência para diferentes ângulos de ataque para um aerogerador de $500 \mathrm{~kW}, 40 \mathrm{~m}$ de diâmetro com controle de potência por passo, com velocidade nominal de $33 \mathrm{rpm}$ [ACKERMANN, 2005].

Como se pode observar na Figura 5.6, para diferentes valores de potência, o valor do ângulo $\alpha$ é alterado para aumentar a força de sustentação aumentando assim a potência para uma mesma velocidade do vento.

Por poder variar o ângulo de ataque, as turbinas com esse tipo de controle conseguem produzir mais energia sob as mesmas condições do que outras que não possuem este tipo de controle.

Outra vantagem do controle por passo é o processo de parada de emergência e o processo de partida. Em altas velocidades do vento, a turbina precisa cessar o seu funcionamento para que o aerogerador não se danifique devido aos altos esforços mecânicos. Para os aerogeradores com controle de passo, basta mudar o ângulo de ataque, ou seja, usar o freio aerodinâmico. Para ter uma partida simples, muda-se o ângulo de passo para que a turbina comece a gerar com ventos mais fracos. 
Apesar dos aerogeradores com controle de passo produzirem mais energia, essa quantidade a mais de energia não é muito maior do que a energia produzida por aerogeradores com controle por estol. Utilizando como base uma turbina com controle por estol de $500 \mathrm{~kW}$, 40 metros de diâmetro e $30 \mathrm{rpm}$, uma outra turbina idêntica, apenas com controle de potência diferente, por passo, a diferença na energia produzida é em torno de apenas $2 \%$ [ACKERMANN, 2005], o que deve-se ao fato de que raramente ocorrem ventos acima da velocidade nominal, região de grande vantagem de geração em sistemas que utilizam controle por passo.

De toda forma, atualmente, existe uma clara predominância de aerogeradores equipados com controle por passo. A Figura 5.7 mostra a preferência por controle de pitch em aerogeradores de $1 \mathrm{MW}$, nos últimos anos.

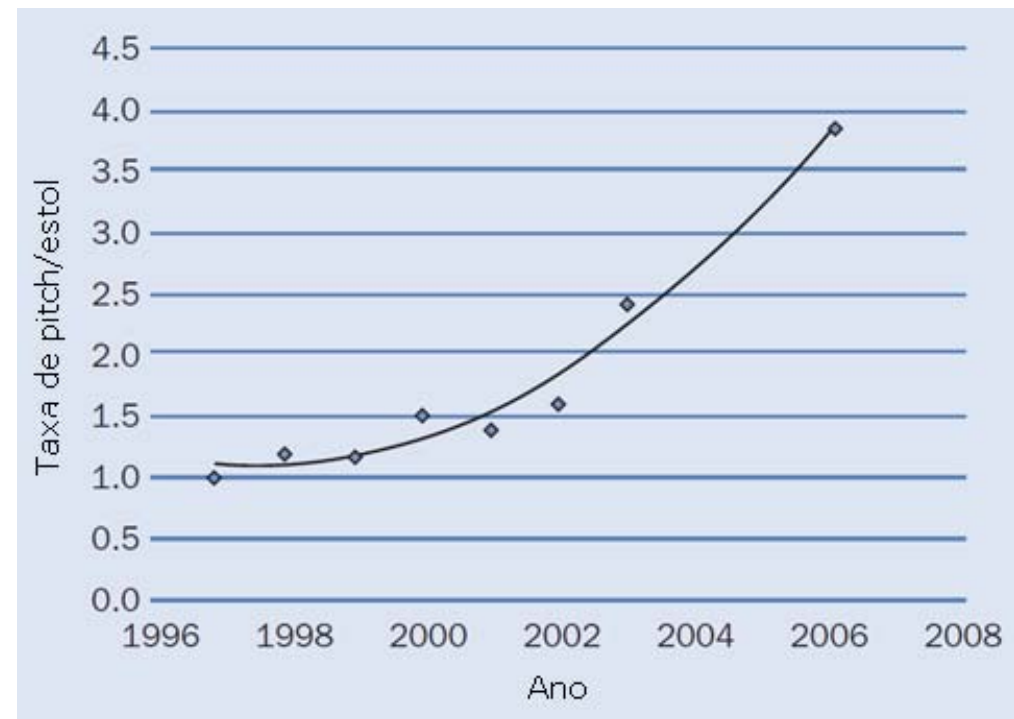

Figura 5.7 - Relação de uso de controle pitch / uso de controle estol. Disponível em http://www.wind-energy-the-facts.org/en/part-i-technology/chapter-3-wind-turbinetechnology/technology-trends/pitch-versus-stall.html

\subsection{CONTROLE DE FREQUÊNCIA DE AEROGERADOR}

Para produzir energia elétrica para a rede, o aerogerador deve obedecer às condições impostas pela mesma. Entre essas condições de suma importância está a frequência, que é padronizada, no Brasil, em $60 \mathrm{~Hz}$. 
A frequência da energia gerada é determinada pelo movimento do rotor do gerador de energia elétrica. O rotor do gerador localizado dentro do aerogerador está ligado à turbina. Porém, o rotor da turbina tem seu giro influenciado pela velocidade do vento, grandeza bastante imprevisível e inconstante. Dessa forma, controlar a frequência da energia gerada exige mecanismos especiais e complexos para tal finalidade.

\subsubsection{Aerogerador com velocidade constante}

Esse modelo de aerogeradores é equipado com motores de indução ligados diretamente a rede e possui máxima eficiência em uma determinada velocidade do vento. Algumas turbinas possuem duas configurações de números de pólos, assim para velocidade de ventos mais baixas teríamos uma configuração com maior número de pólos (8 pólos) e para velocidades mais elevadas teríamos uma configuração com menor número de pólos (de 4 a 6 pólos) [ACKERMANN, 2005].

O aerogerador com velocidade constante apresenta como vantagens ser robusto, simples, de desempenho conhecido e bem aceito na área da energia eólica. Como sua construção é simples, o seu custo acaba sendo baixo. Entretanto, ele apresenta como desvantagens um consumo sem controle de potência reativa e na partida ele possui correntes muito altas, algo em torno de 5 vezes a corrente nominal [MANWELL, 2002].

Esse modelo de aerogerador teve o auge do seu uso no início da década de 90 [ACKERMANN, 2005]. Nos últimos anos, os aerogeradores com velocidade variável ganhou espaço no mercado, entre outros motivos, por reduzir o estresse mecânico que ocorre na turbina com velocidade constante.

\subsubsection{Aerogerador com velocidade variável}

Nos últimos anos, os aerogeradores que operam com velocidade variável têm sido utilizados de forma dominante nas novas instalações de geração eólica [ACKERMANN, 2005].

Para que a energia seja gerada em uma determinada frequência, mesmo com variações de velocidade no gerador, aerogeradores deste tipo são conectados à rede através de 
conversores de frequência. Ou seja, neste caso, o rotor do aerogerador gira de acordo com a velocidade do vento, e não de acordo com a frequência da rede.

A vantagem de o rotor poder girar de acordo com a velocidade do vento reside na possibilidade de otimização de extração de potência do vento. Esta otimização é obtida de acordo com a conhecida curva $\mathrm{Cp} \times \lambda$ das turbinas, em que Cp é o coeficiente de potência $\mathrm{e}$ $\lambda$ é a tip speed ratio (tsr), dada pela equação 5.2.

$$
\lambda=\omega R_{T} / v
$$

Em que,

$\omega=$ velocidade de rotação da turbina[ $[\mathrm{rad} / \mathrm{s}]$;

$R_{T}=$ raio do aerogerador $[\mathrm{m}]$.

A relação entre $\mathrm{Cp}$ e $\lambda$ pode ser vista através da Figura 5.8.

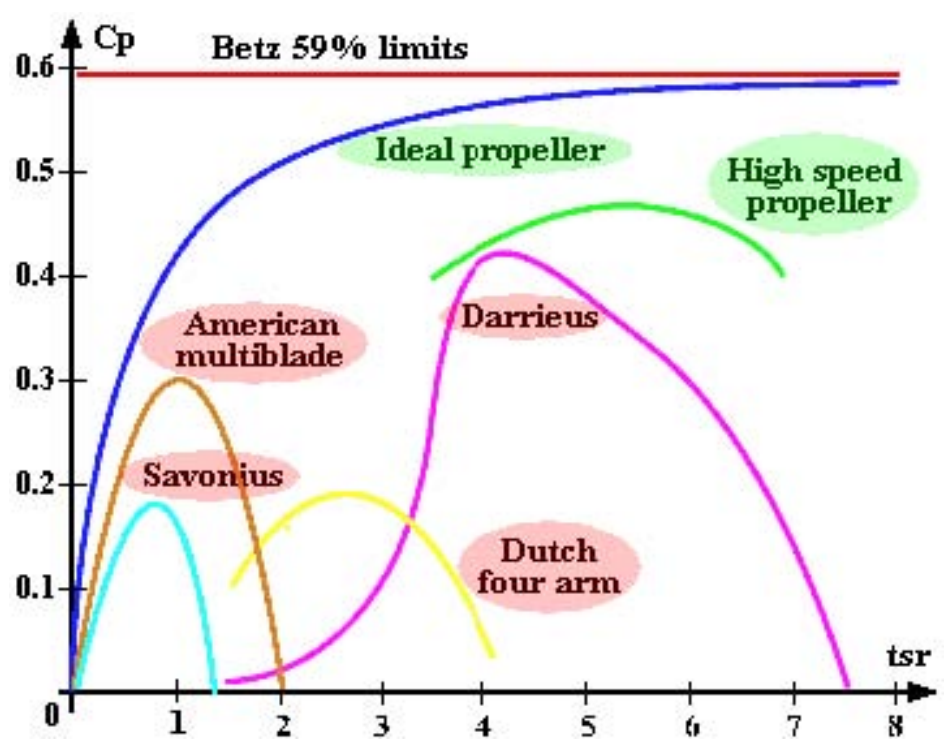

Figura 5.8 - Coeficiente de potência $(\mathrm{Cp})$ versus tip speed ratio $(\lambda)$ para diversos tipos de cataventos. Fonte: windturbine-analysis.com

Como se pode observar na Figura 5.8, existem valores específicos de $\lambda$ para os quais o coeficiente de potência é máximo. Ou seja, o aproveitamento de potência é maior para determinados valores de tip speed ratio. 
Dessa forma, observando a equação 5.2, é possível concluir que, se a velocidade do rotor varia com a velocidade do vento, é possível manter $\lambda$ praticamente constante. Mantendo este valor constante em um ponto da curva $\mathrm{Cp} \times \lambda$ em que $\mathrm{Cp}$ seja o maior possível faz com que o aproveitamento de potência do vento seja otimizado, o que resulta em uma maior produção final de energia.

Além disso, o desacoplamento entre a frequência da rede e a velocidade de rotação do rotor faz com que a carga mecânica sobre o rotor do gerador seja praticamente constante, o que traz benefícios em relação à durabilidade do mesmo [ACKERMANN, 2005].

Adicionalmente, a ligação do gerador à rede via conversora de frequência aumenta a qualidade da energia entregue ao sistema.

Contudo, a presença de conversores de frequência e outros dispositivos eletrônicos encarece este tipo de aerogerador e aumenta os custos de manutenção, além de aumentar o peso e o tamanho de todo o conjunto utilizado na geração, aumentando também as perdas devido à inserção de mais componentes.

\subsection{CONFIGURAÇÕES DE AEROGERADORES}

Podemos classificar as turbinas eólicas também em relação ao controle de velocidade e potência. A Figura 5.9 ilustra os 4 tipos de turbina eólica de acordo com essa classificação: 


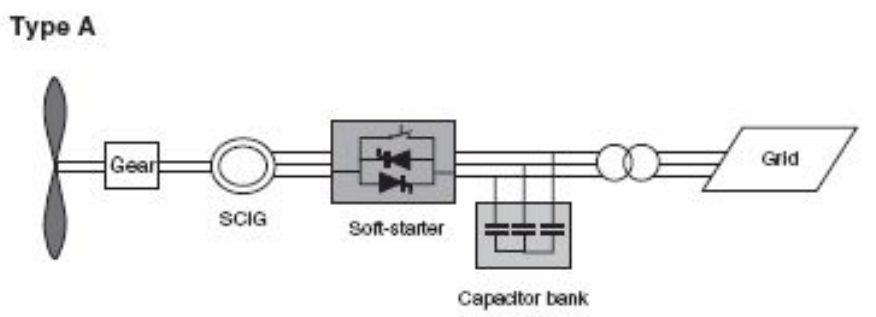

Type B
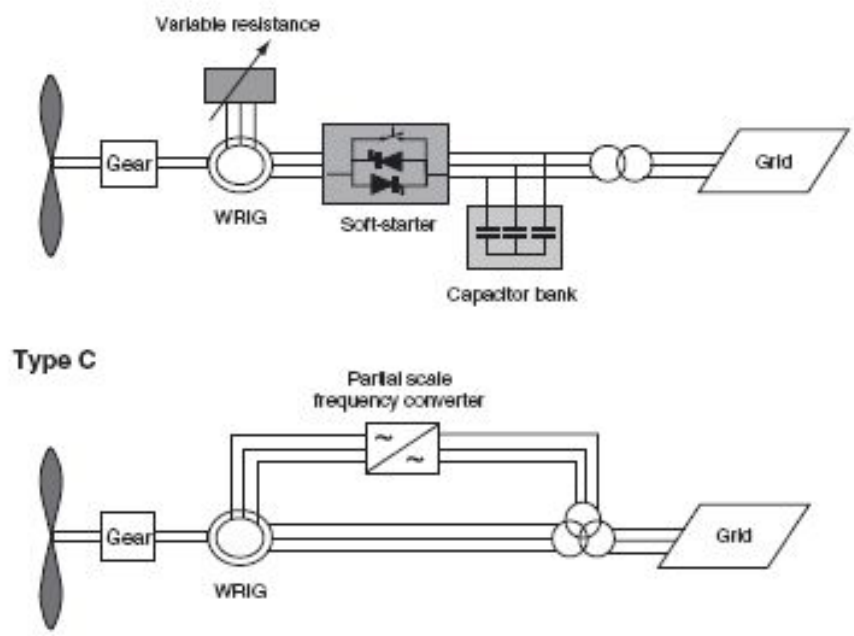

Type D

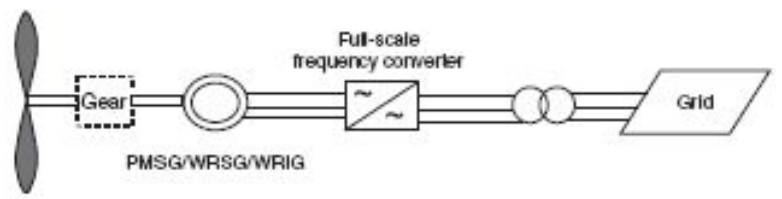

Figura 5.9 - Configurações mais comuns de aerogeradores. [ACKERMANN, 2005]

O tipo A de aerogerador, ilustrado na Figura 5.9, possui um gerador de indução do tipo de gaiola de esquilo e é conectado diretamente a rede através de um transformador. Devido à característica dos geradores assíncronos de consumirem potência reativa da rede, é necessário que se tenha uma compensação de reativo próximo ao gerador. Além do banco de capacitores, essa configuração dos aerogeradores usa um componente de eletrônica de potência utilizando tiristores para controlar a corrente de partida que pode chegar a 5 vezes a corrente nominal [MANWELL, 2002].

O banco de capacitores é de grande importância nessa configuração de geradores devido ao fato de que os agentes distribuidores de energia penalizam consumidores industriais com baixo fator de potência. Sem os bancos de capacitores, a plena carga, a corrente de 
magnetização fornecida pela rede para o estator faz com que o fator de potência seja baixo, podendo assim ser penalizado pelos distribuidores de energia.

Outro problema causado pela falta de compensação de reativo é a instabilidade do sistema em casos de falta. Quando a falta ocorre, o rotor da turbina pode acelerar por instantes e quando a falta é eliminada o gerador de indução retira da rede elétrica uma grande quantidade de potência reativa, o que pode levar a problemas de subtensões.

A configuração do tipo B caracteriza aerogeradores de velocidade variável limitados. Este tipo de configuração utiliza um gerador de indução variável com uma resistência variável conectada aos enrolamentos do rotor. Essa configuração permite que a resistência do rotor seja alterada, o que faz com que o escorregamento seja controlado. Ao controlar o escorregamento, controla-se a potência de saída do gerador [ACKERMANN, 2005]. Esse controle parcial de escorregamento faz com que seja possível controlar uma faixa de velocidades de rotação do rotor, vindo deste fato a limitação de variabilidade de velocidades. O banco de capacitor é utilizado para compensação de reativos. Já o soft starter é utilizado para uma conexão mais suave com a rede, eliminando picos de tensão.

A configuração do tipo $\mathrm{C}$ é semelhante à $\mathrm{B}$ quanto à variabilidade de velocidade. Porém, este tipo pode controlar uma faixa maior de velocidades devido à presença de um conversor parcial de frequência, que permite uma variação de $-40 \%$ a $+30 \%$ em relação à velocidade síncrona [ACKERMANN, 2005]. Nesta configuração é utilizado um gerador de indução duplamente alimentado, ou seja, que possui duas velocidades síncronas diferentes. O conversor também funciona como compensador de reativos para o gerador, além de servir como soft starter.

O tipo D é conhecido como aerogerador de velocidade variável, seguindo nesse sentido a lógica de que o mesmo não tem limitações quanto à variabilidade da velocidade. Para tanto, é utilizado um conversor de frequência completo, que também fornece reativos e serve como soft starter. Nesse tipo de configuração é utilizado o gerador síncrono de pólos permanentes ou bobinados. A desvantagem desta configuração é justamente a necessidade de um conversor completo, que deve ter potência compatível com o gerador utilizado, o que resulta em grandes e caros conversores de frequência. A novidade neste tipo de 
configuração é a opção de existir ou não a caixa de engrenagens que liga a turbina ao rotor do gerador. 


\section{DISPOSIÇÃO DOS AEROGERADORES EM UM PARQUE EÓLICO}

Para que um parque eólico tenha a maior eficiência possível, é de suma importância que os melhores ventos de determinado sítio sejam aproveitados. Desta forma, devem-se dispor os aerogeradores dentro da área do parque de modo que o aproveitamento dos ventos seja otimizado.

\subsection{VELOCIDADE DO VENTO ATRÁS DE UMA TURBINA EÓLICA}

O aerogerador, conforme foi descrito, "captura" parte da energia cinética do vento. Sendo assim, ao passar pelo aerogerador, o vento perde parte de sua energia cinética, o que acarreta em uma perda de velocidade. Como a potência disponível no vento depende da velocidade elevada a uma potência de 3 , uma diminuição na velocidade pode ter resultado extremamente negativo sobre a potência disponível.

A região que se localiza atrás da turbina, em que há diminuição da velocidade do vento devido à perda de energia cinética do vento, é chamada de esteira, cujo efeito espacial pode ser visto na Figura 6.1. Deve-se notar que o efeito de uma turbina no vento que passa por ela não se restringe a alterações no módulo da velocidade do vento, mas também provoca uma zona de turbulência atrás da turbina, afinal, uma turbina é um obstáculo. 


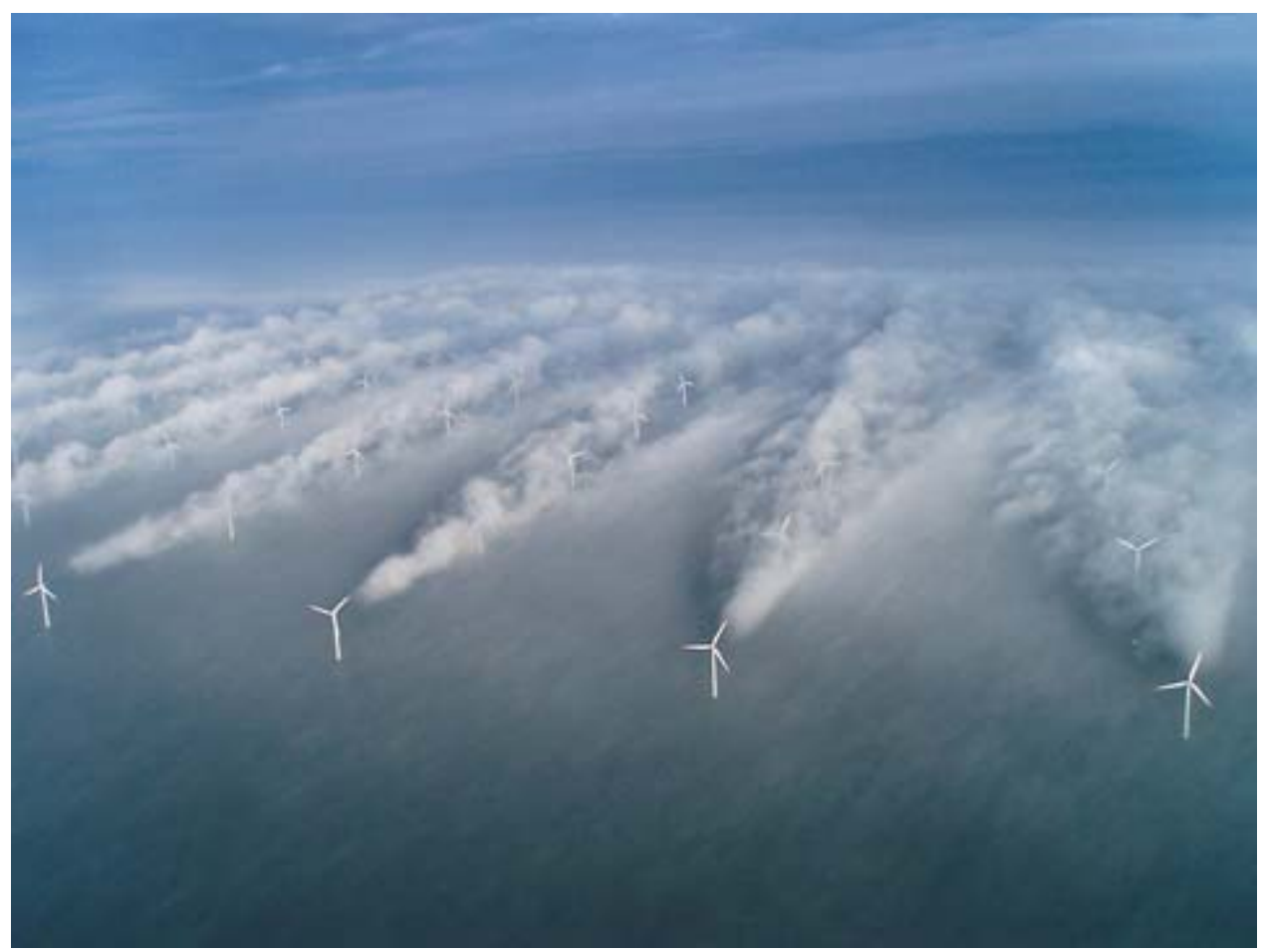

Figura 6.1 - Efeito esteira após aerogeradores em parque eólico off-shore.

A velocidade atrás da turbina e a largura da esteira podem ser encontradas se as condições aerodinâmicas da turbina forem conhecidas. A Figura 6.2 representa graficamente o efeito esteira sobre uma turbina.

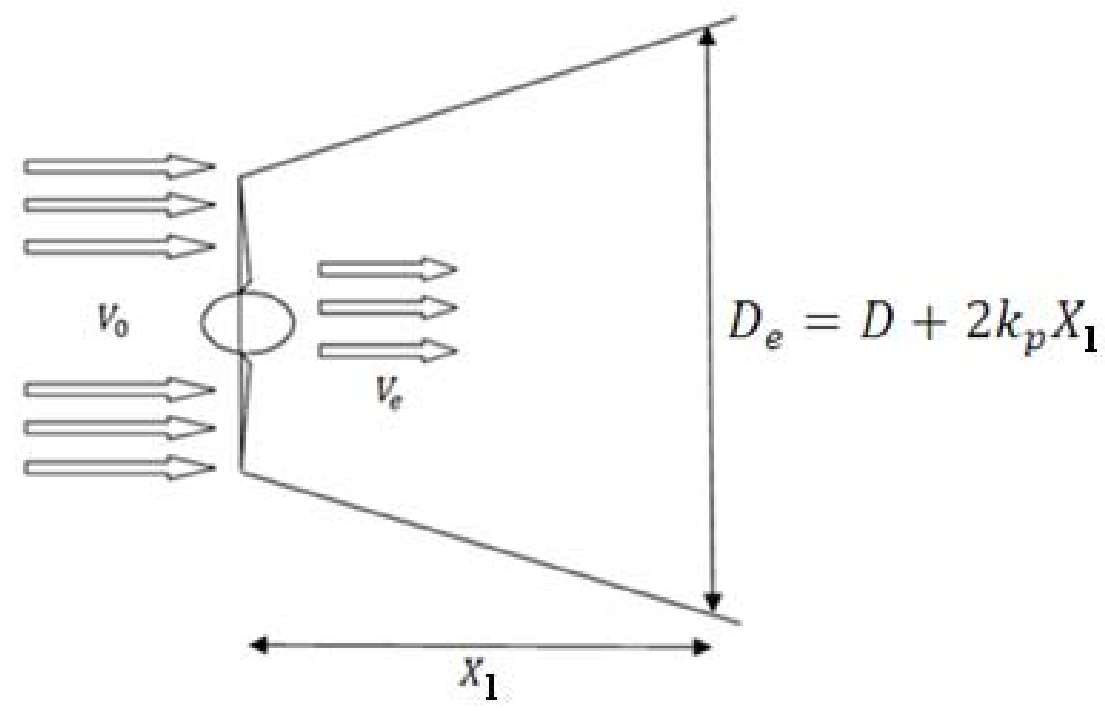

Figura 6.2 - Representação gráfica do efeito esteira em um aerogerador

A velocidade do vento na esteira, $V_{e}$, pode ser representada pela equação 6.1: 


$$
V_{e}=V_{0}\left[1-\left(1-\sqrt{1-C_{t}}\right)\left(\frac{D}{D+2 k_{p} X_{l}}\right)^{2}\right]
$$

Em que,

$V_{0}=$ velocidade do vento antes da turbina $[\mathrm{m} / \mathrm{s}]$;

$V_{e}=$ velocidade do vento na esteira $[\mathrm{m} / \mathrm{s}] ;$

$X_{l}=$ distância da turbina ao local em que se deseja saber informações da esteira [m];

$k_{p}=$ constante de perda da esteira [adimensional];

$C_{t}=$ coeficiente de empuxo da turbina [adimensional];

$\mathrm{D}=$ diâmetro da turbina $[\mathrm{m}]$;

$D_{e}=$ diâmetro da esteira $[\mathrm{m}]$;

A constante de perda $k_{p}$ depende da altura do rotor e da rugosidade do terreno, sendo dada por:

$$
k_{p}=\frac{0,5}{\ln \left(\frac{h}{z_{0}}\right)}
$$

Em que,

$k_{p}=$ constante de perda da turbina [adimensional];

$h=$ altura em relação ao solo [m];

$z_{0}=$ comprimento de rugosidade do terreno $[\mathrm{m}]$.

Já o coeficiente de empuxo, valor relacionado a características aerodinâmicas, da turbina, é dado pela equação 6.3:

$$
C_{t}=\frac{R_{e}}{0,5 \rho v^{2} A_{v}}
$$

Em que,

$C_{t}=$ coeficiente de empuxo da turbina [adimensional];

$R_{e}=$ força de empuxo [N];

$\rho=$ massa específica do ar $\left[\mathrm{kg} / \mathrm{m}^{3}\right]$;

$v=$ velocidade do vento $[\mathrm{m} / \mathrm{s}] ;$

$A_{v}=$ área varrida pelo rotor da turbina $\left[\mathrm{m}^{2}\right]$. 
O coeficiente de empuxo também pode ser dado em função do coeficiente de potência da turbina, informação comumente encontrada em catálogos de fabricantes:

$$
C_{P}=0,5 C_{t}\left(1+\sqrt{1-C_{t}}\right)
$$

Em que,

$C_{P}=$ coeficiente de potência [adimensional];

$C_{t}=$ coeficiente de empuxo [adimensional].

Dessa forma, conhecendo os parâmetros, é possível determinar a velocidade do vento na esteira e, assim, decidir a respeito da disposição de turbinas em uma mesma fila. A Figura 6.3 apresenta um gráfico que mostra a recuperação da velocidade na esteira, em relação à velocidade antes da turbina, tendo como unidade de distância o diâmetro da turbina. Além disso, também se pode observar a recuperação da potência disponível no vento, em relação à potência disponível antes da turbina.

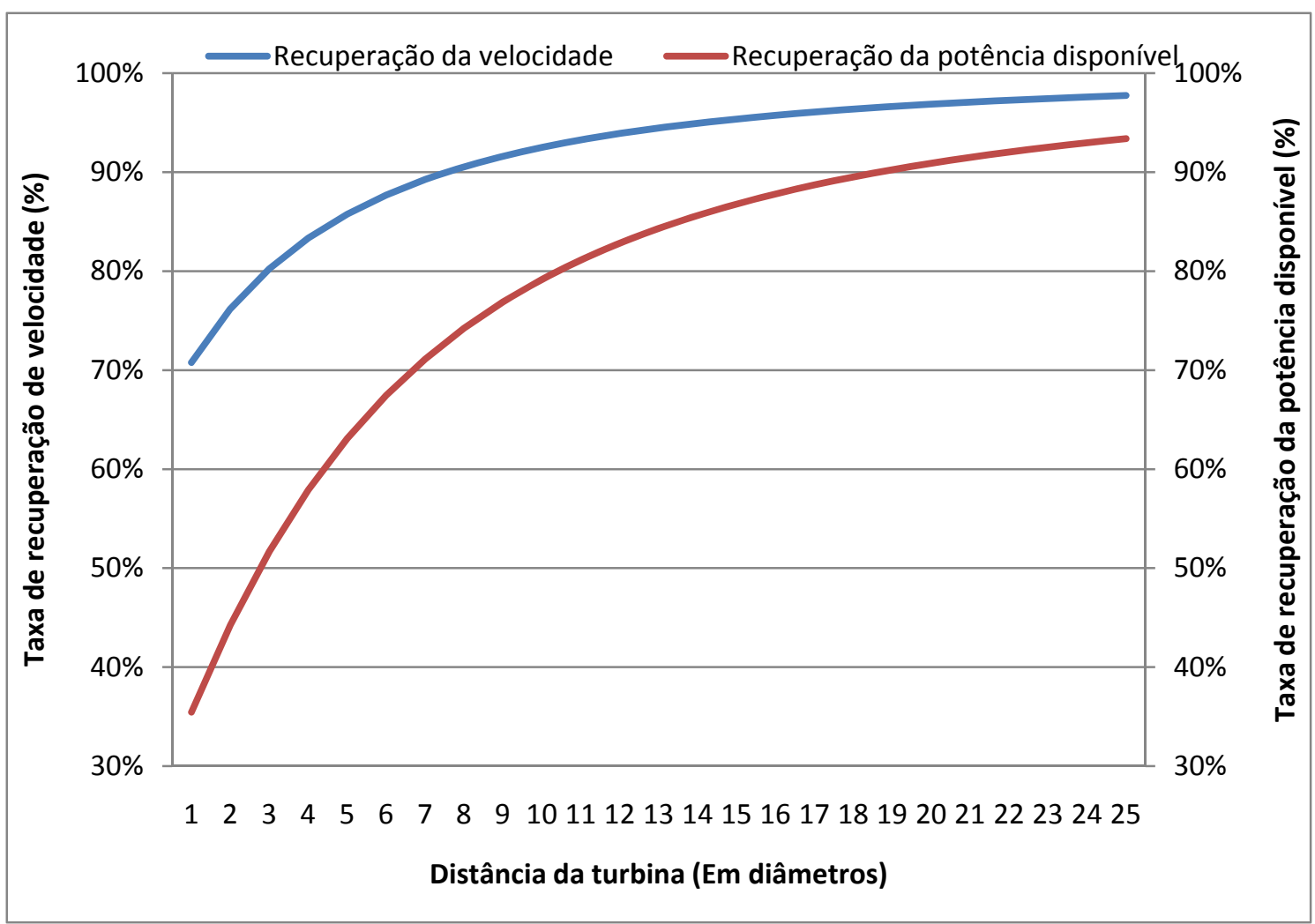

Figura 6.3 - Recuperação da velocidade do vento e da potência disponível ao longo da esteira 
Como se pode observar, a velocidade do vento em um ponto localizado atrás da turbina, a uma distância de 1 diâmetro, tem cerca de $70 \%$ da velocidade do vento que chega na turbina. Isso implica em uma redução dramática na potência disponível no vento, que fica em torno de $35 \%$ da potência disponível antes da turbina.

Fator adicional que deve ser considerado nesse sentido é que, como foi visto, o vento na esteira, principalmente logo após a turbina, é bastante turbulento. Essa turbulência, conforme foi descrito, tem comportamento bastante incerto, o que pode provocar uma grande variação na carga mecânica sobre as pás, o que pode comprometer a estrutura das mesmas, diminuindo-lhes a vida útil.

\subsection{ARRANJOS DE AEROGERADORES EM UM PARQUE EÓLICO}

Logicamente, existem muitos arranjos possíveis de aerogeradores em um parque eólico. Porém, basicamente, os aerogeradores podem ser dispostos em uma única fila, em várias filas, ou em posições sem espaçamento simétrico.

Diversos fatores que fogem do escopo deste trabalho influenciam na escolha do arranjo por parte do empreendedor como uma necessidade de determinada potência mínima instalada, fatores de custo-benefício econômico financeiro, limitação de espaço do parque gerador. Desta forma, este trabalho tratará apenas das características técnicas de cada arranjo.

Conceito importante na avaliação de disposição de um parque eólico é a eficiência do mesmo. A eficiência de um parque pode ser obtida pela seguinte equação:

$$
\eta=\frac{\sum_{i=1}^{n} \text { Energia }_{e f}}{\sum_{i=1}^{n} \text { Energia }_{\text {livre }}}
$$

Em que,

$\eta=$ eficiência do parque eólico [\%]

Energia $_{e f}=$ energia produzida por cada aerogerador dentro do parque [MWh];

Energia $_{\text {livre }}=$ energia produzida por um aerogerador em condições de vento livre de obstáculos [MWh] 


\subsubsection{Arranjo em uma fila}

O arranjo em uma única fila, que pode ser visto na Figura 6.4, é bastante utilizado em regiões de relevo plano, com poucos obstáculos próximos ao parque. Nesse sentido, faz-se o espaçamento entre turbinas de modo que se tenha a menor influência possível de uma turbina sobre o desempenho de outra, buscando minimizar o efeito esteira e alcançar a melhor eficiência possível do parque.

Porém, o cuidado que deve ser tomado neste arranjo é que as turbinas, ao serem viradas pelo controle de ângulo, o yaw control, não formem esteiras que deixem turbinas vizinhas em condições desfavoráveis de vento. Para isso, é necessário que se conheça o perfil de direções do vento na região.

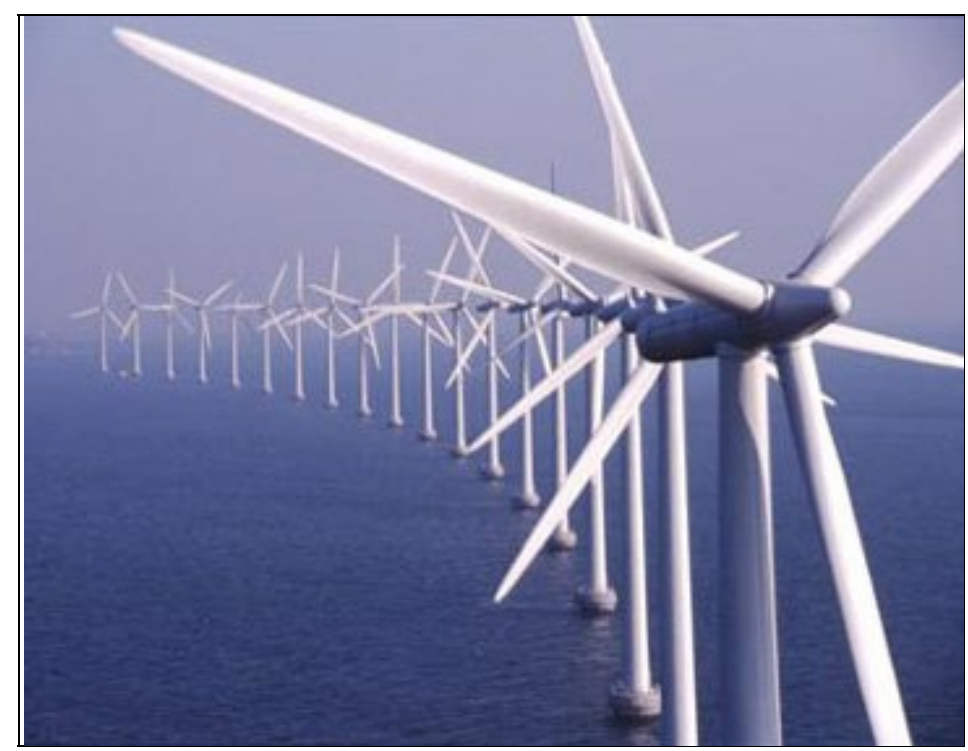

Figura 6.4 - Turbinas dispostas em uma única linha

Desta forma, ao saber o ângulo máximo em que as turbinas se viram, pode-se estimar a distância necessária entre turbinas vizinhas para que nenhuma delas fique sob a esteira de outras, pelo menos na maior parte do tempo.

O efeito da esteira sobre torres vizinhas é ilustrado na Figura 6.5. 


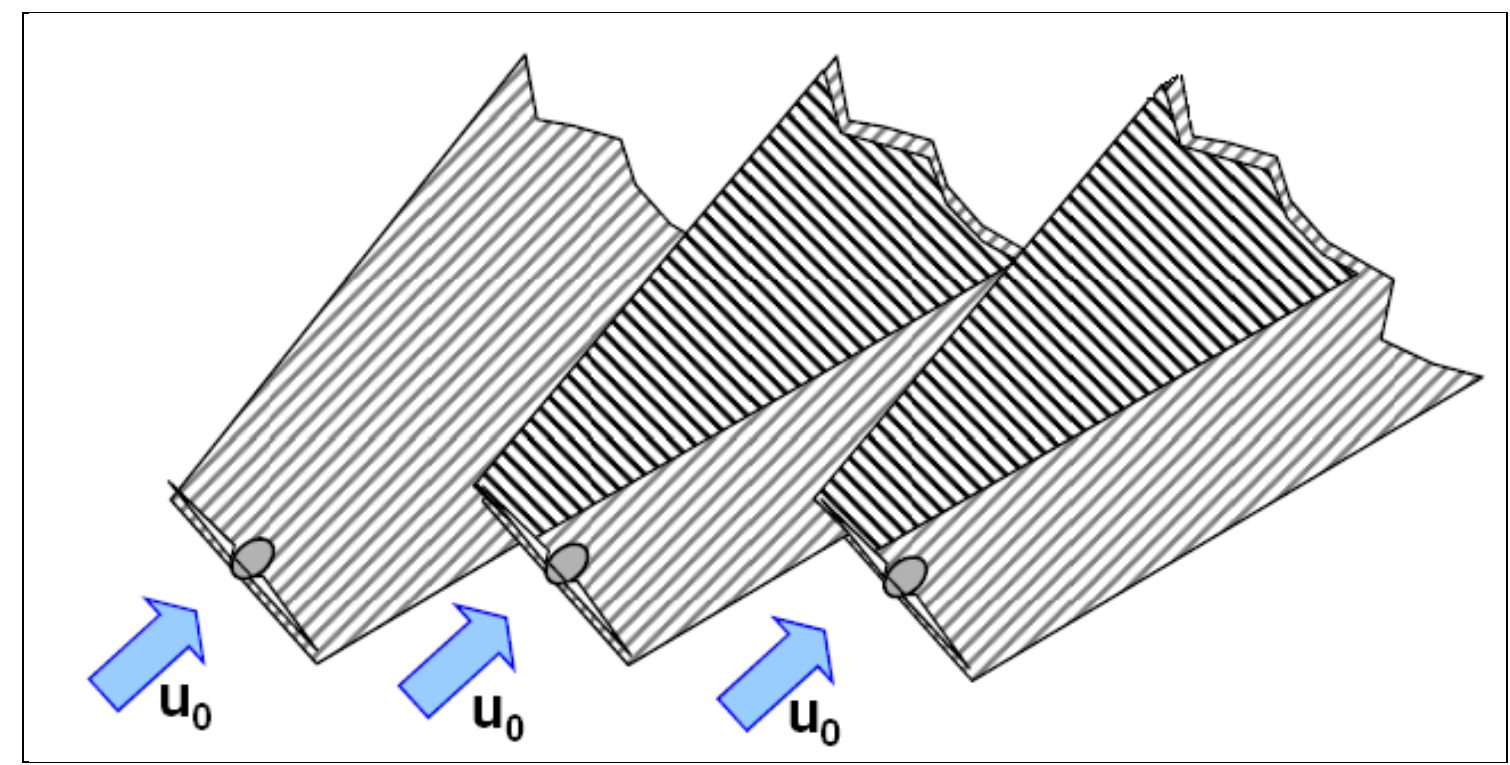

Figura 6.5 - Efeito esteira sobre aerogeradores vizinhos

Exemplo de análise de formação de esteiras sobre torres vizinhas será feito no estudo de caso a ser apresentado mais adiante.

\subsubsection{Arranjo em várias filas}

O arranjo em várias filas (Figura 6.6) tem como característica a utilização ótima da área disponível para o parque. Como a utilização da área é maior, pode-se obter uma maior capacidade instalada, porém, devido ao efeito das esteiras formadas pelos aerogeradores, em geral, a eficiência é menor do que a eficiência obtida com apenas uma fila de aerogeradores.

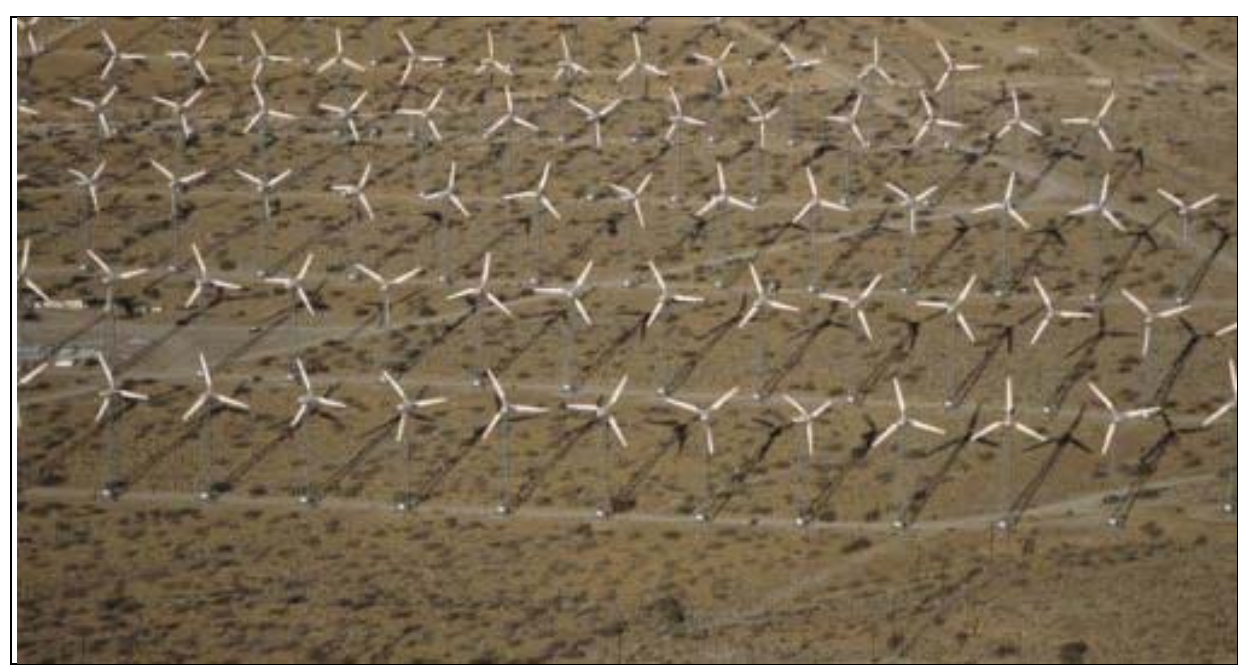

Figura 6.6 - Disposição em várias filas 
Contudo, se a área do parque for grande o bastante para que se aplique um grande espaçamento entre os aerogeradores, a queda de eficiência pode ser contornada.

A utilização deste arranjo também é mais comum em áreas com pouca rugosidade, sem quebra-ventos próximos ao parque.

\subsubsection{Arranjo definido pelo relevo}

Em terrenos complexos, que possuem muitos obstáculos, os aerogeradores devem ser posicionados exatamente nas regiões em que há ventos com maior velocidade. Para tanto, deve ser feito um estudo detalhado do relevo para que se possa estimar corretamente a velocidade do vento em cada ponto. Essa estimativa, bastante complexa, é feita por softwares especializados em micrositing, como, por exemplo, o Wind Farmer ${ }^{\circledR}$, da Garrad Hassan.

Na Figura 6.7 é possível observar um arranjo de aerogeradores que é definido pelo relevo da região, apresentando formações assimétricas.

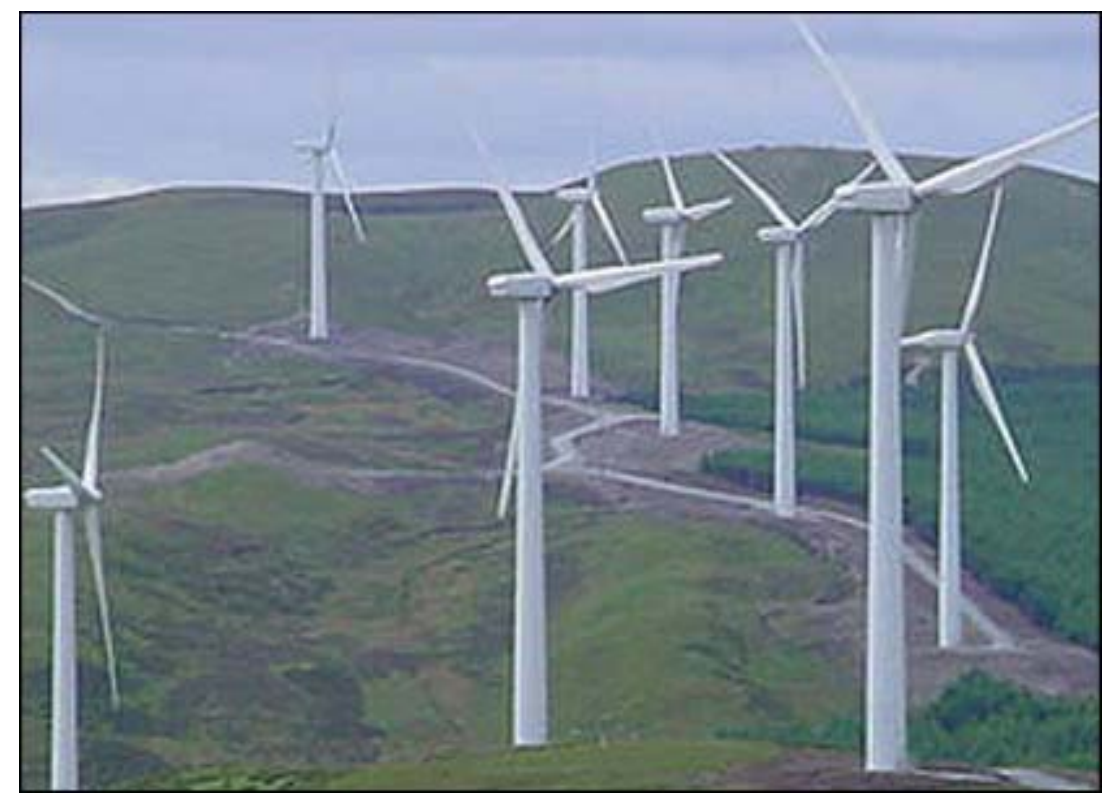

Figura 6.7 - Disposição assimétrica de aerogeradores 


\section{ESTUDO DE CASO: PROJETO DE UM PARQUE EÓLICO NO MUNICÍPIO DE CONDE}

Neste Capítulo, descreve-se o dimensionamento simplificado por etapas de um parque eólico a partir de dados anemométricos já conhecidos disponíveis em atlas eólico. Neste caso, será utilizado o Atlas Eólico do Estado da Bahia [AMARANTE, 2001].

Para o desenvolvimento de toda a análise descrita no Capítulo 7 foi elaborada uma planilha de cálculo contendo todos os conceitos apresentados nos capítulos anteriores. A planilha apresenta uma interface bastante amigável, cabendo ao usuário inserir os dados de medição dos ventos e os dados do sítio em que se deseja realizar o estudo de estimativa de produção de energia. Os dados dos aerogeradores são selecionados dentro de uma base de dados prédefinida, em que o usuário deve apenas escolher um dos modelos disponíveis. Os dados de saída dessa planilha serão os resultados apresentados ao longo deste capítulo. A planilha está disponível no seguinte endereço da internet: http://migre.me/bWV4 .

\subsection{ATLAS EÓLICO DA BAHIA}

O Atlas Eólico do Estado da Bahia foi elaborado pela COELBA - Companhia de Eletricidade do Estado da Bahia, que desde 1994 começou a fazer medições anemométricas para avaliar o potencial eólico do estado. Em 2000, o projeto do Atlas eólico foi incluído no programa de Pesquisa e Desenvolvimento da COELBA.

Este Atlas eólico foi o escolhido para ser base deste trabalho devido à relevância dos dados apresentados. Além dos dados de medição das torres anemométricas, como velocidade e direção dos ventos, o Atlas contém ainda dados sobre o relevo e rugosidade do terreno do Estado que são de grande relevância para os cálculos do projeto de um parque eólico.

As medições anemométricas realizadas foram feitas utilizando torres de $20 \mathrm{~m}$ e $30 \mathrm{~m}$ de altura em 26 locais em todo o Estado. Os dados medidos foram: Velocidade do vento; direção predominante; intensidade de turbulência e gradiente de camada-limite. 
Neste trabalho, usaremos os dados fornecidos no Atlas Eólico do Estado da Bahia para dois lugares: Conde, onde será feito o estudo principal e Irecê, local escolhido para estudo comparativo.

Estes dois lugares demonstraram características favoráveis para o aproveitamento eólico, apresentando áreas essencialmente planas. Caso fossem considerados locais com obstáculos, a análise se tornaria mais complexa e ainda seriam necessários dados mais completos a respeito do relevo de cada sítio. A obtenção de tais dados possui custo elevado e demandaria um tempo que inviabilizaria a realização deste estudo. Tais fatos justificam uma análise menos abrangente que, contudo, não apresenta menor consistência se considerados os objetivos do trabalho.

\section{2 ÁNALISE DOS DADOS ANEMOMÉTRICOS DO SÍTIO}

O Atlas Eólico do Estado da Bahia foi realizado utilizando medições feitas em torres de 20 e 30 metros. No entanto, as torres dos aerogeradores são maiores do que as torres anemométricas utilizadas para fazer as medições.

Como foi dito no Capitulo 4, a velocidade do vento e os parâmetros da função de Weibull variam com a altura. Sendo assim, para começar o estudo de um parque eólico, devemos calcular todos os parâmetros para a altura da torre do aerogerador. Neste trabalho, será considerado para todos os cálculos os dados de medição dos ventos e de rugosidade do terreno da estação de Conde e os dados do aerogerador da ENERCON modelo E70. Os dados dos ventos de terreno, assim como os dados do modelo E70 estão apresentados na Tabela 7.1 e 7.2 , respectivamente:

Tabela 7.1 - Dados de medição do vento e de rugosidade na estação de Conde.

\begin{tabular}{|c|c|c|c|c|}
\hline $\begin{array}{c}\text { Velocidade } \\
\text { Média (m/s): }\end{array}$ & $\begin{array}{c}\text { Altura da Torre } \\
\text { Anemométrica }(\mathbf{m}):\end{array}$ & $\begin{array}{c}\text { Fator de forma } \\
\mathbf{( k ) :}\end{array}$ & $\begin{array}{c}\text { Ângulo de maior } \\
\text { variação da direção } \\
\text { do vento }\left(\mathbf{e m}{ }^{\circ}\right)\end{array}$ & $\begin{array}{c}\text { Rugosidade } \\
\left(\mathbf{z}_{\mathbf{0}}\right)\end{array}$ \\
\hline 5,98 & 20 & 3,09 & 60 & 0,03 \\
\hline
\end{tabular}


Tabela 7.2 - Dados do modelo do aerogerador E70 da ENERCON.

\begin{tabular}{|c|c|c|c|}
\hline Modelo & $\begin{array}{c}\text { Potência nominal } \\
(\mathbf{k W}):\end{array}$ & $\begin{array}{c}\text { Diâmetro do Rotor } \\
(\mathbf{m}):\end{array}$ & $\begin{array}{c}\text { Altura da nacelha } \\
(\mathbf{m}):\end{array}$ \\
\hline E70 & 2300 & 70 & 113 \\
\hline
\end{tabular}

Para o coeficiente de rugosidade utilizado, $z_{0}$, o município de Conde está sendo considerado como um lugar sem fendas, vales e com prédios espaçados, como mostrado na Tabela 4.1.

Como se pode observar, a altura da torre do aerogerador (113m) é maior do que a altura da torre anemométrica $(20 \mathrm{~m})$. Neste caso, devem-se extrapolar os dados para a altura da torre do aerogerador.

Para calcular a velocidade média na altura da nacelha, usa-se a equação 4.2:

$$
\begin{array}{r}
\frac{v_{1}}{v_{2}}=\frac{\ln \left(\frac{h_{1}}{z_{0}}\right)}{\ln \left(\frac{h_{2}}{z_{0}}\right)} \\
v_{1}=v_{2} \frac{\ln \left(\frac{h_{1}}{z_{0}}\right)}{\ln \left(\frac{h_{2}}{z_{0}}\right)}=5,98 \frac{\ln \left(\frac{113}{0,03}\right)}{\ln \left(\frac{20}{0,03}\right)}=7,57 \mathrm{~m} / \mathrm{s}
\end{array}
$$

O fator de forma, $k$, da função de Weibul pode ser calculado a partir da equação 4.6:

$$
k_{2}=k_{1}\left(\frac{1-0,088 \ln \frac{h_{1}}{10}}{1-0,088 \ln \frac{h_{2}}{10}}\right)=3,09\left(\frac{1-0,088 \ln \frac{20}{10}}{1-0,088 \ln \frac{113}{10}}\right)=3,69
$$

O fator de escala, c, pode ser calculado através do fator de forma, $\mathrm{k}$, e da velocidade média. A equação 3.11 determina o fator de escala, c:

$$
c=\frac{\mathrm{V}}{\Gamma\left(1+\frac{1}{k}\right)}=\frac{7,57}{\Gamma\left(1+\frac{1}{3.69}\right)}=8,39 \mathrm{~m} / \mathrm{s}
$$

Assim, os parâmetros da função de Weibull e a velocidade média estão determinados para a altura da torre do aerogerador. A Tabela 7.3 resume os valores calculados: 
Tabela 7.3 - Parâmetros da função de Weibull e velocidade média para a altura do aerogerador E70 no município de conde.

\begin{tabular}{|c|c|c|}
\hline Velocidade Média (m/s): & Fator de forma (k): & Fator de escala (m/s): \\
\hline 7,57 & 3,69 & 60 \\
\hline
\end{tabular}

No caso de uma simulação com vários tipos de aerogeradores, como será feita adiante, é necessário extrapolar os dados para a altura de cada aerogerador.

\subsection{ESTIMATIVA DA ENERGIA PRODUZIDA POR UM AEROGERADOR}

Para estimar a energia gerada por um aerogerador em determinada região é essencial que se conheça a distribuição de velocidades no local, aproximada pela função de distribuição de Weibull, assim como a curva de potência, que determina a potência gerada pela turbina para cada velocidade.

Utilizando como exemplo o aerogerador comercial modelo E70, fabricado pela Enercon Gmbh., a potência de saída para cada velocidade está disponível na Tabela 7.4. 
Tabela 7.4 - Tabela de potência do gerador E70

\begin{tabular}{|c|c|}
\hline $\mathrm{V}(\mathrm{m} / \mathrm{s})$ & $\mathbf{P}(\mathbf{k W})$ \\
\hline 0 & 0 \\
\hline 1 & 0 \\
\hline 2 & 2 \\
\hline 3 & 18 \\
\hline 4 & 56 \\
\hline 5 & 127 \\
\hline 6 & 240 \\
\hline 7 & 400 \\
\hline 8 & 626 \\
\hline 9 & 892 \\
\hline 10 & 1223 \\
\hline 11 & 1590 \\
\hline 12 & 1900 \\
\hline 13 & 2080 \\
\hline 14 & 2230 \\
\hline 15 & 2300 \\
\hline 16 & 2310 \\
\hline 17 & 2310 \\
\hline 18 & 2310 \\
\hline 19 & 2310 \\
\hline 20 & 2310 \\
\hline 21 & 2310 \\
\hline 22 & 2310 \\
\hline 23 & 2310 \\
\hline 24 & 2310 \\
\hline 25 & 2310 \\
\hline
\end{tabular}

Tendo em mãos a distribuição de probabilidades para o local, extrapolada para a altura da nacelha do aerogerador, no caso, $113 \mathrm{~m}$, é possível estimar a geração de energia anual de um aerogerador pela seguinte equação, considerando velocidades de 0 a $25 \mathrm{~m} / \mathrm{s}$ : 


$$
E_{\text {aerogerador }}=\sum_{i=1}^{25} F(v) \cdot P(v) \cdot 8,760
$$

Em que,

$E_{\text {aerogerador }}=$ estimativa anual de geração de energia por um aerogerador [MWh];

$F(v)=$ probabilidade de ocorrência da velocidade $\mathrm{v}$ [adimensional];

$P(v)=$ potência de saída do aerogerador para a velocidade $\mathrm{v}[\mathrm{kW}]$;

Para este caso,

$$
\sum_{i=1}^{25} F(v) \cdot P(v) \cdot 8,760=5676,91 M W h
$$

\subsection{DISPOSIÇÃO DOS AEROGERADORES (MICROSITING)}

Para o sítio em questão, devido ao relevo plano e à ausência de obstáculos próximos, foram simulados casos de disposição de aerogeradores em filas, mais especificamente, para 1 e 2 filas de aerogeradores dispostos simetricamente.

\subsubsection{Disposição em uma fila}

Para a disposição de aerogeradores em 1 fila deve-se estudar a influência que um aerogerador tem sobre o seu vizinho, de modo a garantir que a sombra de um aerogerador não incida sobre outro em situações em que há rotação da nacelha, situação ilustrada na Figura 7.1. 


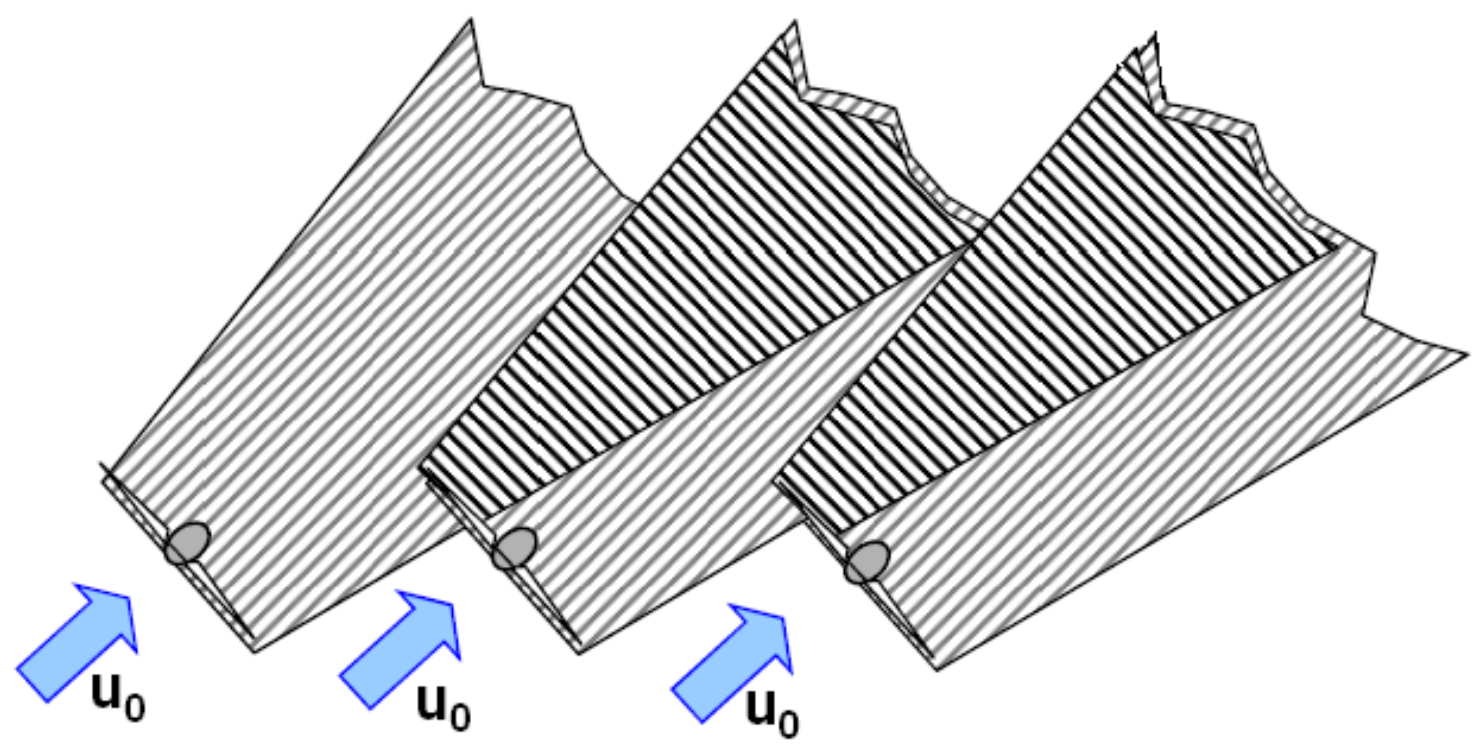

Figura 7.1 - Sombra de aerogeradores nos aerogeradores vizinhos

Neste caso, diz-se que a sombra é parcial, o que acarreta em uma perda na produção de energia e, além disso, em uma carga mecânica desigual nas pás do aerogerador, o que pode provocar um desgaste prematuro da estrutura do aerogerador [MOLLY, 2009].

Para que a sombra de um aerogerador não incida sobre o outro disposto à sua lateral, faz-se necessário um estudo da distância correta entre aerogeradores em uma mesma fila. Nesse sentido, é essencial conhecer a distribuição de direções do vento durante o ano. Para o sítio de Conde, a distribuição pode ser vista na Figura 7.2.

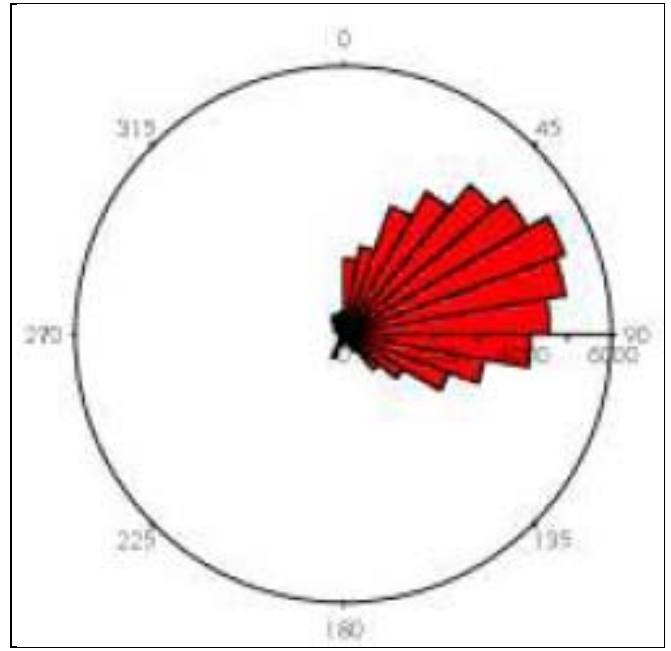


Figura 7.2 - Distribuição de direções do vento no sítio de Conde

Como pode-se notar, a maior ocorrência de ventos localiza-se no setor de aproximadamente $60^{\circ}$ em relação ao Norte. Ao observar os outros setores, nota-se que a direção do vento varia de $0^{\circ}$ até cerca de $120^{\circ}$ em relação ao Norte. Desta forma, pode-se concluir que, em relação à direção principal do vento, há uma variação de no máximo $60^{\circ} \mathrm{a}$ Leste e a Oeste.

Baseando-se na distribuição de ventos, pode-se concluir, então, que a nacelha do aerogerador vira-se no máximo em $60^{\circ}$ para se adequar à direção do vento em cada momento.

Na situação de giro de $60^{\circ}$ a situação pode ser ilustrada da seguinte forma:

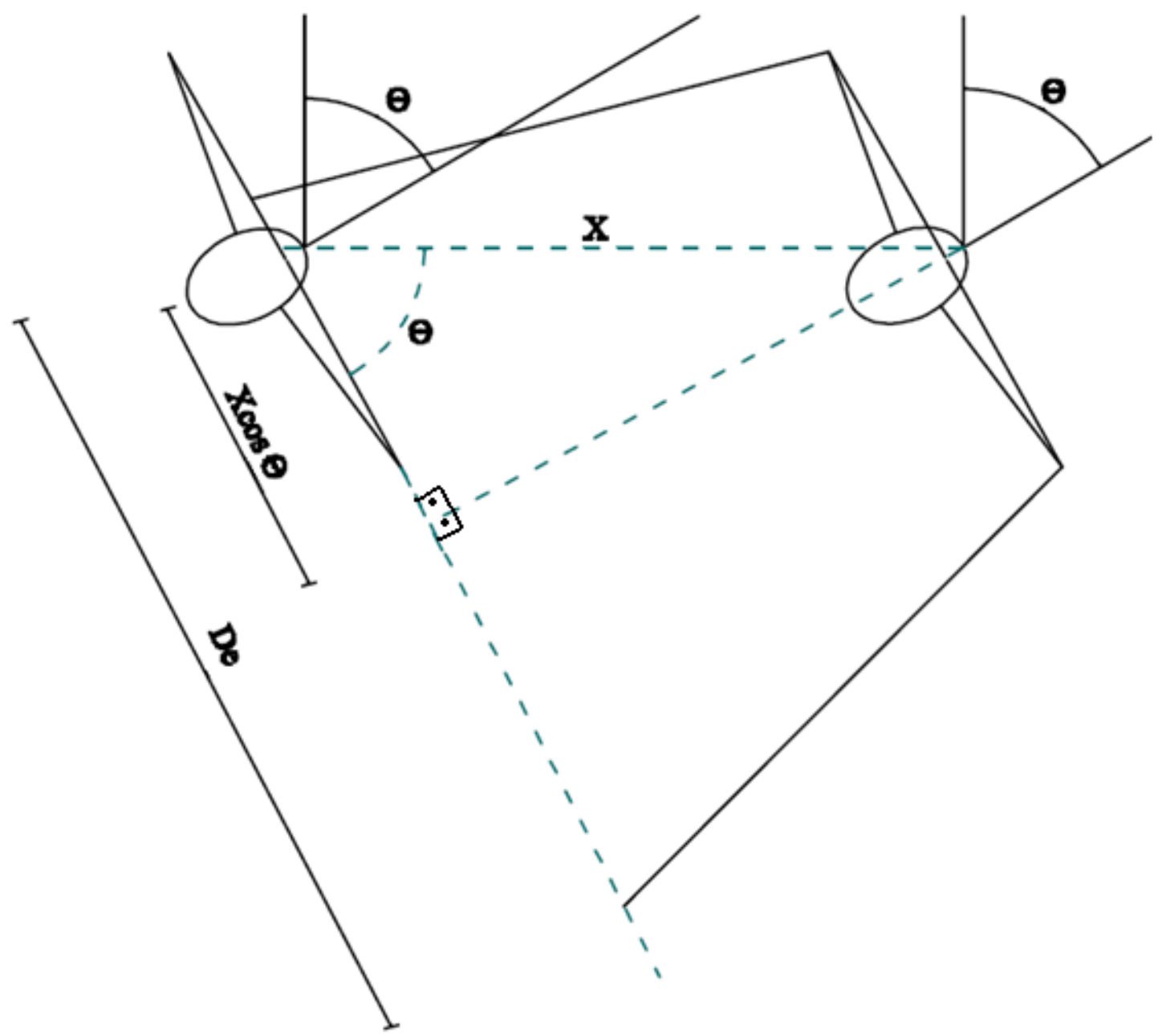

Figura 7.3 - Representação da sombra de uma turbina sobre a turbina vizinha 
Em que,

$\theta=$ ângulo da turbina em relação à direção principal do vento $\left[^{\circ}\right]$;

$\mathrm{X}=$ distância entre as duas turbinas [m];

$\mathrm{De}=$ diâmetro da esteira $[\mathrm{m}]$.

Desta forma, temos que a distância $\mathrm{X}$ entre os aerogeradores deve ser tal que

$$
X \cos \theta-D / 2>D e / 2
$$

Em que,

$\mathrm{X}=$ distância entre as duas turbinas $[\mathrm{m}]$;

$\mathrm{D}=$ diâmetro do aerogerador $[\mathrm{m}]$;

$\mathrm{De}=$ diâmetro da esteira $[\mathrm{m}]$.

Garantindo esta desigualdade, garante-se que a sombra de um aerogerador nunca estará sobre o aerogerador vizinho para determinado ângulo $\theta$. Para fins de simulação, varia-se então o valor de $\mathrm{X}$ até que a desigualdade seja satisfeita.

Em geral, quando se fala em distância de aerogeradores, é bastante comum utilizar o diâmetro do aerogerador como unidade de comprimento, desta forma, considerando apenas valores inteiros de diâmetros, utilizando o aerogerador E70 (diâmetro de 70m) como exemplo, tem-se que, para o sítio de Conde, cujo maior ângulo da turbina em relação ao eixo é $60^{\circ}, X=3$ diâmetros.

Ao obter a informação referente à distância lateral entre aerogeradores é possível determinar o número de aerogeradores passíveis de instalação na área do parque. Para o sítio de Conde considera-se retangular uma área de $3 \mathrm{~km} \times 2 \mathrm{~km}$, o que totaliza uma área de $6 \mathrm{~km}^{2}$. Para calcular o número de aerogerador em uma fila ao longo de todo comprimento do sítio pode-se utilizar a seguinte relação:

$$
N_{t}=\frac{C_{o m p}}{N_{\text {diam }} \times D}+1
$$

Em que,

$N_{t}=$ número de aerogeradores por fila [unidades];

$C_{\text {omp }}=$ comprimento do sítio [m];

$N_{\text {diam }}=$ distância lateral entre aerogeradores vizinhos [diâmetros]. 
Para o caso do sítio de Conde, utilizando aerogeradores do modelo E70, é possível instalar 15 aerogeradores em uma mesma fila.

\subsubsection{Disposição em 2 filas}

Para avaliar o posicionamento de aerogeradores em 2 filas, além da verificação de condições de sombra em relação aos aerogeradores vizinhos, deve-se verificar o impacto que os aerogeradores da primeira fila exercem sobre os aerogeradores da segunda fila.

Como já foi descrito, a presença de um aerogerador à frente de um segundo aerogerador faz com que a velocidade do vento que o segundo recebe seja menor do que a velocidade recebida pelo primeiro, relação descrita pela equação 6.1 .

Dessa forma, deve-se estudar a recuperação da velocidade ao longo da esteira para que se possa escolher um ponto de instalação mais favorável. Para o gerador E70 a recuperação da velocidade ao longo do vento é descrita na Tabela 7.5. 
Tabela 7.5 - Tabela de recuperação da velocidade do vento em função da distância da primeira turbina

\begin{tabular}{|c|c|}
\hline $\begin{array}{l}\text { Distância da } \\
\text { turbina (m) }\end{array}$ & $\begin{array}{c}\text { Recuperação do } \\
\text { vento (\%) }\end{array}$ \\
\hline 70 & $70,78 \%$ \\
\hline 140 & $76,21 \%$ \\
\hline 210 & $80,25 \%$ \\
\hline 280 & $83,35 \%$ \\
\hline 350 & $85,77 \%$ \\
\hline 420 & $87,70 \%$ \\
\hline 490 & $89,26 \%$ \\
\hline 560 & $90,54 \%$ \\
\hline 630 & $91,61 \%$ \\
\hline 700 & $92,51 \%$ \\
\hline 770 & $93,26 \%$ \\
\hline 840 & $93,91 \%$ \\
\hline 910 & $94,47 \%$ \\
\hline 980 & $94,96 \%$ \\
\hline 1050 & $95,38 \%$ \\
\hline 1120 & $95,76 \%$ \\
\hline 1190 & $96,09 \%$ \\
\hline 1260 & $96,38 \%$ \\
\hline 1330 & $96,64 \%$ \\
\hline 1400 & $96,87 \%$ \\
\hline 1470 & $97,08 \%$ \\
\hline 1540 & $97,27 \%$ \\
\hline 1610 & $97,45 \%$ \\
\hline 1680 & $97,60 \%$ \\
\hline 1750 & $97,74 \%$ \\
\hline
\end{tabular}

Desta forma, cabe ao projetista decidir a distância que forneça a recuperação de velocidade que gera a maior relação custo $\mathrm{x}$ benefício para o projeto. 
De forma essencialmente didática, foi escolhida como mínimo de interesse a recuperação de $90 \%$ do vento que incide sobre a primeira turbina. Esse critério leva a obedecer uma distância mínima de 560m, ou 8 diâmetros, em que a recuperação é de 90,54\%, para instalação da $2^{\mathrm{a}}$ fila de turbinas.

Quando ocorre uma diminuição de 9,46\% na velocidade do vento incidente sobre a turbina, há alteração na velocidade média, o que altera a distribuição de Weibull de velocidades do vento. No caso do sítio de Conde, a velocidade média na altura de $113 \mathrm{~m}$, altura da torre do aerogerador E70, foi estimada em 7,5725 m/s. Para a $2^{\text {a }}$ fila a velocidade média é de $6,8565 \mathrm{~m} / \mathrm{s}$. A comparação entre a Distribuição de Weibull para primeira e para a segunda fila pode ser vista na Figura 7.4.

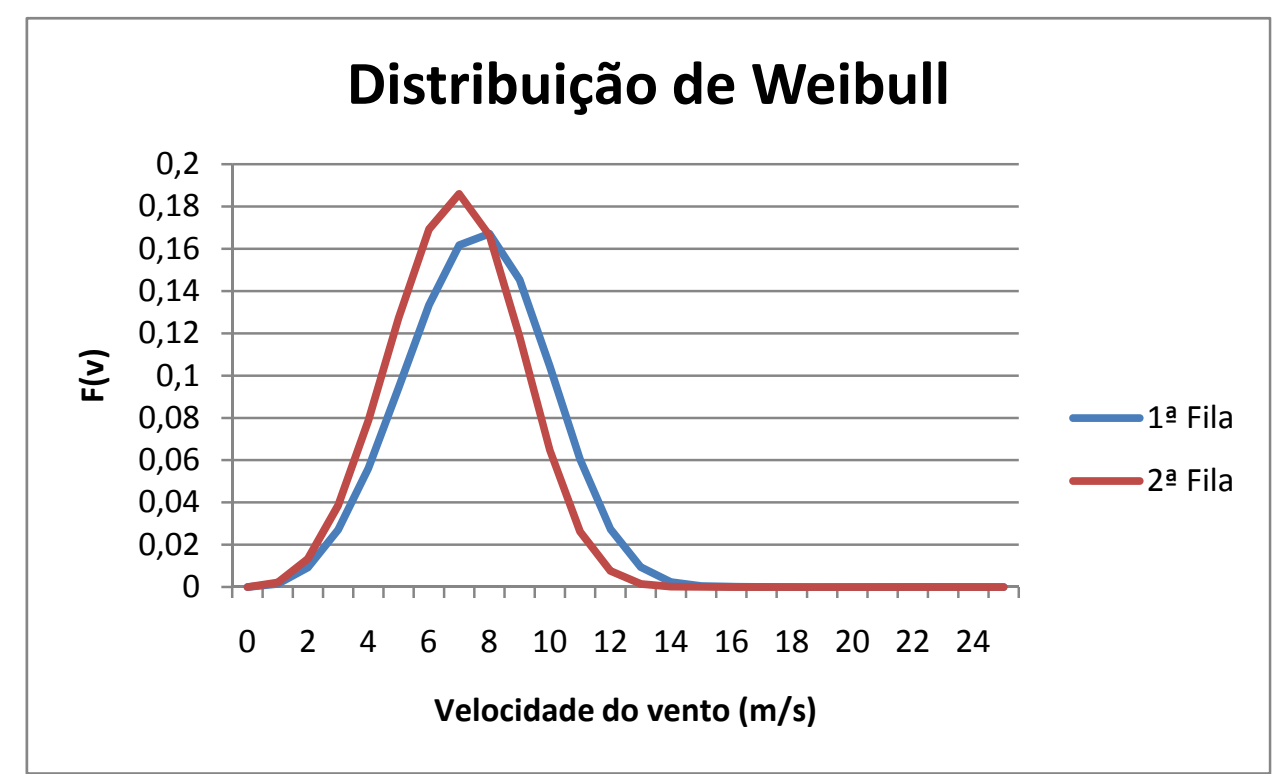

Figura 7.4 - Comparação entre as Distribuições de Weibull para a $1^{\mathrm{a}}$ e para a $2^{\mathrm{a}}$ fila de aerogeradores

Como se pode notar, a alteração na velocidade média de vento resulta numa curva de distribuição deslocada para a esquerda, em que a probabilidade de ocorrência é maior em velocidades mais baixas do que ocorre na $1^{\mathrm{a}}$ fila, como era esperado.

\subsection{ESTIMATIVA DA ENERGIA PRODUZIDA PELO PARQUE EÓLICO}

O sítio de Conde apresenta um relevo bastante plano e livre de obstáculos próximos. Desta forma, para uma análise preliminar, pode considerar que a distribuição de ventos seja homogênea em toda a área do parque. 


\subsubsection{Disposição em 1 fila}

Para a disposição de aerogeradores em 1 fila, como não há influência de uma turbina sobre a outra, a estimativa de energia gerada pelo parque é igual à soma da estimativa de energia para um aerogerador, sendo obtida pela seguinte equação:

$$
E_{\text {parque }}=N_{t} \cdot \sum_{i=1}^{25} F(v) \cdot P(v) \cdot 8,760
$$

Em que,

$E_{\text {parque }}=$ estimativa anual de energia a ser produzida pelo parque [MWh];

$N_{t}=$ número de aerogeradores por fila [unidades];

$F(v)=$ probabilidade de ocorrência da velocidade $\mathrm{v}$ [adimensional];

$P(v)=$ potência de saída do aerogerador para a velocidade $\mathrm{v}[\mathrm{kW}]$.

Utilizando a curva de potência do aerogerador E70 e a função de distribuição de Weibull extrapolada para altura da nacelha desse aerogerador e, ainda, considerando o número de aerogeradores passíveis de instalação em uma fila, calculado de acordo com a equação 7.5, temos o seguinte resultado:

$$
E_{\text {parque }}=N_{t} \cdot \sum_{i=1}^{25} F(v) \cdot P(v) \cdot 8,760=85 \cdot 153,69 \mathrm{MWh}
$$

De posse dos dados de produção anual de energia para o parque é possível obter o fator de carga do mesmo. O fator de carga indica qual a porcentagem da capacidade instalada efetivamente gera energia. Desta forma, o mesmo pode ser dado pela seguinte equação:

$$
f c=\frac{E_{\text {parque }}}{\sum_{i=1}^{n} P_{\text {turbina }} \cdot 8,760}
$$

Em que,

$f c=$ fator de carga [adimensional];

$E_{\text {parque }}=$ estimativa anual de energia a ser produzida pelo parque [MWh];

$P_{\text {turbina }}=$ potência nominal do aerogerador utilizado $[\mathrm{kW}]$;

$n=$ número de aerogeradores [unidades]. 
Substituindo os valores pertinentes ao uso do aerogerador E70 na equação 7.6 obtém-se o valor de $28,18 \%$ para o fator de carga, um valor que se encontra dentro do que é considerado razoável na literatura.

A capacidade instalada do parque é a soma das potências dos aerogeradores instalados, que pode ser calculada pela seguinte equação:

$$
P_{\text {inst }}=N_{f} \sum_{i=1}^{N_{t}} P_{\text {turbina }}
$$

Em que,

$N_{f}=$ número de filas de aerogeradores [unidades];

$P_{\text {inst }}=$ potência instalada do parque $[\mathrm{MW}]$;

$P_{\text {turbina }}=$ potência nominal do aerogerador utilizado[kW];

$N_{t}=$ número de aerogeradores por fila [unidades];

$\mathrm{O}$ aerogerador E70 tem potência nominal de $2.300 \mathrm{~kW}$. Somando a potência dos 15 aerogeradores passíveis de instalação em uma fila, chega-se à capacidade instalada de $34,5 \mathrm{MW}$.

\subsubsection{Disposição em 2 filas}

Para disposição em 2 filas, o cálculo para energia gerada deve ser feito por fila. Isso se deve ao fato de que a produção é diferente para cada fila devido ao efeito esteira que a $1^{\mathrm{a}}$ fila exerce sobre a $2^{\mathrm{a}}$. Desta forma, a energia produzida pode ser dada pela seguinte equação, considerando duas filas idênticas:

$$
E_{\text {parque }}=N_{t} \cdot \sum_{i=1}^{25} F_{1}(v) \cdot P(v) \cdot 8,760+N_{t} \cdot \sum_{i=1}^{25} F_{2}(v) \cdot P(v) \cdot 8,760
$$

Em que,

$E_{\text {parque }}=$ estimativa anual de energia a ser produzida pelo parque [MWh];

$N_{t}=$ número de aerogeradores por fila [unidades];

$F_{1}(v)=$ probabilidade de ocorrência da velocidade v para a $1^{\mathrm{a}}$ filla [adimensional];

$F_{2}(v)=$ probabilidade de ocorrência da velocidade v para a $2^{\text {a }}$ fila [adimensional];

$P(v)=$ potência de saída do aerogerador para a velocidade $\mathrm{v}[\mathrm{kW}]$. 
No caso estudado foi obtido o seguinte resultado:

$$
E_{\text {parque }}=148.831,80 \mathrm{MWh}
$$

O fator de carga obtido, calculado pela equação 7.6, foi o seguinte:

$$
f c=24,62 \%
$$

Nota-se, como esperado, que a disposição em 2 filas de aerogeradores provoca uma diminuição no fator de carga de um parque eólico, apesar da maior quantidade de energia gerada. Dessa forma, a definição do layout do parque tem impacto econômico imediato sobre o mesmo.

A potência instalada, calculada pela equação 7.7, é a seguinte:

$$
P_{\text {inst }}=N_{f} \sum_{i=1}^{N_{t}} P_{\text {turbina }}=69 \mathrm{MW}
$$

Obviamente, considerando filas de aerogeradores idênticas, a potência instalada de um parque com duas filas é o dobro da potência instalada em um parque com apenas uma fila.

\subsection{ANÁLISE COMPARATIVA}

O estudo do dimensionamento de um parque eólico foi feito até aqui apenas para o sítio de Conde e para o aerogerador E70 da ENERCON. No entanto, para efeitos comparativos, foi feito o estudo para outro local, Irecê, e outros 16 aerogeradores de 3 empresas diferentes, além do modelo E70 da ENERCON.

Os resultados utilizados na análise comparativa também são oriundos da planilha utilizada até este momento. Porém, neste caso, foi feito um apanhado dos resultados obtidos para os dois sítios em questão e para todos os aerogeradores disponíveis.

Os dados de medição de cada estação e os dados do sítio estão mostrados nas Tabelas 7.6 e 7.7: 
Tabela 7.6 - Dados de medição dos ventos.

\begin{tabular}{|c|c|c|c|}
\hline \multicolumn{2}{|c|}{ Conde } & \multicolumn{2}{c|}{ Irecê } \\
\hline $\begin{array}{c}\text { Velocidade } \\
\text { Média (m/s): }\end{array}$ & $\begin{array}{c}\text { Altura da Torre } \\
\text { Anemométrica } \\
(\mathbf{m}):\end{array}$ & $\begin{array}{c}\text { Velocidade } \\
\text { Média (m/s): }\end{array}$ & $\begin{array}{c}\text { Altura da Torre } \\
\text { Anemométrica } \\
(\mathbf{m}):\end{array}$ \\
\hline 5,98 & 20 & 5,26 & 20 \\
\hline $\begin{array}{c}\text { Fator de forma } \\
(\mathbf{k}):\end{array}$ & Ângulo (em $\left.{ }^{\circ}\right)$ & $\begin{array}{c}\text { Fator de forma } \\
(\mathbf{k}):\end{array}$ & Ângulo (em $\left.{ }^{\circ}\right)$ \\
\hline 3,09 & 60 & 3,19 & 45 \\
\hline
\end{tabular}

Tabela 7.7 - Dados do terreno.

\begin{tabular}{|c|c|c|}
\hline Comprimento (m) & Largura (m) & Rugosidade z0 (m): \\
\hline 3000 & 2000 & 0,03 \\
\hline
\end{tabular}

Os resultados do estudo de energia produzida em um ano por apenas uma turbina está mostrado nas Tabelas 7.8 e 7.9 e na Figura 7.5. Os resultados obtidos pelos aerogeradores da Gamesa são oriundos de informações parciais do fabricante. Foram utilizados os valores fornecidos pela curva de potência, porém, os dados do coeficiente de potência, $C_{p}$, foram estimados a partir de valores disponíveis na literatura. 
Tabela 7.8 - Resultados do estudo para uma turbina livre de obstáculos em Conde.

\begin{tabular}{|c|c|c|c|}
\hline \multicolumn{4}{|c|}{ Conde } \\
\hline Fabricante & Modelo & $\begin{array}{l}\text { Energia } \\
\text { Gerada } \\
\text { (MWh): }\end{array}$ & $\begin{array}{c}\text { Fator de } \\
\text { carga (\%): }\end{array}$ \\
\hline \multirow{6}{*}{$\begin{array}{l}z \\
0 \\
0 \\
\frac{z}{1} \\
\sum_{I}\end{array}$} & E33 - 330kW & 882,37 & $30,52 \%$ \\
\hline & E44 - 900kW & 1718,573 & $21,80 \%$ \\
\hline & $\mathrm{E} 48-800 \mathrm{~kW}$ & 2259,338 & $32,24 \%$ \\
\hline & E53 - 800kW & 2588,208 & $36,93 \%$ \\
\hline & E70 - 2300kW & 5676,913 & $28,18 \%$ \\
\hline & E82 - 2000kW & 7093,808 & $40,49 \%$ \\
\hline \multirow{5}{*}{ 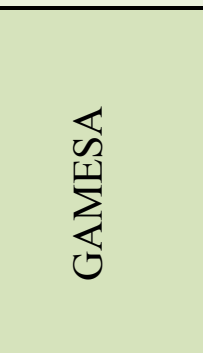 } & G52-850kW & 2248,61 & $30,20 \%$ \\
\hline & G58 - 850kW & 2685,833 & $36,07 \%$ \\
\hline & G80 - 2000kW & 5848,849 & $33,38 \%$ \\
\hline & G87 - 2000kW & 6875,489 & $39,24 \%$ \\
\hline & G90 - 2000kW & 7367,372 & $42,05 \%$ \\
\hline \multirow{6}{*}{ 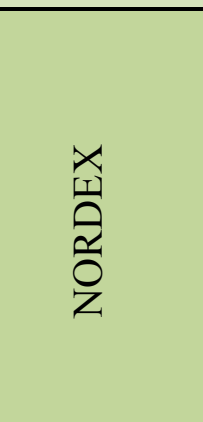 } & N60 - 1300KW & 2799,51 & $24,58 \%$ \\
\hline & S70 - 1500kW & 4201,392 & $31,97 \%$ \\
\hline & S77 - 1500kW & 5003,639 & $38,08 \%$ \\
\hline & N80 - 2500kW & 5405,37 & $24,68 \%$ \\
\hline & N90 - 2300kW & 7304,931 & $36,26 \%$ \\
\hline & $\mathrm{N} 100-2500 \mathrm{~kW}$ & 8958,195 & $40,90 \%$ \\
\hline
\end{tabular}


Tabela 7.9 - Resultados do estudo para uma turbina livre de obstáculos em Irecê.

\begin{tabular}{|c|c|c|c|}
\hline \multicolumn{4}{|c|}{ IRECÊ } \\
\hline Fabricante & Modelo & $\begin{array}{l}\text { Energia } \\
\text { Gerada } \\
\text { (MWh): }\end{array}$ & $\begin{array}{c}\text { Fator de } \\
\text { carga (\%): }\end{array}$ \\
\hline \multirow{6}{*}{ 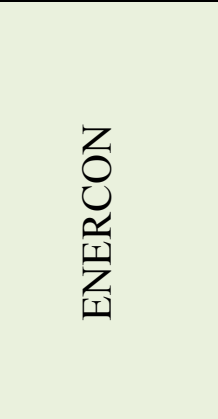 } & E33 - 330kW & 608,65 & $21,05 \%$ \\
\hline & $\mathrm{E} 44-900 \mathrm{~kW}$ & 1155,522 & $14,66 \%$ \\
\hline & $\mathrm{E} 48-800 \mathrm{~kW}$ & 1565,6968 & $22,34 \%$ \\
\hline & E53 - 800kW & 1818,5294 & $25,95 \%$ \\
\hline & E70 - 2300kW & 3838,777 & $19,05 \%$ \\
\hline & E82 - 2000kW & 4958,9831 & $28,30 \%$ \\
\hline \multirow{5}{*}{ 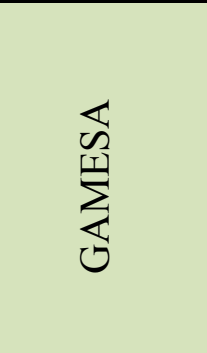 } & G52 - 850kW & 1550,62 & $20,82 \%$ \\
\hline & G58 - 850kW & 1867,0726 & $25,07 \%$ \\
\hline & G80 - 2000kW & 4071,1476 & $23,24 \%$ \\
\hline & G87 - 2000kW & 4862,1229 & $27,75 \%$ \\
\hline & G90 - 2000kW & 5261,5539 & $30,03 \%$ \\
\hline \multirow{6}{*}{ 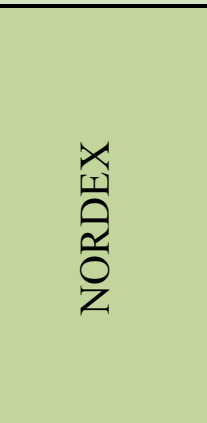 } & N60 - 1300KW & 1887,41 & $16,57 \%$ \\
\hline & S70 - 1500kW & 2823,2078 & $21,49 \%$ \\
\hline & S77 - 1500kW & 3519,6129 & $26,79 \%$ \\
\hline & N80 - 2500kW & 3587,6002 & $16,38 \%$ \\
\hline & N90 - 2300kW & 5075,3236 & $25,19 \%$ \\
\hline & N100 - 2500kW & 6334,8574 & $28,93 \%$ \\
\hline
\end{tabular}




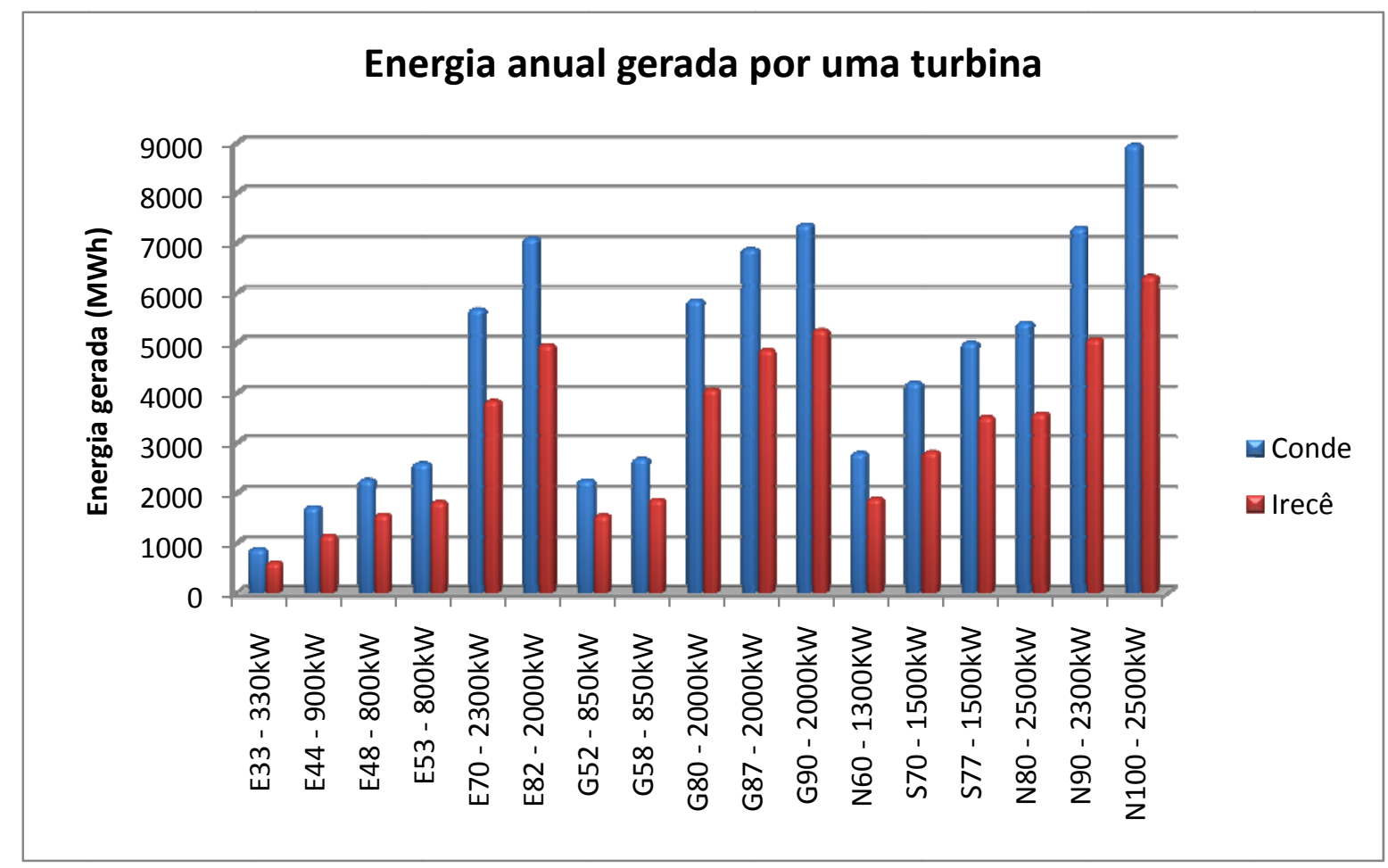

Figura 7.5 - Comparativo de energia gerada pelas 17 turbinas para os 2 sítios.

Neste trabalho, o critério usado para escolha de um aerogerador será de acordo com o fator de carga. $\mathrm{O}$ aerogerador que proporcionar o maior fator de carga para a usina seria $\mathrm{o}$ recomendável para a instalação.

É importante citar que na etapa da escolha do aerogerador, um dos fatores mais importantes é o fator financeiro. Os preços influenciam de maneira direta na escolha dos aerogeradores que serão utilizados no projeto de um parque eólico. No entanto, a análise financeira do projeto de um parque eólico não faz parte do escopo deste trabalho.

As Figuras de 7.6 a 7.8 mostram gráficos de Fator de Carga x Altura do aerogerador para cada fabricante analisado, considerando o desempenho de um aerogerador livre. Já as figuras de 7.9 a 7.11 mostram os gráficos Fator de carga x Potência dos aerogeradores para cada fabricante, também considerando o desempenho de um aerogerador livre. As Figuras de 7.6 a 7.11 são resultantes da análise feita para o sítio de Conde. 


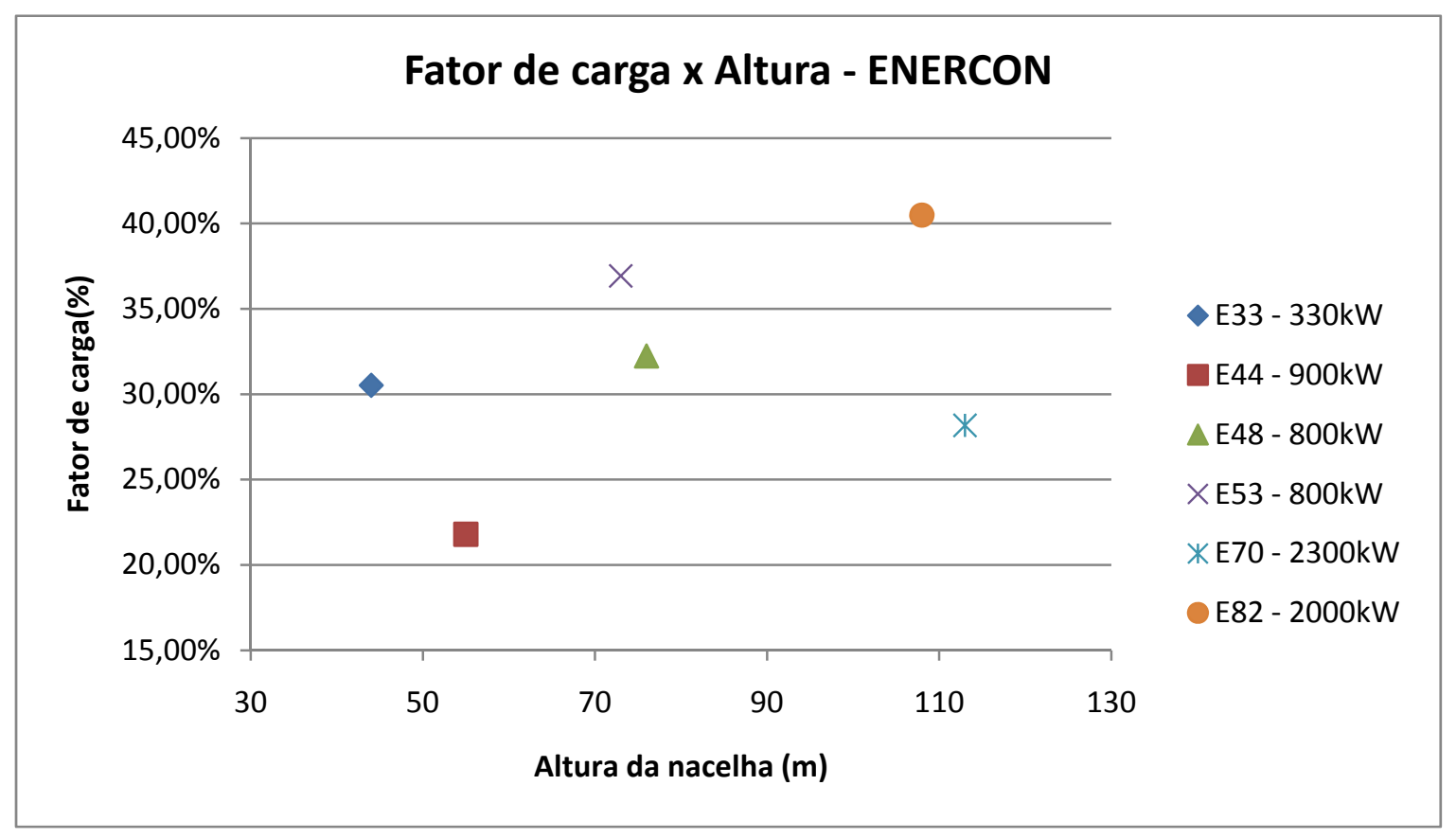

Figura 7.6 - Gráfico de Fator de carga x Altura para o fabricante Enercon.

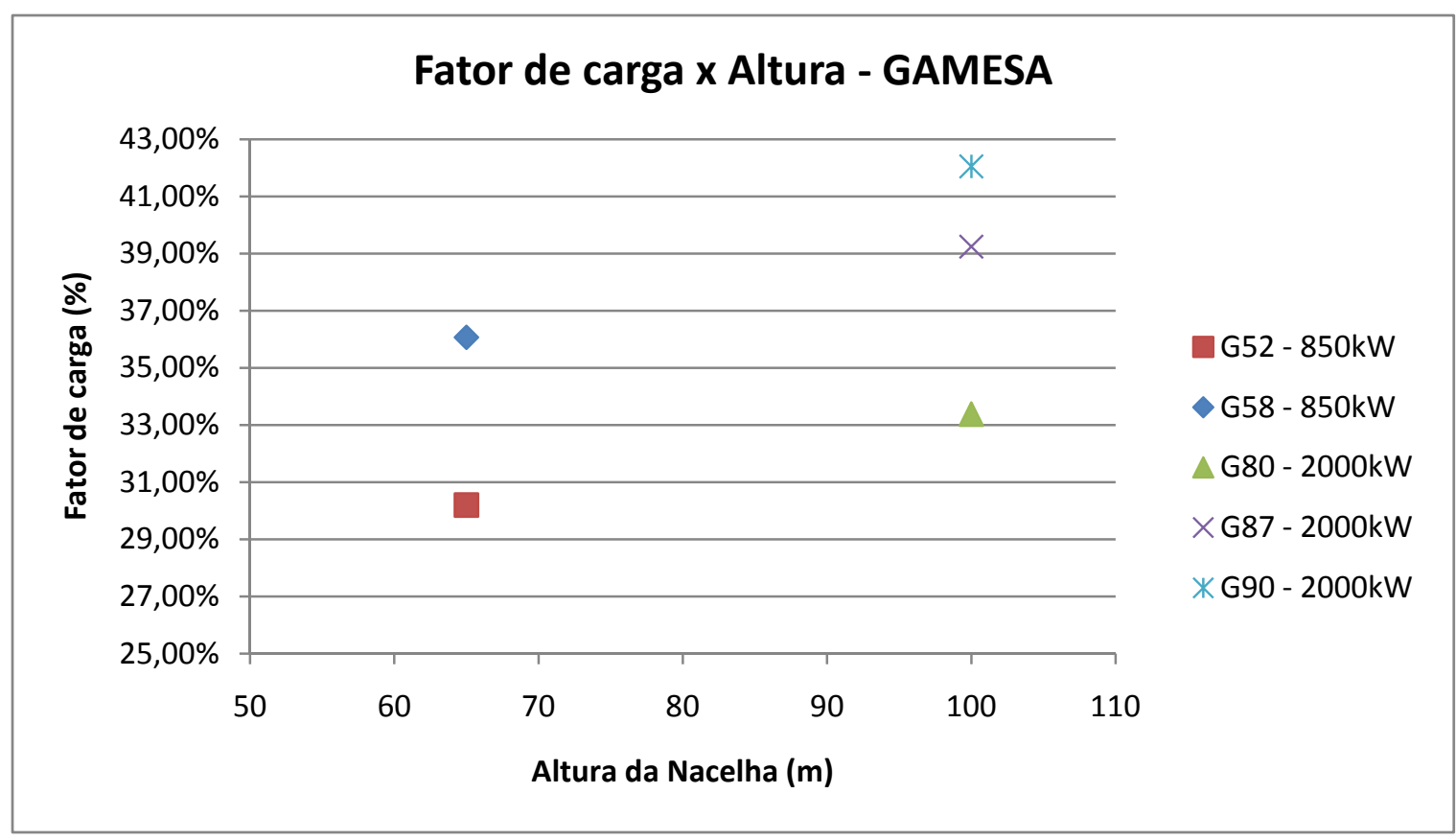

Figura 7.7 - Gráfico de Fator de carga x Altura para o fabricante Gamesa. 


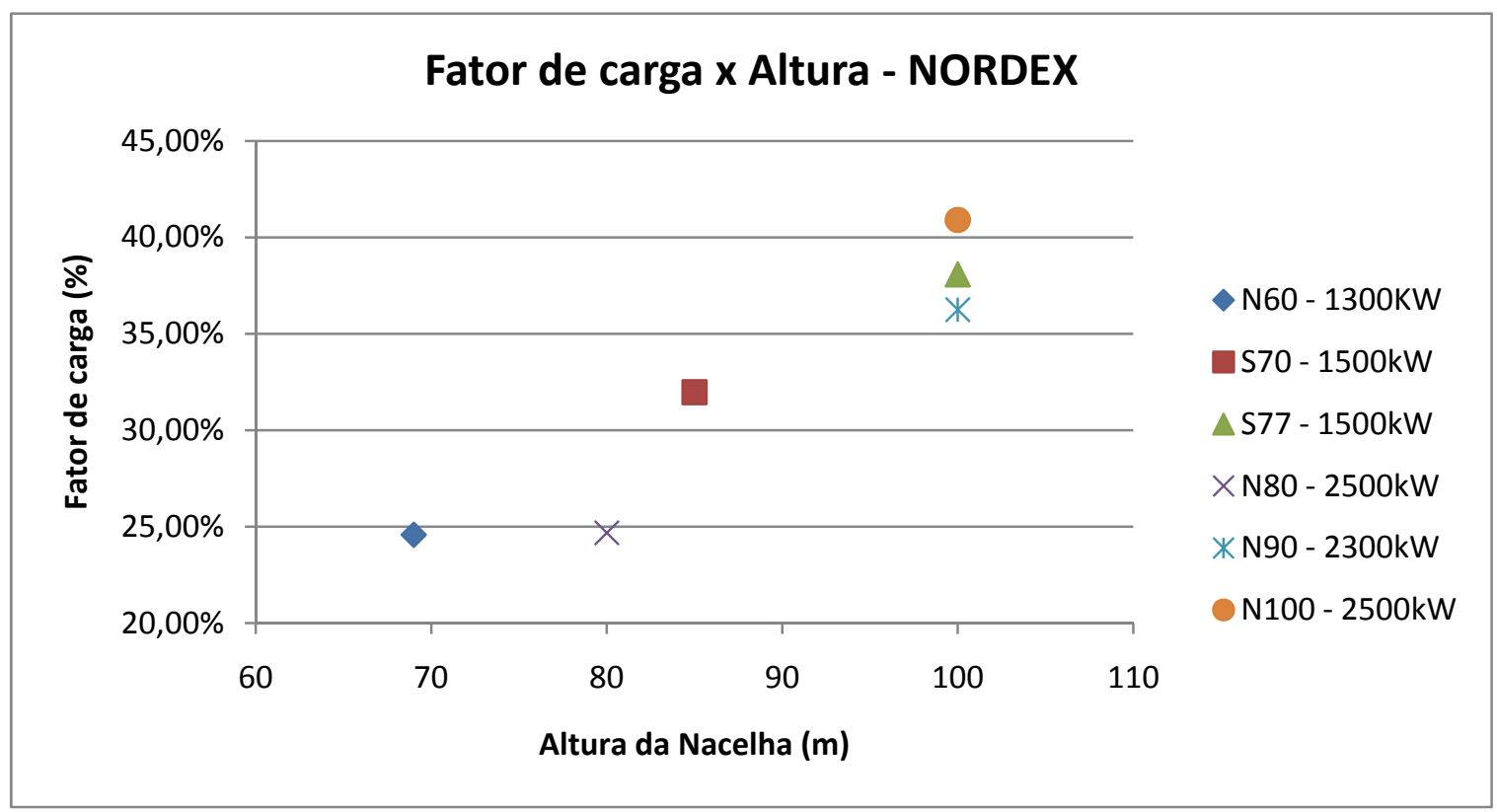

Figura 7.8 - Gráfico de Fator de carga x Altura para o fabricante Nordex.

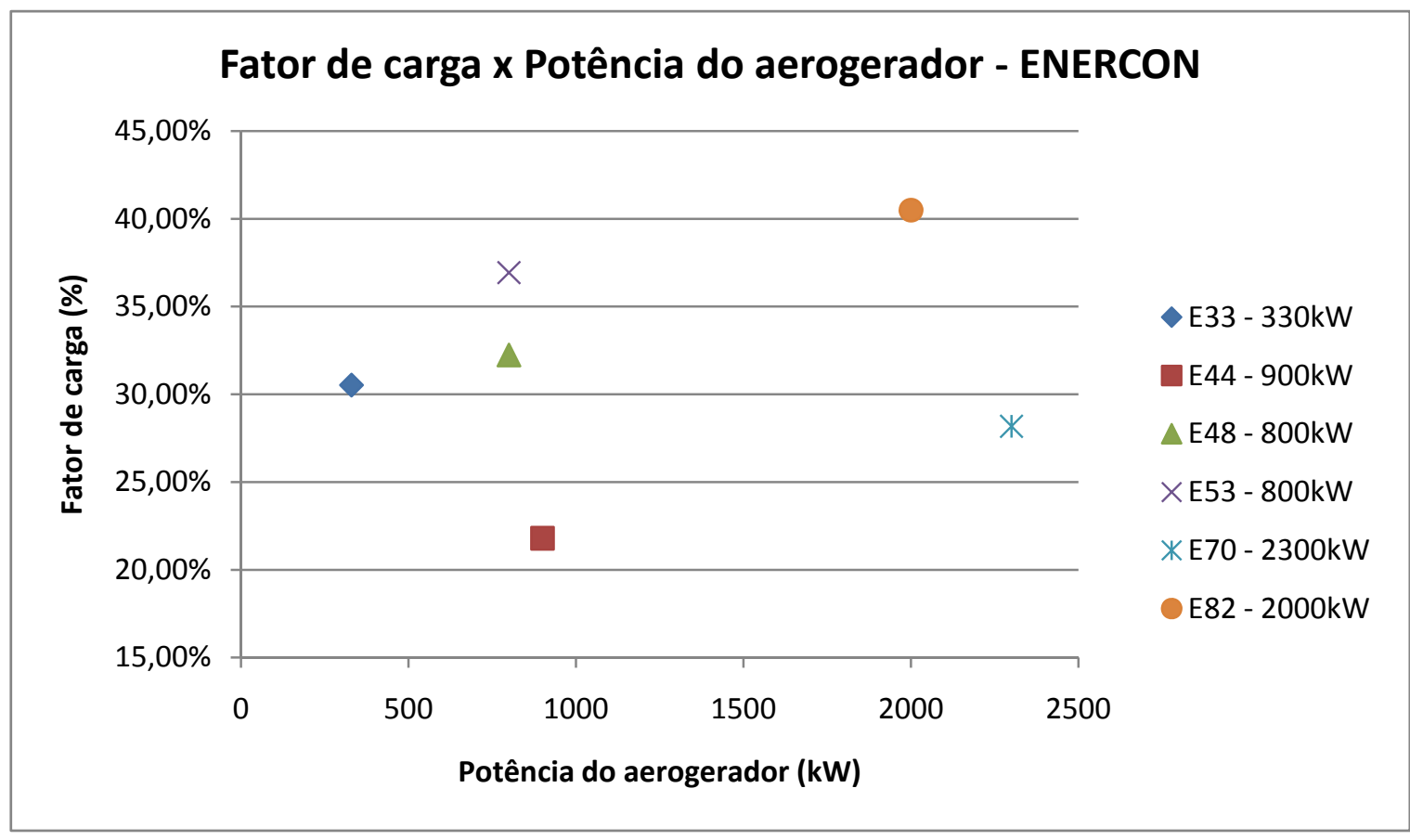

Figura 7.9 - Gráfico de Fator de carga x Potência do aerogerador para o fabricante Enercon. 


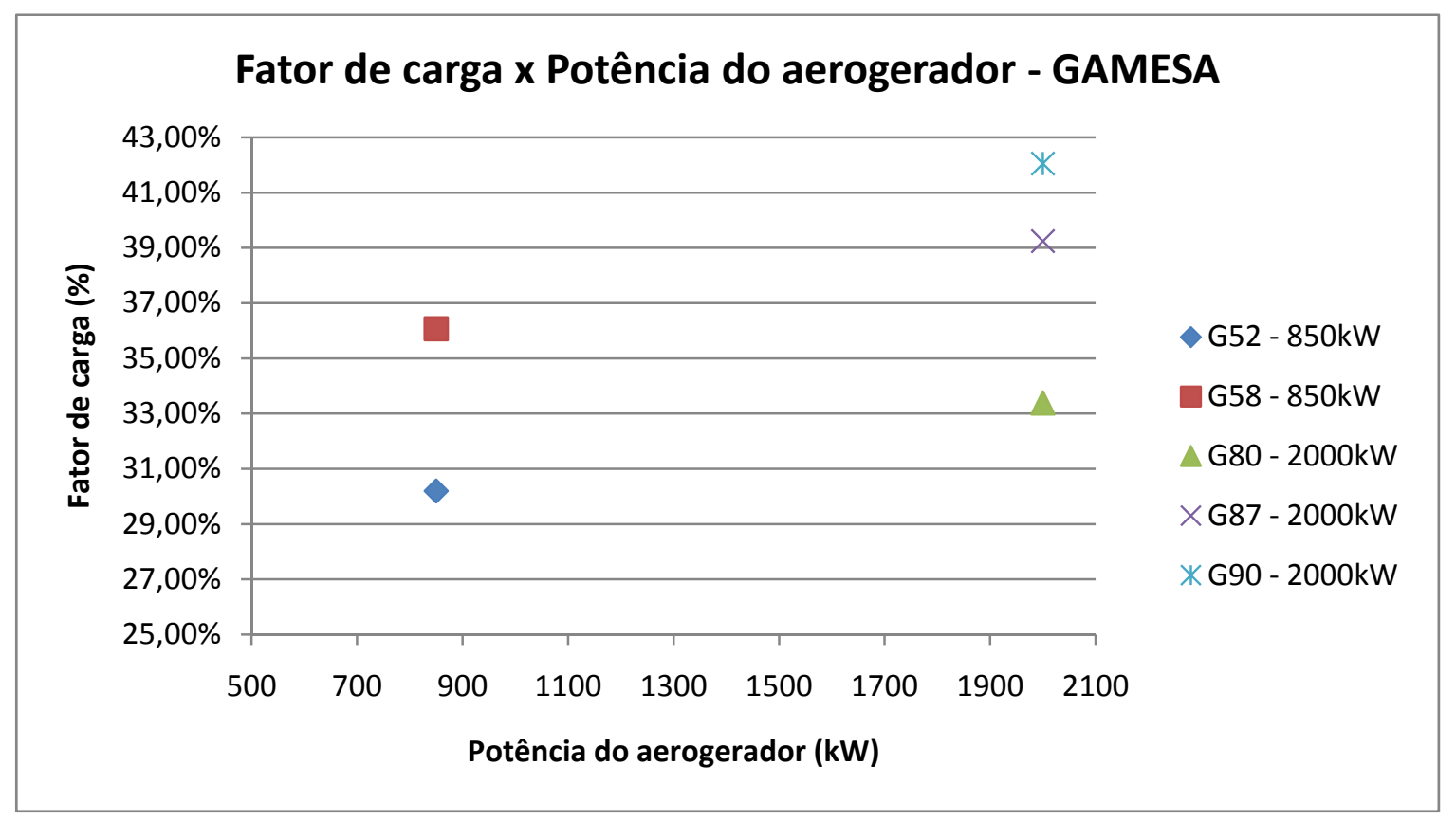

Figura 7.10 - Gráfico de Fator de carga x Potência do aerogerador para o fabricante Gamesa.

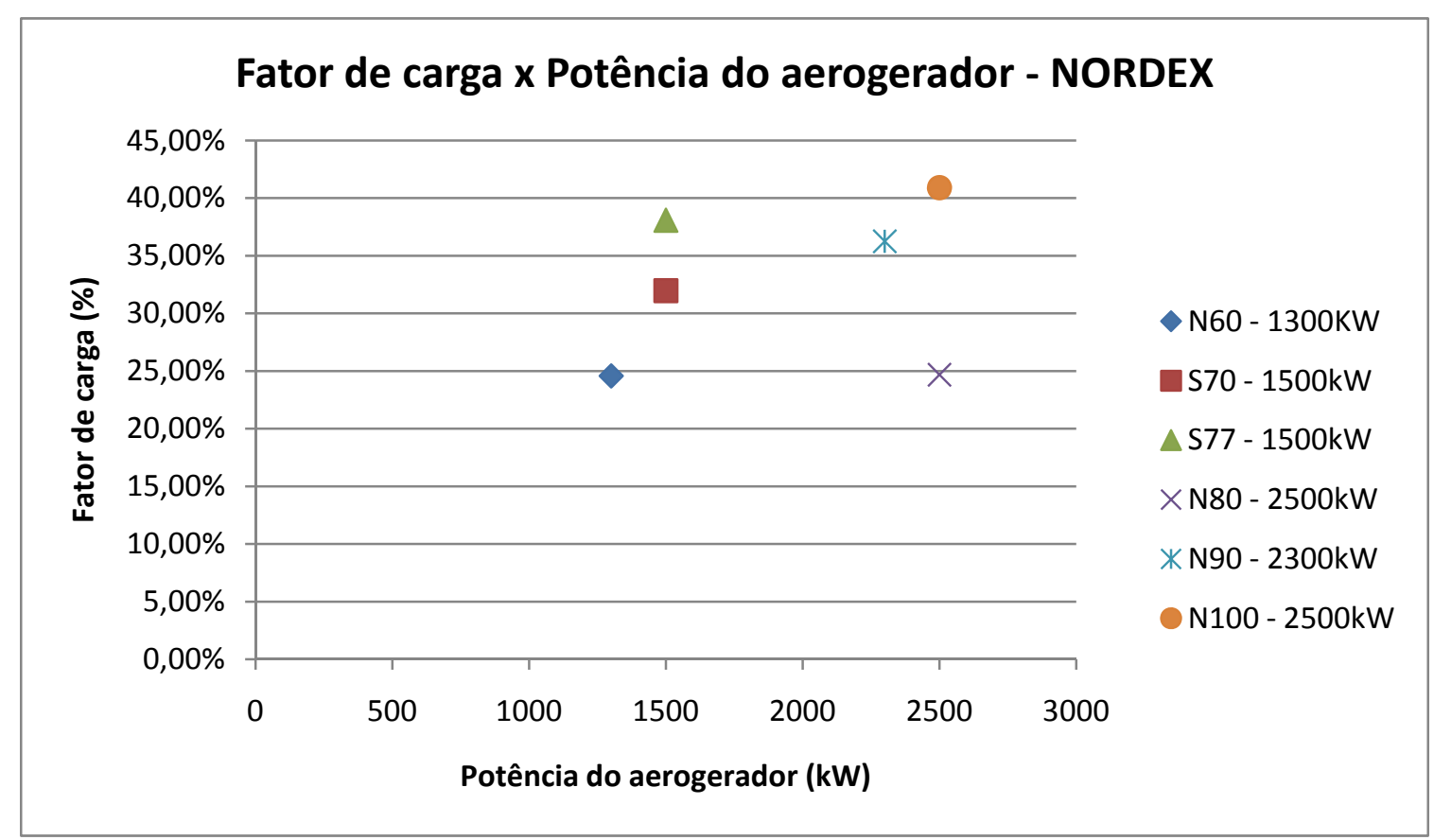

Figura 7.11 - Gráfico de Fator de carga x Potência do aerogerador para o fabricante Nordex.

Nas Figuras de 7.6 a 7.11, observa-se que os maiores fatores de carga não estão diretamente relacionados com os aerogeradores de maior potência ou que possuem nacelha com maior altura. O maior fator de carga ocorre quando há uma maior correlação da curva 
de potência do aerogerador com a função de Weibull. Se a potência nominal da turbina ocorrer em velocidades mais próximas à velocidade média do local onde se pretende instalar o parque eólico, mais energia será gerada. Assim, o fator de carga será maior. Isto ocorre porque quanto mais afastado da velocidade média, a ocorrência das velocidades diminui consideravelmente quando a função de Weibull possui uma forma mais fina ao redor da velocidade média.

A relação da distribuição de Weibull do município de Conde e da curva de potência dos aerogeradores E82 e E70, da Enercon, com o fator de carga está ilustrada na Figura 7.12.

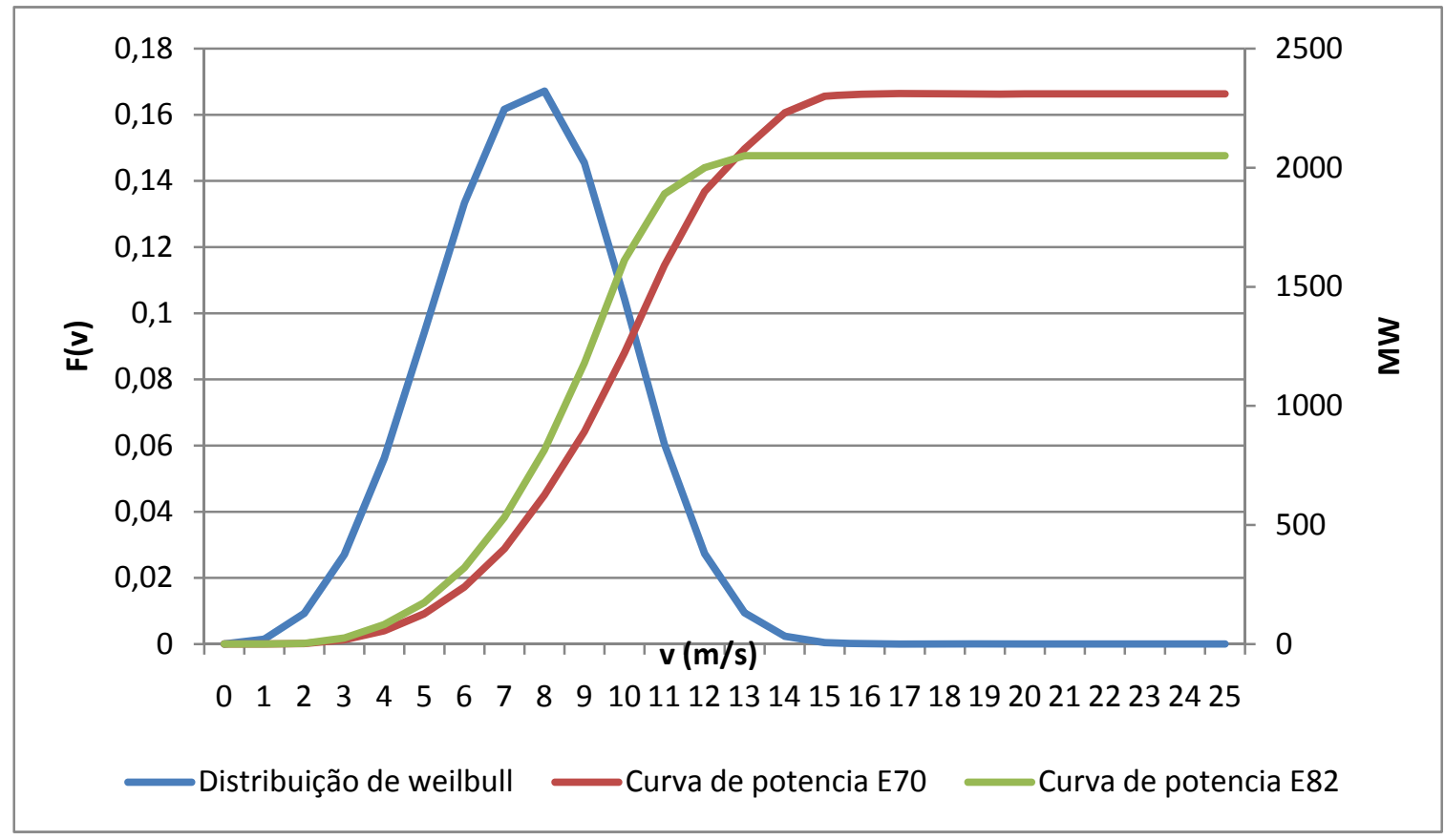

Figura 7.12 - Relação da distribuição de Weibull e da curva de potência com o fator de carga.

A partir da curva de potência dos aerogeradores nota-se que o aerogerador E82, se comparado com o aerogerador E70, fornece potência de saída nominal em uma velocidade mais próxima do ponto mais alto da distribuição de Weibull. Esse fator faz com que o mesmo tenha um fator de carga de 40,49\% em detrimento aos $28,18 \%$ apresentados pelo aerogerador E70. 
O resultado do estudo para o dimensionamento do parque eólico em Conde utilizando a área fornecida está mostrado nas Tabelas 7.10 a 7.12. Já o resultado do estudo para o dimensionamento do parque eólico em Irecê está mostrado nas Tabelas 7.13 a 7.15.

Tabela 7.10 - Resultado do estudo para o dimensionamento do parque eólico em Conde utilizando os modelos da ENERCON.

\begin{tabular}{|c|c|c|c|c|}
\hline Modelo & $\begin{array}{c}\mathrm{N}^{\mathrm{o}} \mathrm{de} \\
\text { turbinas por } \\
\text { fila }\end{array}$ & Configuração & $\begin{array}{l}\text { Energia } \\
\text { Gerada } \\
\text { (MWh): }\end{array}$ & $\begin{array}{c}\text { Fator de } \\
\text { carga } \\
(\%):\end{array}$ \\
\hline \multirow{2}{*}{ E33 - 330kW } & \multirow{2}{*}{31} & 1 Fila & 27353,5 & $30,52 \%$ \\
\hline & & 2 Filas & 47843,9 & $26,69 \%$ \\
\hline \multirow{2}{*}{ E44 - 900kW } & \multirow{2}{*}{23} & 1 Fila & 39527,2 & $21,80 \%$ \\
\hline & & 2 Filas & 68582,7 & $18,91 \%$ \\
\hline \multirow{2}{*}{$\mathrm{E} 48-800 \mathrm{~kW}$} & \multirow{2}{*}{21} & 1 Fila & 47446,1 & $32,24 \%$ \\
\hline & & 2 Filas & 84108,6 & $28,58 \%$ \\
\hline \multirow{2}{*}{ E53 - 800kW } & \multirow{2}{*}{19} & 1 Fila & 49176 & $36,93 \%$ \\
\hline & & 2 Filas & 87625,2 & $32,90 \%$ \\
\hline \multirow{2}{*}{ E70 - 2300kW } & \multirow{2}{*}{15} & 1 Fila & 85153,7 & $28,18 \%$ \\
\hline & & 2 Filas & 148832 & $24,62 \%$ \\
\hline \multirow{2}{*}{ E82 - 2000kW } & \multirow{2}{*}{13} & 1 Fila & 92219,5 & $40,49 \%$ \\
\hline & & 2 Filas & 163108 & $35,81 \%$ \\
\hline
\end{tabular}


Tabela 7.11 - Resultado do estudo para o dimensionamento do parque eólico em Conde utilizando os modelos da GAMESA.

\begin{tabular}{|c|c|c|c|c|}
\hline Modelo & $\begin{array}{c}\mathrm{N}^{0} \text { de turbinas } \\
\text { por fila }\end{array}$ & Configuração & $\begin{array}{c}\text { Energia Gerada } \\
\text { (MWh): }\end{array}$ & $\begin{array}{c}\text { Fator de } \\
\text { carga (\%): }\end{array}$ \\
\hline \multirow{2}{*}{ G52 - 850kW } & \multirow{2}{*}{20} & 1 Fila & 44972,1 & $30,20 \%$ \\
\hline & & 2 Filas & 79813,3 & $26,80 \%$ \\
\hline \multirow{2}{*}{ G58 - 850kW } & \multirow{2}{*}{18} & 1 Fila & 48345 & $36,07 \%$ \\
\hline & & 2 Filas & 86046,7 & $32,10 \%$ \\
\hline \multirow{2}{*}{ G80 - 2000kW } & \multirow{2}{*}{13} & 1 Fila & 76035 & $33,38 \%$ \\
\hline & & 2 Filas & 134378 & $29,50 \%$ \\
\hline \multirow{2}{*}{ G87 - 2000kW } & \multirow{2}{*}{12} & 1 Fila & 82505,9 & $39,24 \%$ \\
\hline & & 2 Filas & 146587 & $34,86 \%$ \\
\hline \multirow{2}{*}{ G90 - 2000kW } & \multirow{2}{*}{12} & 1 Fila & 88408,5 & $42,05 \%$ \\
\hline & & 2 Filas & 157592 & $37,48 \%$ \\
\hline
\end{tabular}

Tabela 7.12 - Resultado do estudo para o dimensionamento do parque eólico em Conde utilizando os modelos da NORDEX.

\begin{tabular}{|c|c|c|c|c|}
\hline Modelo & $\begin{array}{c}\mathrm{N}^{\mathrm{o}} \text { de turbinas } \\
\text { por fila }\end{array}$ & Configuração & $\begin{array}{c}\text { Energia Gerada } \\
\text { (MWh): }\end{array}$ & $\begin{array}{c}\text { Fator de } \\
\text { carga (\%): }\end{array}$ \\
\hline \multirow{2}{*}{ N60 - 1300KW } & \multirow{2}{*}{17} & 1 Fila & 47591,7 & $24,58 \%$ \\
\hline & & 2 Filas & 83045,2 & $21,45 \%$ \\
\hline \multirow{2}{*}{$\mathrm{S} 70-1500 \mathrm{~kW}$} & \multirow{2}{*}{15} & 1 Fila & 63020,9 & $31,97 \%$ \\
\hline & & 2 Filas & 109552 & $27,79 \%$ \\
\hline \multirow{2}{*}{$\mathrm{S} 77-1500 \mathrm{~kW}$} & \multirow{2}{*}{13} & 1 Fila & 65047,3 & $38,08 \%$ \\
\hline & & 2 Filas & 114483 & $33,51 \%$ \\
\hline \multirow{2}{*}{$\mathrm{N} 80-2500 \mathrm{~kW}$} & \multirow{2}{*}{13} & 1 Fila & 70269,8 & $24,68 \%$ \\
\hline & & 2 Filas & 122156 & $21,45 \%$ \\
\hline \multirow{2}{*}{ N90 - 2300kW } & \multirow{2}{*}{12} & 1 Fila & 87659,2 & $36,26 \%$ \\
\hline & & 2 Filas & 154096 & $31,87 \%$ \\
\hline \multirow{2}{*}{ N100 - 2500kW } & \multirow{2}{*}{11} & 1 Fila & 98540,1 & $40,90 \%$ \\
\hline & & 2 Filas & 174275 & $36,17 \%$ \\
\hline
\end{tabular}


Tabela 7.13 - Resultado do estudo para o dimensionamento do parque eólico em Irecê utilizando os modelos da ENERCON.

\begin{tabular}{|c|c|c|c|c|}
\hline Modelo & $\begin{array}{c}\mathrm{N}^{0} \text { de turbinas } \\
\text { por fila }\end{array}$ & Configuração & $\begin{array}{c}\text { Energia Gerada } \\
\text { (MWh): }\end{array}$ & $\begin{array}{c}\text { Fator de } \\
\text { carga (\%): }\end{array}$ \\
\hline \multirow{2}{*}{ E33 - 330kW } & \multirow{2}{*}{46} & 1 Fila & 27998 & $21,05 \%$ \\
\hline & & 2 Filas & 48290,1 & $18,16 \%$ \\
\hline \multirow{2}{*}{ E44 - 900kW } & \multirow{2}{*}{35} & 1 Fila & 40443,3 & $14,66 \%$ \\
\hline & & 2 Filas & 69668 & $12,62 \%$ \\
\hline \multirow{2}{*}{$\mathrm{E} 48-800 \mathrm{~kW}$} & \multirow{2}{*}{32} & 1 Fila & 50102,3 & $22,34 \%$ \\
\hline & & 2 Filas & 87902,6 & $19,60 \%$ \\
\hline \multirow{2}{*}{ E53 - 800kW } & \multirow{2}{*}{29} & 1 Fila & 52737,4 & $25,95 \%$ \\
\hline & & 2 Filas & 92702,2 & $22,81 \%$ \\
\hline \multirow{2}{*}{ E70 - 2300kW } & \multirow{2}{*}{22} & 1 Fila & 84453,1 & $19,05 \%$ \\
\hline & & 2 Filas & 145693 & $16,43 \%$ \\
\hline \multirow{2}{*}{ E82 - 2000kW } & \multirow{2}{*}{19} & 1 Fila & 94220,7 & $28,30 \%$ \\
\hline & & 2 Filas & 163388 & $24,54 \%$ \\
\hline
\end{tabular}

Tabela 7.14 - Resultado do estudo para o dimensionamento do parque eólico em Conde utilizando os modelos da GAMESA.

\begin{tabular}{|c|c|c|c|c|}
\hline Modelo & $\begin{array}{c}\mathrm{N}^{\mathrm{o}} \text { de turbinas } \\
\text { por fila }\end{array}$ & Configuração & $\begin{array}{c}\text { Energia Gerada } \\
\text { (MWh): }\end{array}$ & $\begin{array}{c}\text { Fator de } \\
\text { carga (\%): }\end{array}$ \\
\hline \multirow{2}{*}{ G52 - 850kW } & \multirow{2}{*}{29} & 1 Fila & 44968,1 & $20,82 \%$ \\
\hline & & 2 Filas & 78765,1 & $18,24 \%$ \\
\hline \multirow{2}{*}{ G58 - 850kW } & \multirow{2}{*}{26} & 1 Fila & 48543,9 & $25,07 \%$ \\
\hline & & 2 Filas & 85061,6 & $21,97 \%$ \\
\hline \multirow{2}{*}{ G80 - 2000kW } & \multirow{2}{*}{19} & 1 Fila & 77351,8 & $23,24 \%$ \\
\hline & & 2 Filas & 134896 & $20,26 \%$ \\
\hline \multirow{2}{*}{ G87 - 2000kW } & \multirow{2}{*}{18} & 1 Fila & 87518,2 & $27,75 \%$ \\
\hline & & 2 Filas & 152881 & $24,24 \%$ \\
\hline \multirow{2}{*}{ G90 - 2000kW } & \multirow{2}{*}{17} & 1 Fila & 89446,4 & $30,03 \%$ \\
\hline & & 2 Filas & 156503 & $26,27 \%$ \\
\hline
\end{tabular}


Tabela 7.15 - Resultado do estudo para o dimensionamento do parque eólico em Conde utilizando os modelos da NORDEX.

\begin{tabular}{|c|c|c|c|c|}
\hline Modelo & $\begin{array}{c}\mathrm{N}^{0} \mathrm{de} \\
\text { turbinas } \\
\text { por fila }\end{array}$ & Configuração & $\begin{array}{l}\text { Energia } \\
\text { Gerada } \\
\text { (MWh): }\end{array}$ & $\begin{array}{c}\text { Fator de } \\
\text { carga } \\
(\%):\end{array}$ \\
\hline \multirow{2}{*}{ N60 - 1300KW } & \multirow{2}{*}{26} & 1 Fila & 49072,5 & $16,57 \%$ \\
\hline & & 2 Filas & 84010,9 & $14,19 \%$ \\
\hline \multirow{2}{*}{$\mathrm{S} 70-1500 \mathrm{~kW}$} & \multirow{2}{*}{22} & 1 Fila & 62110,6 & $21,49 \%$ \\
\hline & & 2 Filas & 105668 & $18,28 \%$ \\
\hline \multirow{2}{*}{$\mathrm{S} 77-1500 \mathrm{~kW}$} & \multirow{2}{*}{20} & 1 Fila & 70392,3 & $26,79 \%$ \\
\hline & & 2 Filas & 121770 & $23,17 \%$ \\
\hline \multirow{2}{*}{ N80 - 2500kW } & \multirow{2}{*}{19} & 1 Fila & 68164,4 & $16,38 \%$ \\
\hline & & 2 Filas & 116378 & $13,98 \%$ \\
\hline \multirow{2}{*}{ N90 - 2300kW } & \multirow{2}{*}{17} & 1 Fila & 86280,5 & $25,19 \%$ \\
\hline & & 2 Filas & 149101 & $21,77 \%$ \\
\hline \multirow{2}{*}{ N100 - 2500kW } & \multirow{2}{*}{16} & 1 Fila & 101358 & $28,93 \%$ \\
\hline & & 2 Filas & 175381 & $25,03 \%$ \\
\hline
\end{tabular}

Nas Tabelas 7.10 à 7.15 pode ser observado o efeito da esteira de um aerogerador em outro. Quando o parque eólico é projetado para ter mais de uma fila de turbinas, deve-se espaçar as filas para que a perda de velocidade do vento possa ser recuperada. Neste trabalho, admitiu-se uma perda de no máximo $10 \%$ da velocidade do vento incidente na primeira fila para que pudesse ser instalada uma segunda fila. Com essa perda de $10 \%$ da velocidade, o fator de carga foi reduzido em até 5\%, aproximadamente. Por conta dessa perda de eficiência na produção de energia ao instalar uma segunda fila de aerogeradores, vários parques eólicos instalados no mundo possuem apenas uma fila longa de aerogeradores, ressaltando que uma análise mais profunda deve ser feita nesse sentido de modo a identificar a viabilidade de cada tipo de disposição. Isso quando o relevo não foi o fator determinante para a disposição dos aerogeradores como foi visto em 6.2.3. 


\subsubsection{Comparação com o programa ALWIN}

De forma a consolidar os resultados obtidos, foi utilizado como ferramenta computacional o programa ALWIN. Este programa calcula, entre outras coisas, a previsão de energia produzida por um determinado aerogerador a partir dos dados estatísticos dos ventos em determinado local calculados pelo programa, assim como o fator de carga deste aerogerador.

O programa ALWIN constitui-se em direito autoral do Deutsches Windenergie-Institut e da Ammonit Gesellschaft für MesstechnikmbH e a sua versão livre pode ser acessada a partir do site http://www.ammonit.de/produkte/pu_alw_e.htm.

Para o sítio de Conde e o aerogerador E70 da ENERCON, os resultados obtidos pelo programa ALWIN e pelos cálculos demonstrados neste trabalho estão mostrados na Tabela 7.16.

Tabela 7.16 - Comparação dos resultados obtidos com o programa ALWIN.

\begin{tabular}{|c|c|c|}
\hline Comparação & ALWIN & Planilha \\
\hline Energia Produzida (MWh) & 5879,3 & 5676,9 \\
\hline Fator de Carga (\%) & 29,1 & 28,2 \\
\hline
\end{tabular}

Como pode ser visto na Tabela 7.16, os resultados calculados neste trabalho foram bem próximos dos resultados obtidos utilizando o programa ALWIN, apenas $0,9 \%$ de diferença no fator de carga anual. 


\section{CONCLUSÕES}

\subsection{CONCLUSÕES GERAIS}

Tendo em vista os objetivos de apresentar conceitos e aplicá-los a um estudo preliminar de implantação de um parque eólico foi realizada, em primeiro momento, uma revisão bibliográfica de títulos que servem como referência nesse tipo específico de geração de energia. A partir dos conceitos obtidos nessas referências, foi possível elaborar uma ferramenta computacional, no caso, uma planilha de cálculo, que pudesse fornecer os resultados necessários à análise preliminar de um parque eólico a partir de um atlas eólico.

Dos resultados obtidos a partir da planilha de cálculo foi possível observar aspectos relevantes como fator de carga, influência da disposição de aerogeradores dentro de um parque eólico, potência instalada, adequação de aerogeradores a cada perfil de distribuição de ventos e, finalmente, estimativa anual de produção de energia de um parque eólico.

Ao comparar os resultados obtidos com os resultados típicos descritos na literatura e provenientes de outro software livre, ALWIN, disponibilizado pelo Deutsches Windenergie-Institut (DEWI) e pela Ammonit Gesellschaft für MesstechnikmbH, foi possível notar que os resultados encontrados pela planilha desenvolvida foram ao encontro dos valores disponíveis na literatura, apresentando-se bastante semelhantes aos obtidos pelo programa ALWIN no que diz respeito a estimativa anual de geração de energia.

\subsection{RECOMENDAÇÕES PARA ESTUDOS FUTUROS}

Existe uma enorme quantidade de tópicos e pormenores relacionados à energia eólica que não foram tratados neste texto. Como exemplo, pode-se citar a conexão de parques eólicos a smart grids, análise transitória e dinâmica dos sistemas, elaboração de modelos analíticos de aerogeradores, entre uma infinidade de outros temas.

Contudo, caso exista interesse no detalhamento e no estudo da aplicabilidade dos resultados encontrados neste trabalho, seria interessante realizar uma análise de conexão do parque eólico hipotético à rede básica, tópico que não foi abordado neste texto. Além 
disso, conforme foi comentado ao longo do texto, uma análise financeira da implantação do parque eólico seria bastante útil para definir critérios mais robustos de escolha de aerogeradores e da disposição dos mesmos dentro do parque. 


\section{REFERÊNCIAS}

ACKERMANN, T., “Wind Power in Power Systems”,1 edição, John Wiley \& Sons,2005.

AMARANTE, O.A.C.; ZACK, J. ; BROWER, M. ; DE SÁ, A.L., “Atlas de Potencial Eólico Brasileiro”, CEPEL, 2001.

AMARANTE, O.A.C, “Atlas de potencial eólico do Estado da Bahia", COELBA/ELETROBRÁS, 2001.

ANEEL, Agência Nacional de Energia Elétrica, Banco de Informações de Geração. Disponível em http://www.aneel.gov.br/aplicacoes/capacidadebrasil/capacidadebrasil.asp Acessado em 16/11/2009.

CUSTÓDIO, R.S., “Energia eólica para produção de energia elétrica”, $1^{\text {a }}$ Edição, Centrais Elétricas Brasileiras S.A. - Eletrobrás, 2009.

GLOSSARY OF METEOROLOGY - American Meteorological Society. Disponível em http://amsglossary.allenpress.com/glossary Acessado em 16/11/2009.

GWEC, GLOBAL WIND ENERGY COUNCIL, “Global Wind Report 2008”, 2009.

MANWELL, J.F.; McGOWAN, J.G.; ROGERS, A.L., "Wind Energy Explained: Theory, Design and Application", Wiley, 2002.

MME, Ministério de Minas e Energia, "Plano Decenal de Expansão de Energia”, 2009.

MOLLY, J. P., “Energia Eólica: Técnica, Planejamento, Economia e Risco”, DEWI Gmbh., Rio de Janeiro, 2009.

PEREIRA, E. B., “Mapas eólicos no Brasil”, INPE, Rio de Janeiro, 2009. 
TROEN, I.; PETERSEN, E.L., "European Wind Atlas”, Risø National Laboratory, Roskilde, 1989. 